NBER WORKING PAPER SERIES

\title{
THE ANALYTICS OF THE GREEK CRISIS
}

\author{
Pierre-Olivier Gourinchas \\ Thomas Philippon \\ Dimitri Vayanos
}

Working Paper 22370

http://www.nber.org/papers/w22370

\author{
NATIONAL BUREAU OF ECONOMIC RESEARCH \\ 1050 Massachusetts Avenue \\ Cambridge, MA 02138 \\ June 2016
}

We are grateful to Miguel Faria-e-Castro for outstanding research assistance. We thank Olivier Blanchard and Markus Brunnermeier, our discussants at the 31st NBER Macroeconomics Annual conference, as well as Gikas Hardouvelis, Maurice Obstfeld, Jonathan Parker, and other participants at that conference, for very helpful comments. The views expressed herein are those of the authors and do not necessarily reflect the views of the National Bureau of Economic Research.

At least one co-author has disclosed a financial relationship of potential relevance for this research. Further information is available online at http://www.nber.org/papers/w22370.ack

NBER working papers are circulated for discussion and comment purposes. They have not been peer-reviewed or been subject to the review by the NBER Board of Directors that accompanies official NBER publications.

(C) 2016 by Pierre-Olivier Gourinchas, Thomas Philippon, and Dimitri Vayanos. All rights reserved. Short sections of text, not to exceed two paragraphs, may be quoted without explicit permission provided that full credit, including (C) notice, is given to the source. 
The Analytics of the Greek Crisis

Pierre-Olivier Gourinchas, Thomas Philippon, and Dimitri Vayanos

NBER Working Paper No. 22370

June 2016, Revised July 2016

JEL No. E2,E3,E4,E5,E6,F3,F4

\begin{abstract}
$\underline{\text { ABSTRACT }}$
We provide an empirical and theoretical analysis of the Greek Crisis of 2010. We first benchmark the crisis against all episodes of sudden stops, sovereign debt crises, and lending boom/busts in emerging and advanced economies since 1980. The decline in Greece's output, especially investment, is deeper and more persistent than in almost any crisis on record over that period. We then propose a stylized macro-finance model to understand what happened. We find that a severe macroeconomic adjustment was inevitable given the size of the fiscal imbalance; yet a sizable share of the crisis was also the consequence of the sudden stop that started in late 2009. Our model suggests that the size of the initial macro/financial imbalances can account for much of the depth of the crisis. When we simulate an emerging market sudden stop with initial debt levels (government, private, and external) of an advanced economy, we obtain a Greek crisis. Finally, in recent years, the lack of recovery appears driven by elevated levels of non-performing loans and strong price rigidities in product markets.
\end{abstract}

Pierre-Olivier Gourinchas

Department of Economics

University of California, Berkeley

530 Evans Hall \#3880

Berkeley, CA 94720-3880

and CEPR

and also NBER

pog@econ.berkeley.edu

Thomas Philippon

New York University

Stern School of Business

44 West 4th Street, Suite 9-190

New York, NY 10012-1126

and NBER

tphilipp@stern.nyu.edu
Dimitri Vayanos

Department of Finance, OLD 3.41

London School of Economics

Houghton Street

London WC2A 2AE

UNITED KINGDOM

and CEPR

and also NBER

d.vayanos@1se.ac.uk 


\section{Introduction and Motivation}

The economic crisis that Greece has been experiencing from 2008 onwards has been particularly severe. Real GDP per capita stood at approximately $€ 22,600$ in 2008 , and dropped to $€ 17,000$ by 2014 , a decline of $24.8 \%$ The unemployment rate was $7.8 \%$ in 2008 , and rose to $26.6 \%$ in 2014 . The entire Greek banking system became insolvent during the crisis, and a large-scale recapitalization took place in 2013. In 2012, Greece became the first OECD member country to default on its sovereign debt, and that default was the largest in world history. Greece received financial assistance from other Eurozone (EZ) countries and the International Monetary Fund (IMF), and the size of this bailout package was also the largest in history.

The implications of the Greek crisis extended well beyond Greece. The bailout package that Greece received was large partly because of fears of contagion to other countries in the EZ and to their banking systems. Moreover, at various stages during the crisis, the continued membership of Greece in the EZ was put in doubt. This tested the strength and the limits of the currency union, and of the European project more generally.

This paper provides an 'interim' report on the Greek crisis ('interim' in the sense that the crisis is still unfolding). We proceed in three steps. First, we describe the main macroeconomic dynamics that Greece experienced before and during the crisis. Second, we put these dynamics in perspective by benchmarking the Greek crisis against all episodes of sudden stops, sovereign debt crises, and lending boom/busts in emerging and advanced economies since 1980. Third, we develop a DSGE model designed to capture many of the relevant features of the Greek crisis and help us identify its main drivers.

The global financial crisis that began in 2007 in the United States hit Greece through three interlinked shocks. The first shock was a sovereign debt crisis: investors began to perceive the debt of the Greek government as unsustainable, and were no longer willing to finance the government deficit. The second shock was a banking crisis: Greek banks had difficulty financing themselves in the interbank market, and their solvency was put in doubt because of projected losses to the value of their assets. The third shock was a sudden stop: foreign investors were no longer willing to lend to Greece as a whole (government, banks, and firms), and so the country could not finance its current account deficit.

To many observers, that last shock was a startling development. After all, the very existence of a common currency, and therefore of an automatic provision of liquidity against good collateral through

\footnotetext{
${ }^{1}$ GDP per capita comes from Eurostat and is expressed in 2010 Euros.
} 
its common central bank, was supposed to insulate member countries against a sudden reversal of private capital of the kind experienced routinely by Emerging Market economies (EM). Just like a sudden stop on California or Texas could not happen since Federal Reserve funding would substitute instantly and automatically for private capital, the common view was a sudden stop could not happen to Greece or Portugal since European Central Bank (ECB) funding would substitute instantly and automatically for private capital $\left.\right|^{2}$ The belief that sudden stops were a thing of the past may have in turn contributed to the emergence of mounting internal and external imbalances, in Greece and elsewhere in the EZ (Blanchard and Giavazzi (2002)). Yet, at the onset of the crisis, Greece and other EZ members did experience a classic sudden stop. The built-in defense mechanisms of the EZ were activated and the ECB provided much needed funding to the Greek economy. How much, then, did this sudden stop contribute to the subsequent meltdown and through what channels? And what was the contribution of other factors? These are among the questions that we seek to address in this paper.

The first main result that emerges from our macro-benchmarking exercise is that Greece's drop in output (a 25\% decline in real GDP per capita between 2008 and 2013) was significantly more severe and protracted than during the average crisis. This applies to the sample of countries that experienced sudden stops; to the sample that experienced sovereign defaults; to the sample that experienced lending booms and busts; and even to the sample that experienced all three shocks combined (we call these episodes "Trifectas"). The collapse in investment (75\% decline between 2008 and 2013) was even more severe. Importantly, we find that the difference in output dynamics is not driven by the exchange-rate regime. Countries whose currency remains pegged experience a larger output drop on average than countries with floating rates. But unlike these countries, whose output rebounds after a few years, Greece's output continued to drop, to a significantly lower level.

One possible explanation for the severity of Greece's crisis is the high level of debt-government, private, and external - at the onset of the crisis. Greece's government debt stood at $103.1 \%$ of output in 2007 , its net foreign assets at $-99.9 \%$ of output, and its private-sector debt at $92.4 \%$ of output. On the former two measures, Greece fared worse than Ireland, Italy, Portugal, and Spain, the four other major EZ countries hit by the crisis. Greece fared worse than those countries also on its government deficit and current-account deficit, which stood at $6.5 \%$ and $15.9 \%$ of output, respectively, in 2007 . And debt levels in Greece were more than twice as large than in the average of the emerging-market

\footnotetext{
${ }_{2}^{2}$ Ingram (1973) was among the first to articulate the view that sudden stops could not happen in a currency union, with the corollary that there was no need to monitor external imbalances. Against this view, Garber (1999) argued that the European payment system (Target) at the core of the European Monetary Union could itself propagate a speculative attack.
} 
economies which account for most of the crisis episodes in our sample.

To identify the role of debt, as well as of other factors such as the sudden stop of private capital, in driving the severity of the Greek crisis, we turn to our DSGE model. The model is designed to capture in a simple and stylized manner the three types of shocks that hit Greece. It also captures a rich set of interdependencies between the shocks. The model features a government, two types of consumers, firms, and banks. The government can borrow, raise taxes, spend, and possibly default on its debt. Consumers differ in their subjective discount rate. Impatient consumers are those who borrow in equilibrium, subject to a debt limit. Firms can borrow and invest, and face sticky wages and prices. Consumers and firms can borrow from banks and can default on their debts. The rates at which the government, consumers, and firms can borrow depend on the probability with which these entities can default and on the losses given default. In turn, the expected costs of default (probability times losses) depend on the ratio of debt to income.

In the model, a sovereign risk shock increases the government's funding costs. The government responds by increasing taxes and reducing expenditures, which exerts a contractionary effect on the economy. In turn, the decline in output increases the expected costs of default on private-sector loans, causing funding costs for consumers and firms to rise and investment to drop. Conversely, a sudden stop increases directly the rate at which consumers and firms can borrow, causing investment, consumption and output to decline. The decline in fiscal revenues pushes up sovereign yields and has an adverse impact on public debt dynamics. Hence, in our model, sovereign risks and private sector risks are intertwined and shocks to one sector of the economy can affect funding costs and default rates throughout all sectors.

We estimate the model using Bayesian methods and annual data on government revenue and spending, household debt, non-performing loans in the private sector, borrowing rates for the government and the corporate sector, as well as price and wage inflation. The model features eight stochastic shocks in each year, identical to the number of variables that we use in the estimation. We find that the model does an excellent job of matching additional variables such as output, investment, and the current account (which the model was not asked to replicate). We then perform two tasks with the model. First, we decompose the movements in output, investment, and other key variables into the contribution of each type of shock. This helps us determine which shocks were the most important in driving the crisis dynamics. Second, we use the model to perform a number of "counterfactuals" to identify the role played by different aspects of the institutional environment. We examine, in particu- 
lar, how the dynamics of output and investment would have been different if debt levels in Greece were set at the average of emerging-market economies; if banks' funding costs had not increased during the crisis, as a possible effect of a European banking union; if the Greek government had followed a more virtuous fiscal path in the years preceding the crisis; and if prices and wages had been more flexible.

As in Agatha Christie's 'Murder on the Orient Express', our model indicates that many forces contributed to the 'murder' of the Greek economy. Yet a few factors stand out. First and most importantly, given the size of the fiscal imbalances, a substantial fiscal correction was inevitable. According to our estimates, fiscal consolidation accounted for approximately $50 \%$ of the output drop from peak to trough. Much of the remainder is explained by the increase in funding costs for the private sector ("sudden stop" in our model) and the sovereign ("sovereign risk shock"). The combination of the two shocks accounted for an additional $40 \%$ of the output drop from peak to trough, with the sudden stop driving more than half of the effect.

Lastly, our estimates indicate that markup shocks in product markets and a surge in non-performing loans contributed significantly to the lack of recovery in 2014 and 2015: in the the absence of these shocks, output in 2014-15 would have recovered approximately $35 \%$ of its peak-to-trough drop. These findings indicate that the external dimension of the crisis may slowly be fading, and that the forces holding back the Greek economy are now largely domestic and microeconomic: the recovery will entail cleaning up non-performing loans, and facilitating the adjustment of prices relative to wages. The lack of a sufficient price adjustment may have been due to limited competition in goods and services markets, as well as to a rise in firms' costs stemming from factors such as the uncertainty about EZ exit and the taxation of key inputs.

The effects of the shocks described above were made larger by high leverage and low price flexibility. Our counterfactual exercises allow us to examine more directly the effects of these factors. We find that if the levels of government, private, and external debt in Greece had been comparable to those in the average of the emerging-market economies (so smaller by about half), the peak-to-trough decline in output would have been smaller by about a third. And the same conclusion holds if the prices and wages had been twice as flexible.

\section{The Greek Economy Before and During the Crisis.}

This section describes the dynamics of key macroeconomic variables in Greece before and during the crisis. We focus on the behavior of output and investment, as well as on the accumulation of 
debt- government, private, and external. We also describe the three shocks through which the global financial crisis affected Greece (sudden stop, sovereign debt crisis, and banking crisis) as well as their interrelationships. This sets the stage for the empirical exercise in Section 3, and motivates some of the modeling choices and analysis in Sections 46 .

\section{$2.1 \quad$ Pre-Crisis}

Output. Figure 1 plots GDP per capita in 2014 US dollars, adjusted for Purchasing Power Parity (PPP), and in a log scale, from 1980 onwards. In this figure, as well as in subsequent figures and tables in this Section, we compare Greece to the four other major Eurozone (EZ) countries that were hit by the EZ crisis: Ireland (IE), Italy (IT), Spain (ES), and Portugal (PT).

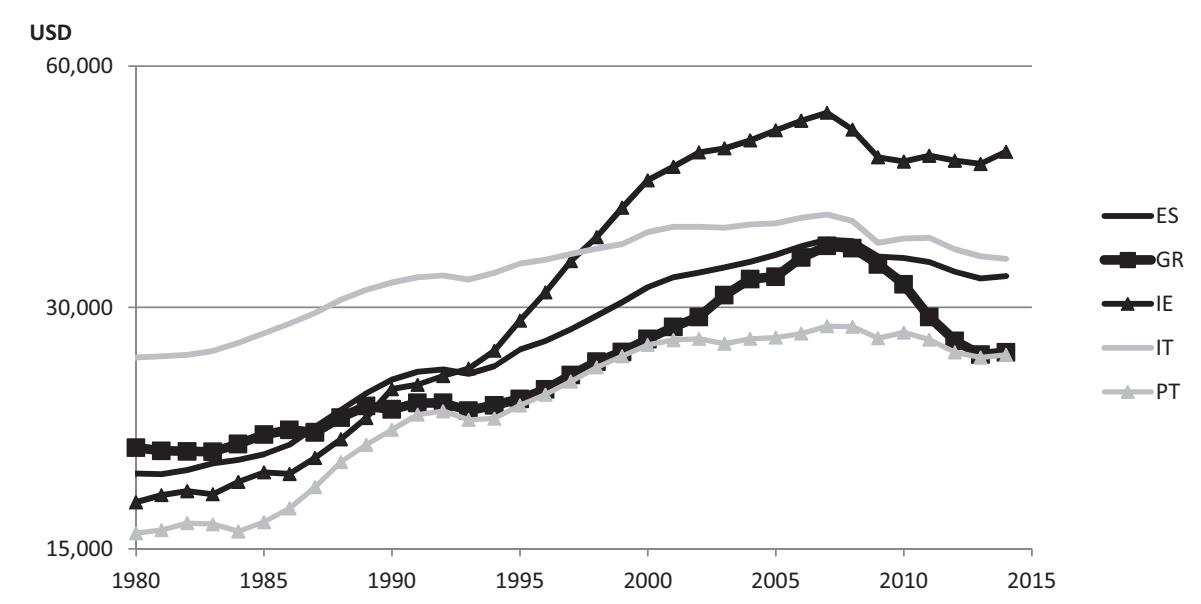

Figure 1: GDP per capita for Greece and other EZ crisis countries, 1980-2014. The data come from The Conference Board Total Economy Database. GDP is expressed in 2014 US dollars, is adjusted for PPP using 2011 weights, and is plotted in a log scale.

As of 1980, Greek GDP per capita was above that of Ireland, Portugal, and Spain. During the 1980s Greece experienced relative stagnation, and was overtaken by Ireland and Spain. Greece grew faster during the period 1996-2000 and especially from 2001, when it entered the Eurozone (EZ), until 2008. By 2008, Greece had almost caught up with Spain.

Motivated by Figure 1. we divide the period 1996-2014 into three sub-periods: the period 19962000, during which Greece experienced a boom in anticipation of EZ entry; the period 2001-2008 during which the boom continued with Greece inside the EZ; and the crisis period 2009-2014. In the tables constructed in the rest of this section, we report averages of macroeconomic variables for the three sub-periods. In some of the tables we also compare with the year 1995, which we take as indicative of 
the Greek economy before the (actual or anticipated) effects of EZ entry ${ }^{3}$

\begin{tabular}{c|cccc}
\hline \multicolumn{4}{c}{ Total investment } \\
\hline & 95 & $96-00$ & $01-08$ & $09-14$ \\
\hline ES & 22.0 & 23.7 & 28.8 & 21.0 \\
GR & $\mathbf{2 0 . 4}$ & $\mathbf{2 3 . 1}$ & $\mathbf{2 3 . 7}$ & $\mathbf{1 4 . 6}$ \\
IE & 18.2 & 22.3 & 26.1 & 16.2 \\
IT & 19.0 & 19.4 & 21.1 & 18.6 \\
PT & 23.3 & 26.5 & 23.9 & 17.4 \\
\hline
\end{tabular}

\begin{tabular}{c|cccc|ccccc|cccc}
\hline \multicolumn{4}{c}{ Corporate Investment } & \multicolumn{3}{c}{ Residential Investment } & \multicolumn{3}{c}{ Public Investment } \\
\hline & 95 & $96-00$ & $01-08$ & $09-14$ & 95 & $96-00$ & $01-08$ & $09-14$ & 95 & $96-00$ & $01-08$ & $09-14$ \\
\hline ES & 11.7 & 13.0 & 13.9 & 12.0 & 6.0 & 7.0 & 10.7 & 5.7 & 4.3 & 3.7 & 4.2 & 3.3 \\
GR & $\mathbf{8 . 4}$ & $\mathbf{1 0 . 5}$ & $\mathbf{1 0 . 3}$ & $\mathbf{7 . 7}$ & $\mathbf{8 . 6}$ & $\mathbf{8 . 8}$ & $\mathbf{9 . 2}$ & $\mathbf{3 . 7}$ & $\mathbf{3 . 4}$ & $\mathbf{3 . 8}$ & $\mathbf{4 . 2}$ & $\mathbf{3 . 2}$ \\
IE & 10.6 & 12.3 & 11.4 & 11.0 & 5.2 & 7.1 & 10.6 & 2.7 & 2.4 & 2.9 & 4.1 & 2.5 \\
IT & 11.3 & 11.8 & 12.9 & 10.8 & 5.1 & 4.8 & 5.3 & 5.1 & 2.6 & 2.8 & 2.9 & 2.7 \\
PT & 11.6 & 13.8 & 13.7 & 11.1 & 7.3 & 7.7 & 6.1 & 3.1 & 4.4 & 5.0 & 4.1 & 3.2 \\
\hline
\end{tabular}

Table 1: Investment in Greece and other EZ crisis countries, 1995-2014, as percentage of GDP. The data come from AMECO. Investment is measured by the series "Gross fixed capital formation: total economy," and does not include inventories. Residential investment is measured by "Gross fixed capital formation: dwellings;" corporate investment by "Gross fixed capital formation: private sector" minus residential investment; and public investment by "Gross fixed capital formation: government."

Investment. Table 1 reports the level of investment in Greece during the periods 1996-2000, 20012008, and 2009-2014, and compares with 1995. The table also decomposes investment into corporate, residential, and public, and compares with Ireland, Italy, Portugal, and Spain. Greece experienced the second-largest increase in corporate investment from 1995 to 1996-2000, after Portugal. Corporate investment remained at that elevated level during 2001-2008. Thus, EZ entry and its anticipation was associated with a significant rise in corporate investment in Greece. That rise, however, occurred from a low base, and corporate investment remained significantly lower than in the other countries.

Unlike Ireland and Spain, Greece did not experience a significant increase in residential investment from 1995 to 1996-2008. Residential investment was already high in 1995, however, and the real-estate boom in Ireland and Spain only meant that residential investment in those countries caught up with and exceeded somewhat that in Greece.

Net Foreign Assets. The fast growth of Greek GDP per capita during the period 1996-2008 was associated with an increase in external indebtedness. Figure 2 plots net foreign assets (NFA) from

\footnotetext{
${ }^{3}$ An average during the period 1980-1995 would have been more informative of the state of the Greek economy before EZ entry. We use only the year 1995 because data before 1995 are not available or precise enough.
} 


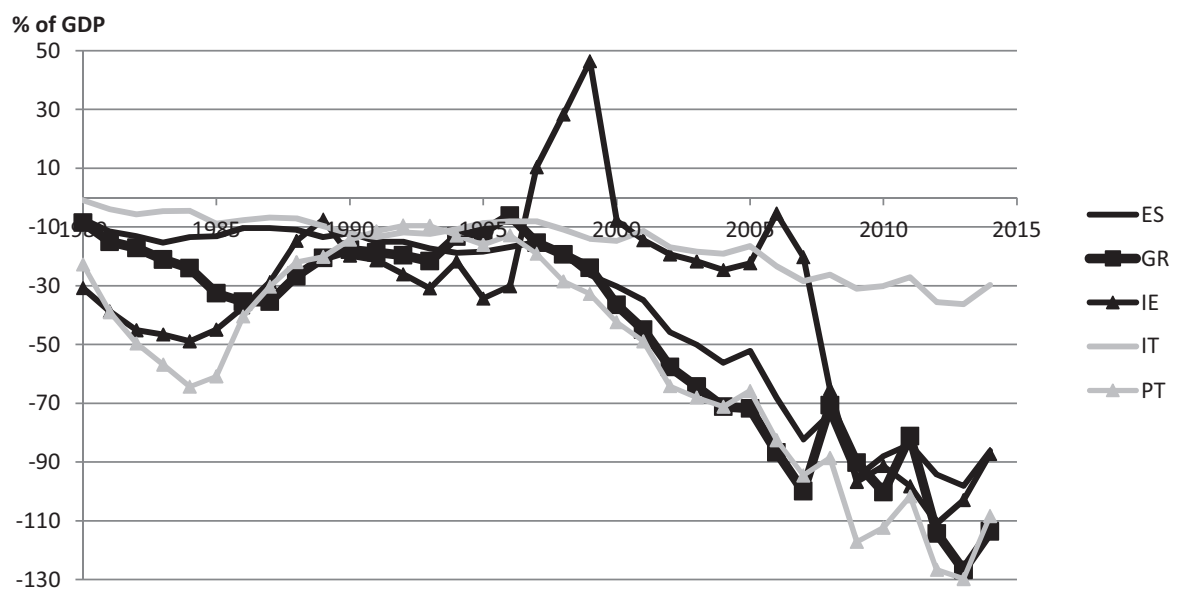

Figure 2: Net foreign assets in Greece and other EZ crisis countries, 1980-2014, as percentage of GDP. The data come from Lane and Milesi-Ferretti (2007).

1980 onwards, as percentage of GDP. NFA for Greece were negative throughout that period. They were a relatively small fraction of GDP in absolute value until the mid-1990s, and they subsequently declined to a much more negative fraction. Greece's NFA position deteriorated at a comparable rate to Portugal's and Spain's, while Ireland experienced a more abrupt deterioration. The behavior of Greece's NFA from the mid-1990s onwards is indicative of large current account deficits. Table 2 reports the level of the current account in Greece, Ireland, Italy, Portugal, and Spain during the periods 1996-2000, 2001-2008, and 2009-2014, and compares with 1995. The table decomposes the current account into (i) net exports and (ii) the sum of net current transfers and net primary income.

\begin{tabular}{c|cccc|ccccc|cccc}
\hline \multicolumn{4}{c}{ Current Account Surplus } & \multicolumn{4}{c}{ Net Exports } & \multicolumn{4}{c}{ Net Current Transfers plus } \\
\hline & 95 & $96-00$ & $01-08$ & $09-14$ & 95 & $96-00$ & $01-08$ & $09-14$ & 95 & $96-00$ & $01-08$ & $09-14$ \\
\hline ES & -1.2 & -2.0 & -6.7 & -1.6 & -1.0 & -1.1 & -4.1 & 0.8 & -0.2 & -0.9 & -2.6 & -2.4 \\
GR & $\mathbf{- 2 . 8}$ & $\mathbf{- 5 . 7}$ & $\mathbf{- 1 1 . 7}$ & $\mathbf{- 7 . 3}$ & $\mathbf{- 8 . 3}$ & $\mathbf{- 9 . 1}$ & $\mathbf{- 1 0 . 6}$ & $\mathbf{- 5 . 9}$ & $\mathbf{5 . 5}$ & $\mathbf{3 . 4}$ & $\mathbf{- 1 . 1}$ & $\mathbf{- 1 . 4}$ \\
IE & 2.6 & 1.2 & -2.3 & 1.7 & 10.9 & 12.0 & 12.4 & 19.2 & -8.3 & -10.8 & -14.7 & -17.5 \\
IT & 2.0 & 1.5 & -1.1 & -1.0 & 3.7 & 2.8 & 0.1 & 0.4 & -1.7 & -1.3 & -1.2 & -1.4 \\
PT & -3.4 & -7.7 & -9.8 & -4.5 & -6.4 & -9.1 & -8.5 & -3.0 & 3.0 & 1.4 & -1.3 & -1.5 \\
\hline
\end{tabular}

Table 2: The current account in Greece and other EZ crisis countries 1995-2014, as percentage of GDP. The data come from AMECO. Net exports are measured by the series "Net exports of goods and services;" net current transfers by "Net current transfers from the rest of the world;" and net primary income by "Net primary income from the rest of the world." The current account surplus is the sum of the three series.

Greece's current account deteriorated from 1995 to 1996-2000, and deteriorated further during 2001-2008. The deterioration from 1996-2000 to 2001-2008 was particularly severe: $6.0 \%$ of GDP, larger than in the other countries. During 2001-2008, Greece was running an average current account 
deficit of $11.7 \%$ of GDP, also larger than in the other countries.

The deterioration of Greece's current account from 1995 onwards was primarily driven by a decline in net current transfers and net primary income. Net current transfers to Greece declined partly because of the drop in EU subsidies, especially after the 2005 EU enlargement, as funds were redirected to new entrants that were poorer than Greece. Net primary income declined also because workers' remittances became smaller as Greece became a net immigration country, and because of growing interest payments on Greece's rising external debt. Greece's trade balance also deteriorated, through that period, reaching -10.6 percent of GDP during the period 2001-2008.

The increase in Greece's current account deficit from 1995 to 1996-2000 was associated with an increase in corporate investment and hence in productive capacity. Indeed, the current account deficit increased by $2.9 \%$ of GDP, corporate investment increased by $2.1 \%$, and public investment by $0.4 \%$. The increase in the current account deficit from 1996-2000 to 2001-2008, however, was associated with an increase in consumption. Indeed, the current account deficit increased by $6.0 \%$ of GDP, total saving declined by $6.7 \%$, and corporate investment dropped slightly. The decline in total saving from 1996-2000 to 2001-2008 was primarily driven by private saving, which declined by $4.3 \%$ of GDP 4

Government Debt. Figure 3 plots government debt from 1980 onwards, as percentage of GDP. As of 1980, government debt in Greece was $21.4 \%$ of GDP, lower than in all other countries except for Spain. Debt rose sharply during the 1980s, and by 1993 it had reached $94.4 \%$ of GDP, a level larger than in all other countries except for Italy. A combination of fiscal tightening to meet the criteria for EZ entry, and sharply lower interest rates in anticipation of that entry, helped stabilize and even reduce slightly the ratio of debt to GDP — to $88.5 \%$ in 1999. Budget discipline became looser after EZ entry, and especially after 2007. As a consequence, debt to GDP increased - to $103.1 \%$ in 2007 and $126.8 \%$ in 2009 - despite the fast growth in GDP during the period 2001-2008.

While debt to GDP increased only mildly from 1999 to 2007, there was a sharp increase in the amount of the debt held by foreign entities, and a consequent decrease in the amount held domestically. That trend was due mainly to the decline in private saving. Figure 4 plots gross government external debt for Greece, and compares with the same series for Portugal and Spain, and with Greece's NFA 5

\footnotetext{
${ }^{4}$ The fact that in the years immediately preceding and following EZ entry poorer members of the union -like Greecewould run large current account deficits was not a surprise. Rather, it is precisely what theory suggests should happen when countries catch-up and converge, as argued by Blanchard and Giavazzi (2002) in an influential paper that examined the experience of Greece and Portugal. That paper too noted that Greece did not experience an investment boom following EZ entry and that the decline in saving was mostly driven by private saving.

${ }^{5}$ Figure 4 starts in 1999 rather than 1980 because data before 1999 are not available. Subsequent figures also start
} 


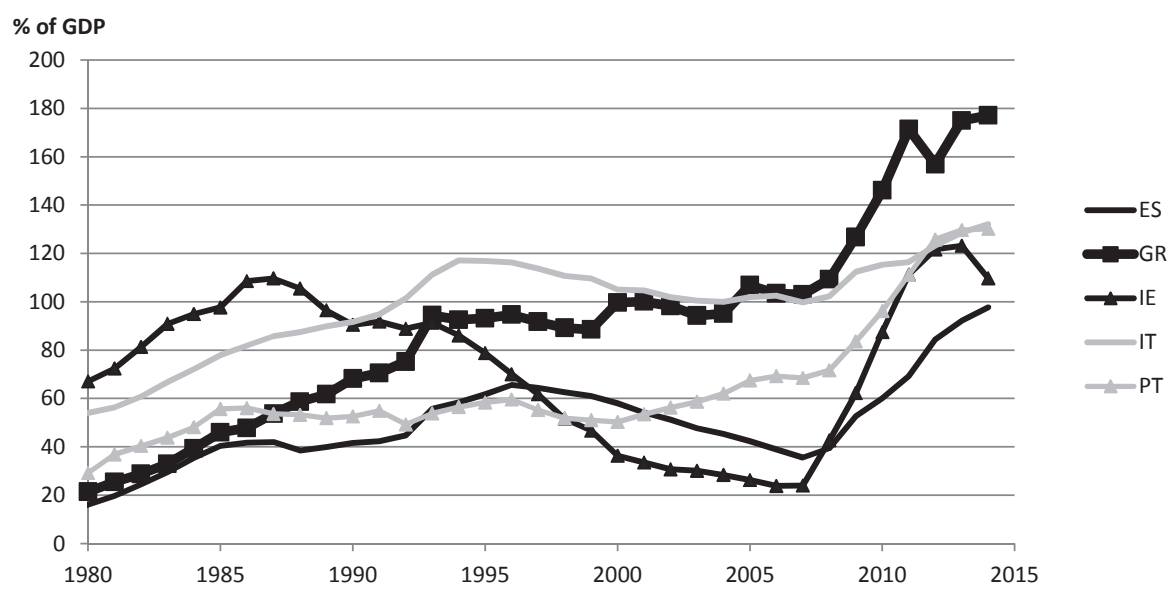

Figure 3: Government debt in Greece and other EZ crisis countries, 19802014, as percentage of GDP. The data come from AMECO, series "General government consolidated gross debt."

Gross government external debt for Greece essentially coincides with the negative of NFA. By contrast, gross government external debt for Portugal and Spain is significantly lower than the negative of those countries' NFA (which are not plotted but are similar to Greece's from Figure 22). Figure 4 thus indicates that Greece's current account deficit essentially financed government borrowing ${ }^{6}$

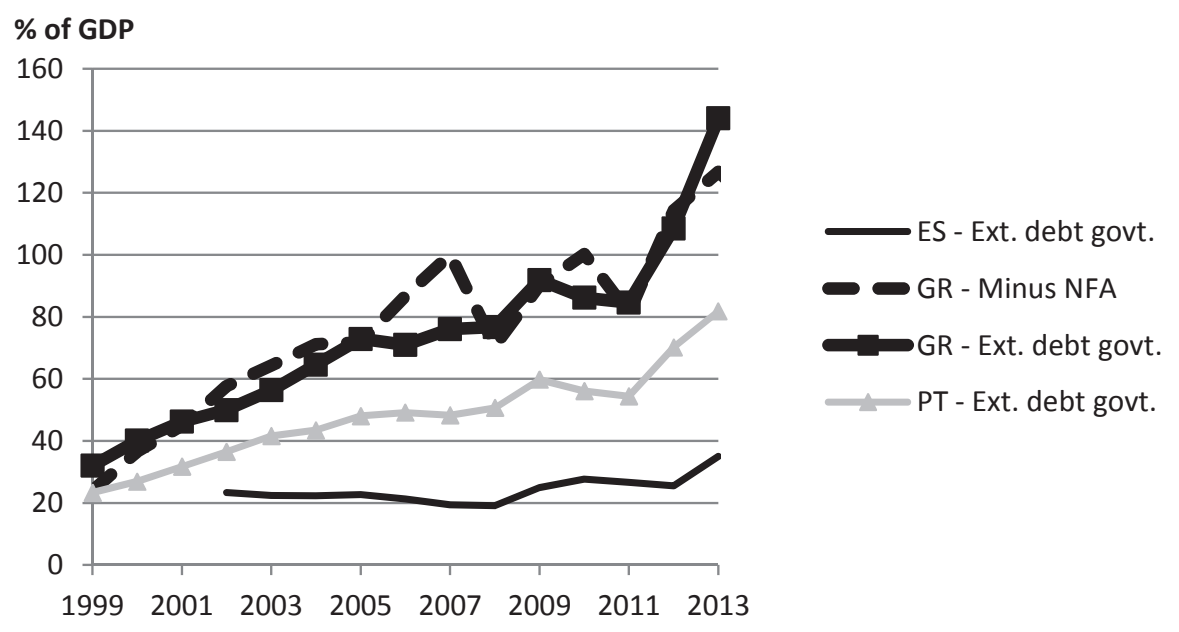

Figure 4: Gross government external debt for Greece, Portugal, and Spain, 1999-2013, as percentage of GDP. The data come from the ECB, series "Gross External Debt - Government." The data are quarterly, and we report the average over each year.

Figure 5 plots government deficit as percentage of GDP. The figure compares Greece to Italy, which later than 1980 for the same reason.

${ }^{6}$ While Figure 4 plots gross rather than net government external debt, gross external assets of the Greek government were negligible, as shown by Hyppolite (2016). 
was the most similar to Greece in terms of the size of its government debt until the crisis, and to the EU average. The figure shows that Greece's public finances improved in the run-up to EZ entry, but worsened steadily post-entry. The pre-entry improvement was similar to that in Italy and the EU average. Unlike in Greece, however, the latter series remained relatively stable post-entry and until the crisis.

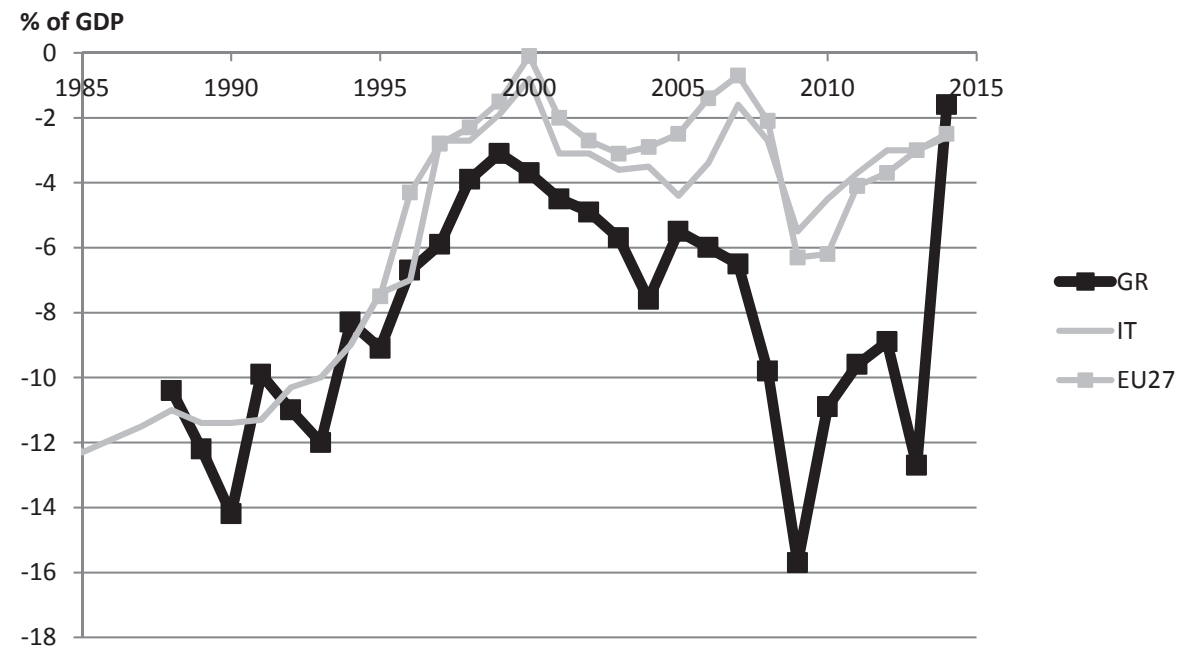

Figure 5: Government deficit in Greece, Italy, and the EU average, 1985-2014, as percentage of GDP. The data come from the EC, series "Surplus (Net lending or net borrowing; general government)."

Banks and Credit. From the mid-1990s and until the crisis, Greece experienced a boom in private credit. An extensive program of financial liberalization that took place in the late 1980 s and the 1990s paved the way for the credit boom. It was also fueled by easier access to foreign capital following EZ entry (and the anticipation of it). Figure 6 plots bank loans to the non-financial private sector for Greece, Ireland, Italy, Portugal, and Spain, as percentage of GDP.

Private-sector loans to GDP were significantly lower in Greece than in the other countries before EZ entry: they stood at $34.1 \%$ of GDP in 1998 , compared to $60.8 \%$ in Italy, $74.6 \%$ in Spain, $80.31 \%$ in Portugal, and $82.8 \%$ in Ireland. Loans to GDP grew faster in Greece than in any other country, however, after EZ entry. As of 2008, they stood at 103.0\%, a ratio smaller than Ireland's, Portugal's, and Spain's, but larger than Italy's.

To finance their increasing lending activity, Greek banks became more reliant on wholesale funding through the interbank market. Figure 7 plots gross external debt for Greek banks, and compares with 


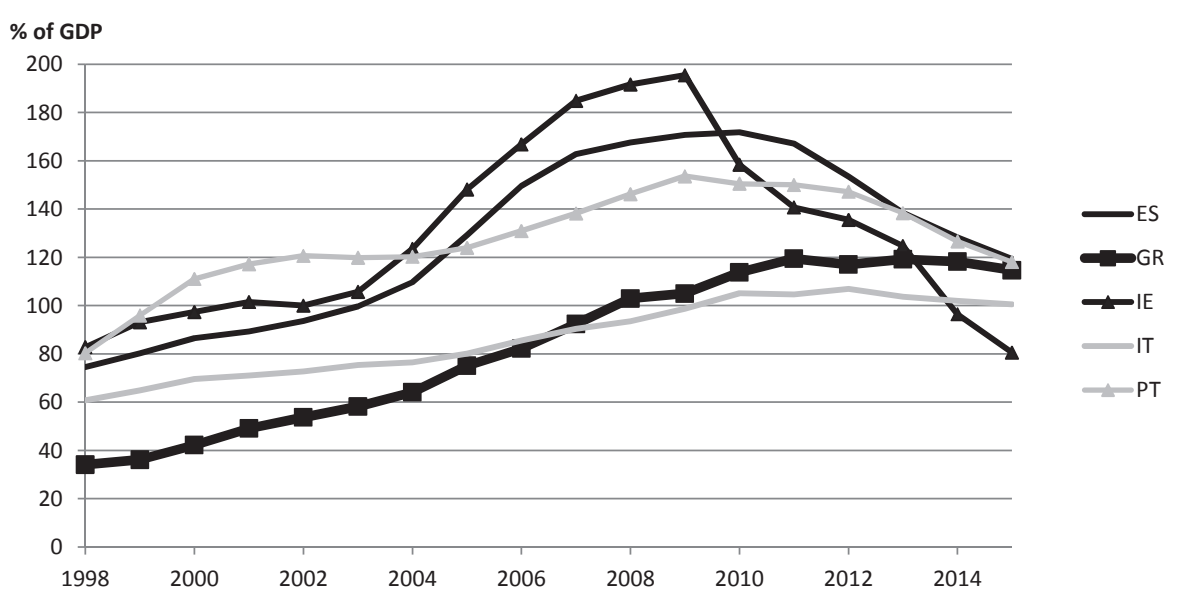

Figure 6: Bank loans to the private sector excluding financial firms in Greece and other EZ crisis countries, 1998-2014, as percentage of GDP. The loans data come from the Bank of Greece (BoG) in the case of Greece and from the European Central Bank (ECB) in for the other countries. (The ECB series for Greece is almost identical to the BoG series, except for an increasing divergence during the period 2004-2009, which leads to a discontinuity between 2009 and 2010 in the ECB series. The divergence is likely due to a change in loan classification by the BoG, which has not been incorporated in the ECB database.) The loan data are monthly and are sampled in December of each year.

Italy, Portugal, and Spain. Gross external debt of banks consists mainly of interbank loans. Gross external debt of Greek banks increased from $12.3 \%$ of GDP in 1999 to $46.2 \%$ of GDP in 2008. As in the case of private-sector loans to GDP, the growth rate was higher than in the other countries, and the 2008 level was smaller than Portugal's, and Spain's, but larger than Italy's.

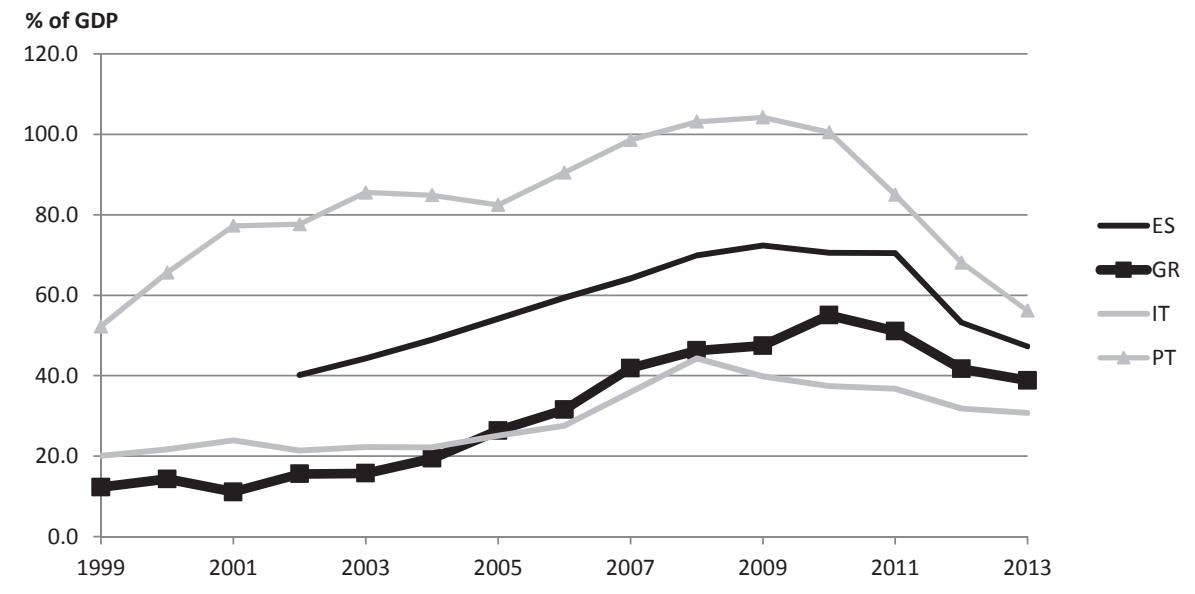

Figure 7: Gross external debt of financial firms for Greece and other EZ crisis countries, 1999-2013, as percentage of GDP. The data come from the ECB, series "Gross External Debt - MFIs." The data are quarterly and we report the average over each year. We exclude the series for Ireland, which rises up to $425 \%$ of GDP, so that the series for the other countries can be seen more clearly. 


\subsection{Crisis}

The Three Shocks. The global financial crisis that began in 2007 found Greece in a highly vulnerable position. As of 2007, Greece's current account deficit had reached 15.9\% of GDP, NFA stood at -99.9\%, government deficit at $6.5 \%$, and government debt at $103.1 \%$. On all four measures, Greece fared worse than Ireland, Italy, Portugal, and Spain. Greece's banking system was also vulnerable. While the ratio of private-sector loans to GDP in Greece was lower than in Ireland, Portugal, and Spain, the exposure of Greek banks to their sovereign was larger than in those countries.

Greece was hit by three interdependent shocks during the crisis. The first shock was a sovereign debt crisis: investors began to perceive the debt of the Greek government as unsustainable, and were no longer willing to finance the government deficit. The second shock was a banking crisis: Greek banks had difficulty financing themselves, and their solvency was put in doubt because of projected losses to the value of their assets. The third shock was a sudden stop: foreign investors were no longer willing to lend to Greece as a whole (government, banks, and firms), and so the country could not finance its current account deficit, nor roll over its maturing gross liabilities.

The three shocks were interlinked. The banking crisis made the government's fiscal problems worse. This was because the government had to inject equity capital into the banks, and had to provide them with guarantees so that they could borrow in the interbank market. Moreover, because banks had to curtail their lending, the economy slowed down and the government's tax revenues declined. These channels were at play starting from the Fall of 2008, when Greek banks faced significant difficulties financing themselves in the interbank market. The Greek government passed a law in December 2008 that provided support to the banks, in the form of guarantees and equity capital.

Conversely, the sovereign crisis made the banks' liquidity and solvency problems worse. This was because concerns about default risk by the Greek government reduced the value of the Greek banks' government-bond portfolio, and this put the banks' solvency in doubt. Moreover, the government had to engage in significant fiscal tightening, and the ensuing recession meant that firms and households had difficulty repaying their loans, adding to the banks' solvency problems. Finally, the guarantees given by the government to Greek banks diminished in value. That applied both to the guarantees intended to help the banks borrow in the interbank market, and to the government-supplied deposit insurance. Hence, banks had more difficulties financing themselves, and their liquidity problems worsened. These channels were at play starting from September 2009, when investors began to perceive the debt of the Greek government as unsustainable. 
Both the sovereign and the banking crises were closely linked to the sudden stop. Indeed, most of government debt was held by foreign investors: out of government debt equal to $103.1 \%$ of GDP in 2007, the debt held by foreign investors was $76.1 \%$ of GDP. Greek financial firms had also significant foreign debt: their gross external debt was $41.8 \%$ of GDP in 2007. Since the Greek government and Greek banks intermediated most of the flow of foreign capital to Greece, the withdrawal of foreign capital meant that both sectors' access to funds was seriously impaired.

Ireland, Italy, Portugal, and Spain were hit by some or all of the same shocks. The shocks' effects were more severe in the case of Greece, however, given the country's larger vulnerability 7

Assistance to the Sovereign, and Sovereign Default. In May 2010, Greece agreed to follow an adjustment program financed and monitored by European institutions and the IMF. Under the terms of the agreement, Greece received a loan so as to avoid a default on its private creditors and reduce its government deficit more smoothly. In exchange, it had to engage in significant fiscal tightening and implement a battery of structural reforms. The agreed loan amount was 110bn Euros, or $44 \%$ of Greece's 2010 GDP. Out of that amount, 80bn came from other EZ countries and the remaining 30bn from the IMF. The first adjustment program was rolled over into a second, agreed in February 2012. A third program began in August 2015.

In March 2012, Greece agreed a debt restructuring with its private creditors. Under the terms of this Private Sector Involvement (PSI), privately-held government debt with face value 199.2bn Euros was replaced by debt with face value $92.1 \mathrm{bn}$. Greece was the only EZ country to default on its creditors. Assistance to the Banks, Recapitalizations, and Capital Controls. In addition to the loans made to the Greek government under the adjustment programs, assistance was provided to Greece through ECB loans to its banking system. These loans were administered either directly from the $\mathrm{ECB}$, with a low interest rate and stringent collateral requirements, or indirectly via the Bank of Greece (BoG) as emergency liquidity assistance (ELA), with a higher interest rate and less stringent collateral requirements. ECB loans were necessary to address the liquidity problems of Greek banks. They rose from 48bn Euros in January 2010 to a maximum of 158bn Euros in February 2012, then dropped to a minimum of 45bn Euros in November 2014, and then rose again to a maximum of $122 \mathrm{bn}$ in September 2015. ECB loans were at their maxima around times when there was a high perceived risk of Greece exiting the EZ (Grexit). The risk of Grexit was high around the double election of May and June 2012, and during the first half of 2015 after a new Greek government opposed to the

\footnotetext{
${ }^{7}$ Ireland and Spain had significantly lower levels of public debt. Italy had much lower levels of net external debt. Portugal was in a position somewhat similar to Greece, although with smaller government debt and deficits.
} 
adjustment programs had been elected in January 2015.

Greek banks went through a series of recapitalizations. Losses on the banks' government-bond portfolio reduced the capital of all banks and rendered most of the large ones insolvent. Some of the banks were resolved, and their deposits and some of the loans were transferred to the four largest banks. The latter were recapitalized. The resolution and recapitalization process was completed in July 2013, and involved 38.9bn Euros of public funds, which were loaned to Greece. An additional 3.1bn Euros were raised by private investors. That first, large-scale recapitalization was followed by a second in April and May 2014, when the banks raised 8.3bn Euros, solely from private investors. A third recapitalization took place in the fourth quarter of 2015. The total amount that was raised then was $13.7 \mathrm{bn}$ Euros, of which 8bn Euros was raised from private sources via new investment and debtequity conversions. The second and third recapitalizations were made necessary because of increased projected losses on banks' loans to the private sector.

Macroeconomic developments. We finally review the macroeconomic developments during the crisis period 2009-2014, following a roughly similar order as for the pre-crisis period. Greek GDP per capita declined sharply during the crisis, as shown in Figure 1. The decline was $25.8 \%$ between 2008 and 2014. It was much sharper than in Ireland (6.1\%), Italy (10.3\%), Portugal (7.8\%), and Spain $(9.6 \%)$.

The decline in GDP was accompanied by a large decline in investment. The latter decline can be seen in Table 1 by comparing the crisis period with the pre-crisis one. It can be seen more sharply by comparing investment in 2014 to that in 2008. Investment in 2014 was less than half of its 2008 value, having dropped by $12.2 \%$ of GDP. Both the relative and the absolute declines were larger than in Ireland, Italy, Portugal, and Spain. The level of investment in 2014 was also significantly lower than in the other countries.

During the crisis, Greece reduced and almost eliminated its current account deficit. That deficit stood at $2.2 \%$ of GDP in 2014, down from $16.5 \%$ in 2008 . The adjustment occurred entirely through a drop in investment. Total saving did not change: government saving increased as a result of the fiscal tightening that took place during the crisis, but that effect was offset by a decline in private saving. Private saving in Greece declined between 2008 and 2014, while they increased in Ireland, Italy, Portugal, and Spain. Conversely, government saving increased in Greece during the same period, while they declined in the other countries. Thus, the austerity undergone by Greece during the crisis was more severe than in the other countries. 
During the crisis, public debt to GDP followed explosive dynamics, rising from $103.1 \%$ in 2007 and $126.8 \%$ in 2009 to $177.1 \%$ in 2014 . The increase resulted from the deficits ran during the crisis and from the drop in GDP. The debt restructuring agreed in 2012 countered these effects somewhat 8 Greece eliminated its primary budget deficit in 2014 - it ran a primary surplus of $0.4 \%$ in that year.

The ratio of private-sector loans to GDP declined slowly during the crisis. As Figure 6 shows, it stood at almost the same level as Portugal's and Spain's in 2014, and above Ireland's and Italy's. The slow decline of private-sector loans to GDP in Greece is due to the sharp decline in GDP and the relatively slow pace of resolving non-performing loans.

\section{Benchmarking the Greek Crisis.}

The previous section argued that Greece experienced three quasi simultaneous and interlinked shocks: a sudden stop, with the abrupt withdrawal of private foreign capital starting in 2009; a sovereign debt crisis, with rapidly deteriorating fiscal accounts in 2008 and 2009, culminating in a sovereign default in 2012; and a banking crisis with the bursting of a boom in credit to the private non-financial sector in 2008 and 2009. This section provides a systematic comparison between Greece and other countries experiencing each type (and sometimes combinations) of similar shocks.

\subsection{The Incidence of Crisis}

We begin by identifying episodes of sudden stops, sovereign defaults and lending booms/busts.

Sudden stops. Starting with the work of Dornbusch and Werner (1994), Calvo et al. (2006), Adalet and Eichengreen (2007) and many others, an abundant literature has explored the macroeconomic consequences of a sudden reversal in foreign lending. Calvo et al. (2006), in particular, compiled a list of 33 sudden stop episodes between 1980 and 2004 for a sample of 31 emerging markets. In the authors' classification, a sudden stop is identified by the combination of (a) a reversal in capital flows, (b) an increase in emerging market bond spreads, capturing times of global stress on financial markets, and (c) a large drop in domestic output. Mendoza (2010) adopts a similar classification, while Korinek

\begin{tabular}{l}
\hline${ }^{8}$ The figures for Greek government debt during the crisis overstate the value of the debt, especially when Greece is \\
compared to other high-debt countries such as Italy and Portugal. This is because Greek debt is computed in nominal \\
terms, by adding the principal (face value) payments that are due in all future years, rather than by adding all principal \\
and coupon payments after discounting them at appropriate market rates. This overstates the value of the debt because \\
assistance loans by the EZ during the crisis came with long maturities and below market interest rates. In particular, the \\
average interest rate on Greek debt is smaller than for Italy and Portugal. For estimates of Greek debt in present-value \\
terms see, for example, Schumacher and Weder di Mauro (2015). \\
\hline
\end{tabular}


and Mendoza (2014) extend the Calvo et al. (2006) sample to 2012 and to advanced economies 9 As in these earlier papers, we define the year $t$ of a sudden stop episode as the year of a sharp reduction in foreign lending that coincides with a large decline in output ${ }^{10}$ With this criterion, we identify 49 sudden stop events, 36 for emerging market economies and 13 for advanced economies (see Table 3).

Sovereign defaults. We identify sovereign debt crisis as in Gourinchas and Obstfeld (2012). The year $t$ of a sovereign debt crisis corresponds to the year identified with a default on domestic or external public debt, as tabulated by Reinhart and Rogoff (2009), Cantor and Packer (1995); Chambers (2011); Moody's (2009); Sturzenegger and Zettelmeyer (2007) 11 Since 1980, we record 64 default episodes in emerging market economies, and one in an advanced economy: Greece in 2012.

Lending booms/busts. Credit boom episodes are defined as in Gourinchas et al. (2001), from the deviation of the ratio of credit to the non-financial sector to output from its trend ${ }^{12}$ A lending boom episode is recorded when this cyclical deviation exceeds a given boom threshold. The year $t$ of the lending boom then coincides with the year in which the maximum (positive) deviation of credit to GDP occurs. Our calculations identify 114 lending boom episodes, 96 of which in emerging market economies.

Finally, we identify 'Trifecta' episodes: sovereign defaults that coincide with a lending boom and a sudden stop 13 We find nine such crises for emerging markets, including well-known episodes such as Mexico in 1982, Chile and Uruguay in 1983, Indonesia and Russia in 1998, Ecuador in 1999, Argentina and Turkey in 2001 and Uruguay again in 2003. Again, Greece is the only advanced economy to have experienced a 'Trifecta' crisis in our sample.

Table 3 reports the incidence of each type of crisis for advanced and emerging market economies. It illustrates the relative prevalence of sovereign defaults, lending booms and 'Trifecta' crises among emerging economies. By contrast, sudden stops are roughly distributed in proportion to the number of countries in each group in our sample.

We compare each type of episode to the Greek crisis. For the purpose of this exercise, we consider that the Greek episode begins in 2010 ${ }^{14}$

\footnotetext{
${ }^{9}$ Like Calvo et al. (2006), Korinek and Mendoza $(2014)$ focus on 'systemic' sudden stops that occur in times of turmoil on global bond markets.

${ }^{10}$ The appendix provides additional details. In short, we identify large output drops when the peak-to-trough cumulated output decline in a recession exceeds the median cumulated output decline within group (advanced or emerging markets). A sudden stop occurs when this large output drop overlaps a capital flow reversal episode, defined as a year-on-year decline in net capital inflows that is more than two standard deviations away from the country mean.

${ }^{11}$ See Gourinchas and Obstfeld (2012) for details.

${ }^{12}$ See details in the appendix.

${ }^{13}$ Technically, we record a 'Trifecta' episode when the sovereign default event toccurs during a lending boom episode and during a sudden stop episode.

${ }^{14}$ Different dimensions of the Greek crisis unfolded at different times. According to our dating procedure, the lending
} 


\begin{tabular}{cccccc}
\hline & Sudden Stop & Sovereign Default & Lending Boom & Trifecta & \# Countries \\
\hline & & & & & \\
Advanced Economies & 13 & 1 & 18 & 1 & 22 \\
Emerging Markets & 36 & 64 & 96 & 9 & 57 \\
Total & 49 & 65 & 114 & 10 & 79 \\
\hline
\end{tabular}

Table 3: Crises Incidence in Advanced and Emerging Economies, 1980-2014. Details on how each type of episode is identified are in the appendix.

\subsection{The data.}

We construct a database of macro variables for a large sample of advanced and emerging economies between 1980 and 2014 $\sqrt[15]{5}$ The sample contains 22 advanced economies (including Greece) and 57 emerging market economies, distributed across six broad regions. The list of emerging market economies includes all countries classified as emerging according to leading outlets and are therefore reasonably well integrated into global bond markets 16

In the spirit of a large literature in international macroeconomics, we examine the behavior of key macroeconomic variables around the three types of shocks discussed above : sudden stops, sovereign debt crises, and lending boom/busts episodes, as well as Trifecta crises 17 Our event study considers the response of eight macroeconomic variables: output, consumption, investment, exports and imports of goods and services, the current account, credit to the non-financial sector, and public debt. The data is collected from the World Bank's Development Indicators, the IMF's International Financial Statistics and Reinhart and Rogoff (2009) estimates of total (domestic and external) gross public debt for a large number of countries ${ }^{18}$ In addition to these macroeconomic variables, we use Reinhart and Rogoff (2004) and Ilzetzki et al. (2010) de facto exchange rate regime classification and sort countries into 'pegs' or 'floats' based on the exchange rate regime in the year preceding the episode. Further, we split 'pegs' into 'de-peggers', i.e. countries that abandon their peg within two years of the shock, and 'strict peggers' who maintain their peg for at least two years. This will allow us to contrast

boom peaked in 2008, the sovereign default occurred in 2012 and the collapse in output during the sudden stop episode occurred in 2013. Nevertheless 2010 is a natural starting point since specific concerns about the Greek economy arose first in late 2009. The 5-yr spread between Greece and Germany was 120bp in September 2009, but climbed to 277bp by January 2010, before reaching 680 bp by April of that year.

${ }^{15}$ We choose to begin in 1980 because of data availability and also because this period marks a phase of growing international financial integration, especially for emerging market economies.

${ }^{16}$ Our list includes all countries listed as emerging economies in either J.P. Morgan's EMBIG index, the FTSE's Group of Advanced or Secondary Emerging Markets, the MSCI-Barra classification of Emerging or Frontier economies and the Dow Jones list of Emerging Market Economies. We add to these countries Israel, Hong-Kong and Singapore, all countries that are now often included in the group of advanced economies but belong to the group of emerging market economies for most of the sample. The list of countries in our sample is included in the appendix.

${ }^{17}$ See Eichengreen et al. (1995) and Kaminsky and Reinhart (1999) for seminal contributions.

${ }^{18}$ Detailed sources for each variable are provided in the appendix. 
the macroeconomic response of countries based on their post-shock exchange rate regime. This is an important consideration given the argument -often heard- that the main constraint on the Greek economy is its lack of nominal exchange rate flexibility (for instance see Krugman (2012)).

\subsection{Findings}

Figure 8 reports the output response to a typical sudden stop across the 48 episodes (excluding Greece). It measures output per capita, relative to its pre-crisis level at t-2, in 100-log points, so that a value of $x$ indicates that output per capita is $e^{x / 100}$ times pre-crisis output. The figure also includes point-wise one-sided $10 \%$ confidence intervals (the greyed area), as well as the trajectory of Greek output (in red with bullets) during the 2010 episode. As expected, since our definition of sudden stops requires a large output drop, the mean response indicates a sharp decline in output, marginally significant, close to $10 \%$ below its peak in the year of the sudden stop, followed by a gradual recovery. By year $t+2$, output has typically recovered to its pre-crisis level and continues to expand. Two facts are relevant here. First, Greece experienced a strikingly worse output decline. By 2013, i.e. $t+3$, Greek output per capita was $25 \%$ below it pre-crisis level $\left(e^{-0.29}=0.75\right)$, significantly below the average response and showing few signs of recovery. Second, unlike the typical sudden stop, Greece's output path was 'backloaded.' The initial recession in 2009 and $2010(t-1$ and $t)$ is similar to a typical sudden stop episode and milder than the subsequent decline in Greek output. By contrast, typical episodes are 'front loaded' with a more pronounced ' $V$ ' shape 19 This is not surprising if we consider that Greece's sudden stop was of a particular nature. As discussed in the previous section, the sudden withdrawal of foreign lending was accommodated initially via ECB lending against collateral, and after 2010 via official assistance from the IMF and the European Union. Hence there was no sharp immediate downturn, as is typical when countries experience sudden loss of market access.

Claim 1. The Greek crisis was significantly more severe, persistent and backloaded than the typical sudden stop.

Figure 9 reports a similar analysis for the consumption and investment ratios to output. As for output, each variable is expressed in 100-log points, relative to its value at $t$-2, i.e. at the beginning of the episode. Equivalently, this figure reports the growth differential between consumption or investment

\footnotetext{
${ }^{19} \mathrm{By}$ dating the Greek crisis in 2010 instead of later - see fn. 14. it may appear as if we mechanically make the Greek output collapse more protracted compared to other episodes where the output collapse may have started before $t-2$. This is not a concern: the median duration of output collapses in our sample of sudden stops is 1.5 years for advanced economies and 1 year for emerging market economies. Only two output collapses last for six years or longer: Bosnia between 2008 and 2014 (six years) and Ukraine between 1992 and 1999 (seven years). Hence our choice of 2010 as the crisis year for Greece does not affect the results.
} 


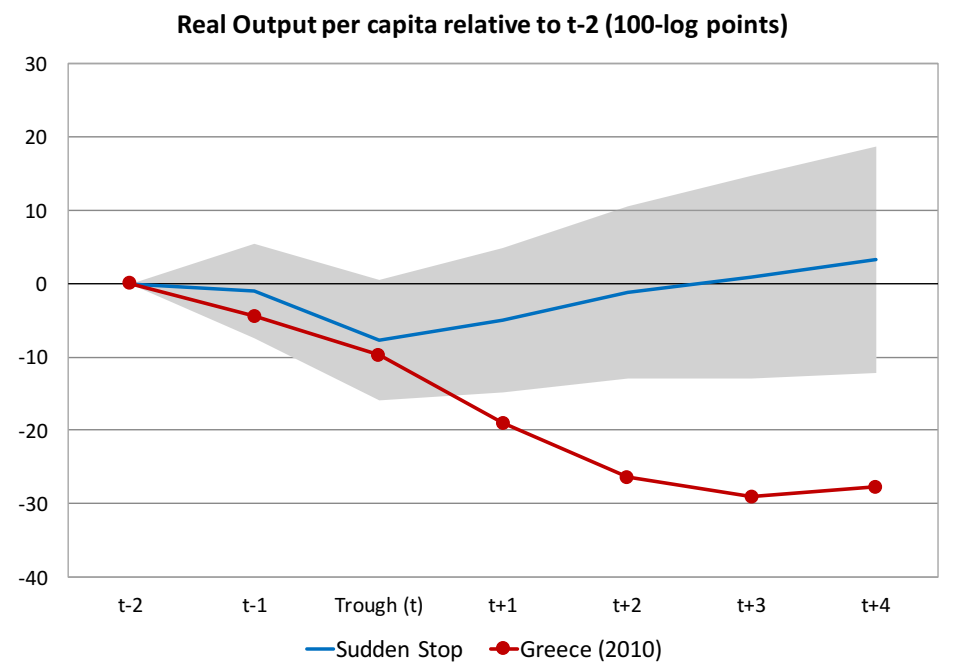

Figure 8: The response of output to a sudden stop. The figure reports real output per capita relative to period $t-2$, in 100 log-points for a typical sudden stop episode (with output collapse) and for Greece in the 2010 crisis. See the appendix for data sources.

and output since $t-2$. The left panel reports the consumption-to-output ratio. In a typical sudden stop, consumption mostly moves in line with output. Instead, Greek consumption grew modestly faster than output, although not significantly so. The right panel reports the investment-to-output ratio. Greek investment collapsed dramatically, much more so than in a typical sudden stop. By 2013, i.e. $t+3$, the investment-to-output ratio was less than half of its pre-crisis level $\left(e^{-0.76}=0.47\right)$, while a typical sudden stop sees a decline of $20 \%$ to $30 \%$. Given the decline in output per capita documented in Figure 8, real investment per capita collapsed by almost two-thirds between 2008 and $2013(0.75 \times 0.47=0.35)$.

Claim 2. The collapse in Greek aggregate investment in this crisis was unprecedented in its persistence and magnitude, in comparison to the typical sudden stop.

A sudden withdrawal of foreign capital is only one of the shocks that Greece experienced since 2009 and one might be concerned that the previous comparison might be too unfavorable to Greece. For instance, like Greece in 2010, Argentina in 2001, Chile in 1983 or Indonesia in 1998, among others, experienced a simultaneous drying-up of foreign capital, a sovereign default and a collapse in lending, i.e. a 'Trifecta' shock. These episodes are amongst the worst documented economic crises in postwar 

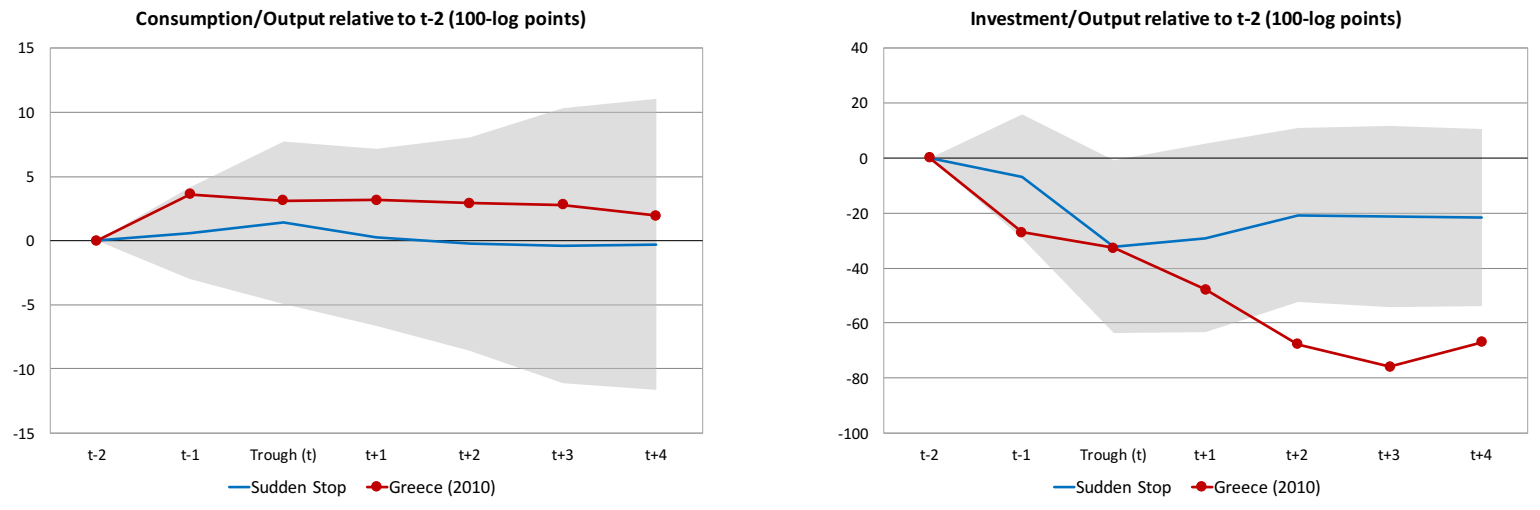

Figure 9: The response of consumption and investment to a sudden stop. The figure reports the consumption-output ratio (left panel) and the investment output ratio (right panel) relative to period $t-2$, in 100 log-points for a typical sudden stop episode (with large output collapse) and for Greece in 2010. See the appendix for data sources.

history, often accompanied by a banking crisis, and unprecedented levels of economic hardship and political turmoil. In light of the economic and political dislocation associated with it, one would expect the Greek crisis to be on a comparable scale. To investigate this, Figure 10 reports the average output response to each of the following shocks: a sovereign default, a lending boom/bust, as well as the 'Trifecta' shock that consists of these two shocks occurring during a sudden stop episode. As an additional point of comparison, the figure also includes the average output response for Ireland, Italy, Portugal and Spain, i.e. the other peripheral countries most affected by the Eurozone crisis (under the label 'IIPS'). Finally, the graph also includes $10 \%$ point-wise one-sided confidence intervals for the 'Trifecta' shocks.

The figure illustrates how much of an outlier the Greek crisis truly was. While output per capita initially declined in line with that of a 'Trifecta' crisis, by 2011 (i.e. $t+1$ ), output had declined significantly more and kept falling. By contrast, in a typical 'Trifecta' crisis, output is back to its precrisis level by $t+3$. The figure allows us to make a number of additional points. First, 'Trifecta' crises are more severe than a typical default crisis, although the differences are small and often insignificant. Second following a lending boom, output keeps growing. This is because many lending booms in our sample are not always followed by an economic downturn or crisis, as noted also by Gourinchas et al. (2001) and Ranciere et al. (2008). Lastly, the trajectory for the 'IIPS' countries illustrates that, in these countries too, the crisis has been much more persistent then expected, with output still $7 \%$ below 


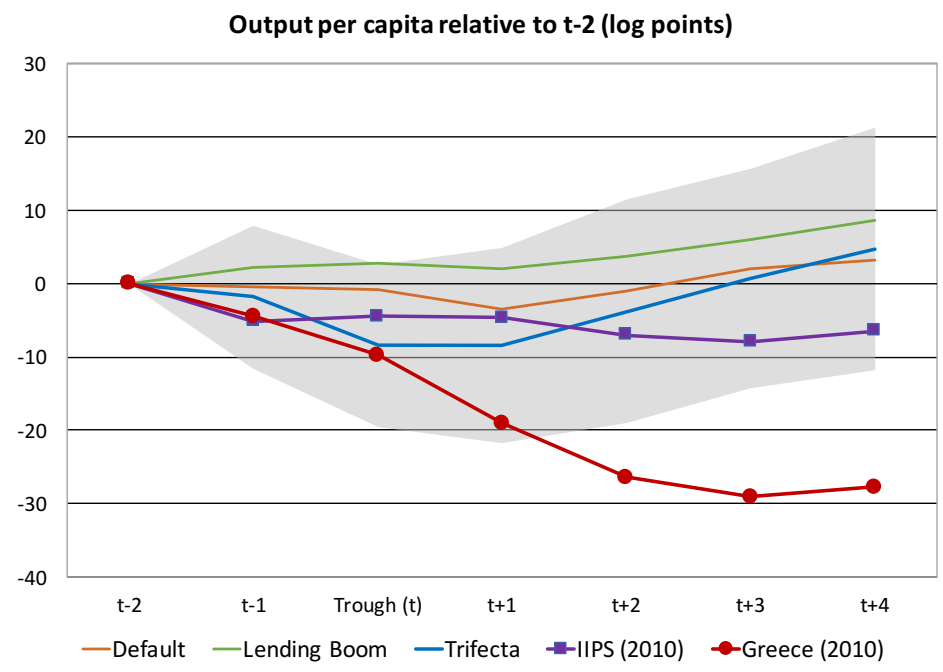

Figure 10: The response of output to various crises. The figure reports the mean output per capita relative to period $t-2$, in $100 \log$-points for various episodes, and for Greece in 2010. 10\% one-sided point-wise confidence intervals for 'Trifecta' episodes. See the appendix for data sources.

pre-crisis level as of $2014(t+4)$.

Claim 3. The collapse in Greek output per capita has been significantly more severe and more persistent than the typical 'Trifecta' crisis.

Figure 11 makes the same point even more vividly. The panel on the left reports the output trajectory for all countries that experienced a sudden stop in our sample. The panel on the right presents similar results for all 'Trifecta' episodes. Both panels also report the Greek 2010 episode. As is clear from both figures, Greece's economic performance is cumulatively much worse than all episodes from the last 35 years, including crises such as Argentina in 2001, or Uruguay in 1983, with the single exception of the United Arab Emirates crisis of 200920

We next consider the role of the exchange rate regime. Our dataset includes information on the de-facto exchange rate regime from Reinhart and Rogoff (2004) and Ilzetzki et al. (2010). We use this data to construct an indicator of the exchange rate regime in the year of the shock and the preceding year (peg/float). We further subdivide pegs based on whether countries maintain their peg for at

\footnotetext{
${ }^{20}$ The economy of the United Arab Emirates experienced a sudden stop episode in 2009, as a consequence of the burst of a real estate bubble, and the sharp decline in oil and natural gas prices in the immediate aftermath of the Global Financial Crisis. real output per capita declined by 11 percent, 10.7 percent and 16.4 percent in 2007, 2008 and 2009 respectively, culminating with the collapse of Dubai World in November 2009.
} 

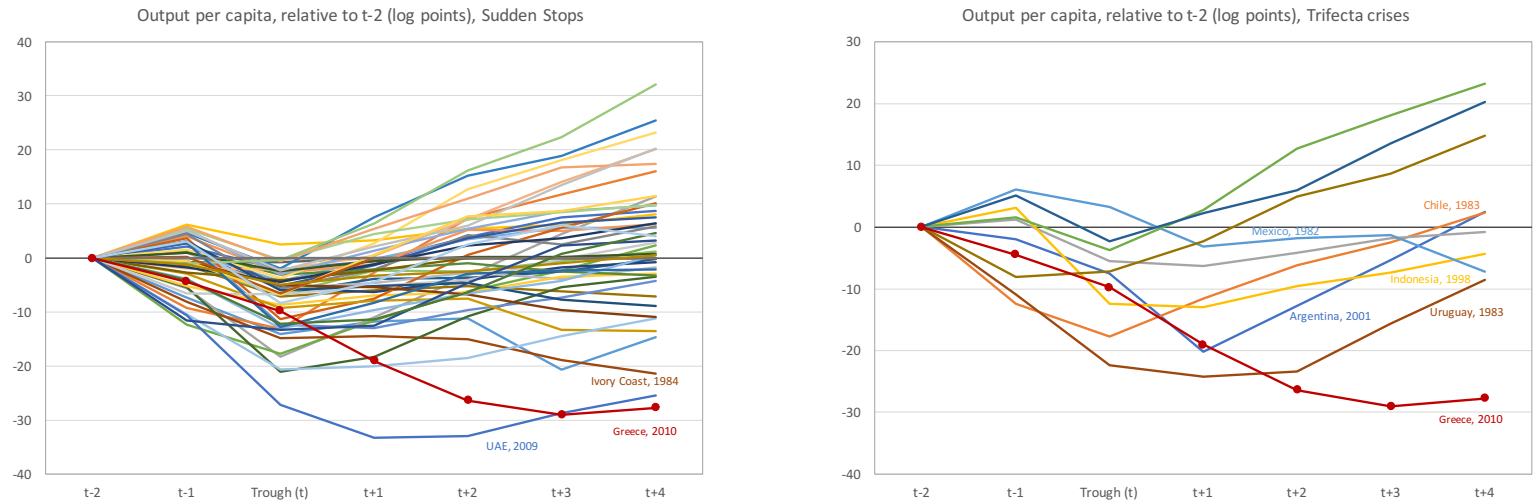

Figure 11: The distribution of output responses to sudden stops and 'Trifecta' crises The figure reports output per capita relative to period $t-2$, in $100 \log$-points for each sudden stop episode (left panel), and for each 'Trifecta' crises (right panel), together with Greece in 2010. See the appendix for data sources.

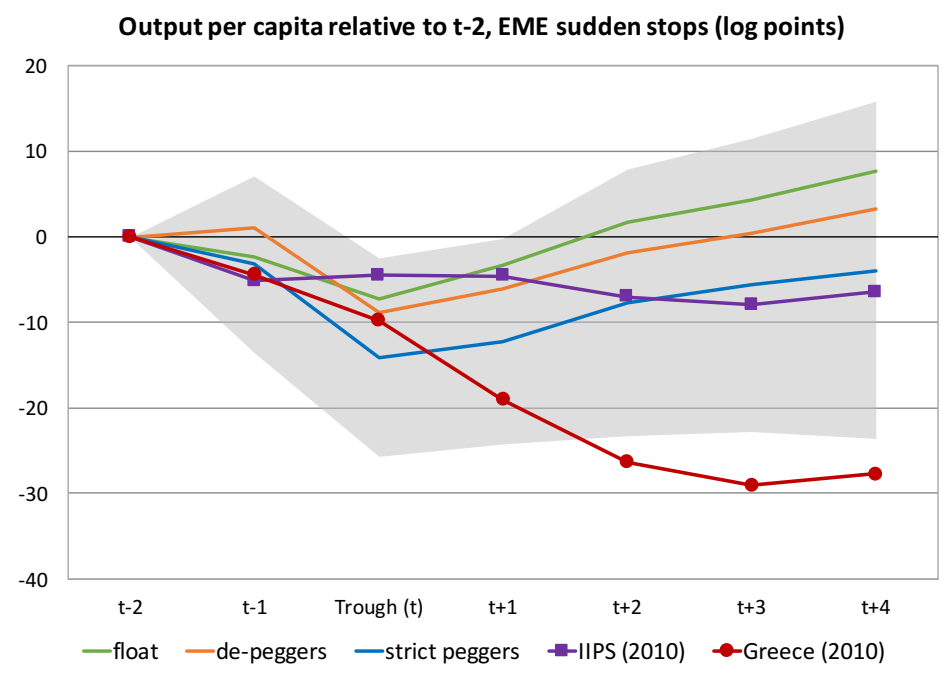

Figure 12: The role of the exchange rate regime. The figure reports output per capita relative to period $t-2$, in 100 log-points for Emerging Market Sudden Stops, by exchange rate regime, together with Greece in 2010. $10 \%$ one-sided point-wise confidence intervals for 'strict peggers'. See the appendix for data sources. 
least two years after the crisis (strict peggers) or abandoned it (de-peggers) ${ }^{21}$ Figure 12 contrasts the output response following an emerging market sudden stop for de-peggers, strict peggers and floaters, together with that of Greece and of the IIPS countries. The figure also includes $10 \%$ point-wise onesided confidence intervals for strict peggers. Unsurprisingly, we find that strict peggers experience a worse adjustment than de-peggers, who in turn perform worse than floaters: by $t+4$, output is still $4 \%$ below its pre-crisis level for strict peggers, while it is 3\% (resp. 8\%) above trend for de-peggers (resp. floaters): a more flexible exchange rate regime is associated with a less severe and less persistent crisis. Greece's experience is very singular in that respect as well: its output loss is much larger and significantly more persistent than for countries that maintained their exchange rate. By contrast, the experience of the 'IIPS' countries is more in line with that of 'strict peggers', albeit less severe in 2010 and $2011(t$ and $t+1)$.

There are two ways to think about this result. One possible interpretation is that the severity of the Greek crisis cannot be attributed entirely to the strictures of the common currency, since it significantly underperformed other 'strict fixers.' This would direct our attention towards other features of the Greek economy than just the exchange rate regime. This is not the only interpretation. Clearly, countries can and often choose their exchange rate regime in response to the economic environment. Therefore, the sample of 'strict fixers' may consist precisely of countries who stand to lose relatively less from keeping the exchange rate pegged in the aftermath of a sudden stop. This could be the case in particular if these countries were experiencing a relatively modest decline in output. To investigate this question further, Figure 13 reports the data for strict fixers, alongside that for Estonia, Latvia and Greece. Both Latvia and Estonia experienced severe recessions following their 2009 sudden stop episode. Estonia's output per capita declined by $19 \%$ between 2007 and 2009, while that of Latvia declined by $17 \%$ between 2007 and 2010. Nevertheless, both countries chose to maintain their peg to the euro and 'doubled down' by subsequently adopting the common currency, in January 2011 for Estonia and January 2014 for Latvia. Overall, both countries have an experience similar to that of the full sample of strict peggers. Yet, it could hardly be argued that the costs of maintaining a fixed exchange rate were small for either country. Instead, their decision to carry forward and adopt the Euro can be related to historical and geo-strategic reasons, in particular the desire to anchor their country firmly in the West. Both countries, therefore, adopted the euro despite the large short run costs associated with doing so: the comparison of their trajectory with Greece's is unlikely to suffer from a strong selection bias. It is

\footnotetext{
${ }^{21}$ We classify countries into peggers and floaters based on the 'fine classification' of Ilzetzki et al. (2010). Peggers have an index smaller than 9. The sample consists of 20 floats, 10 strict peggers, 15 de-peggers and 2 others.
} 


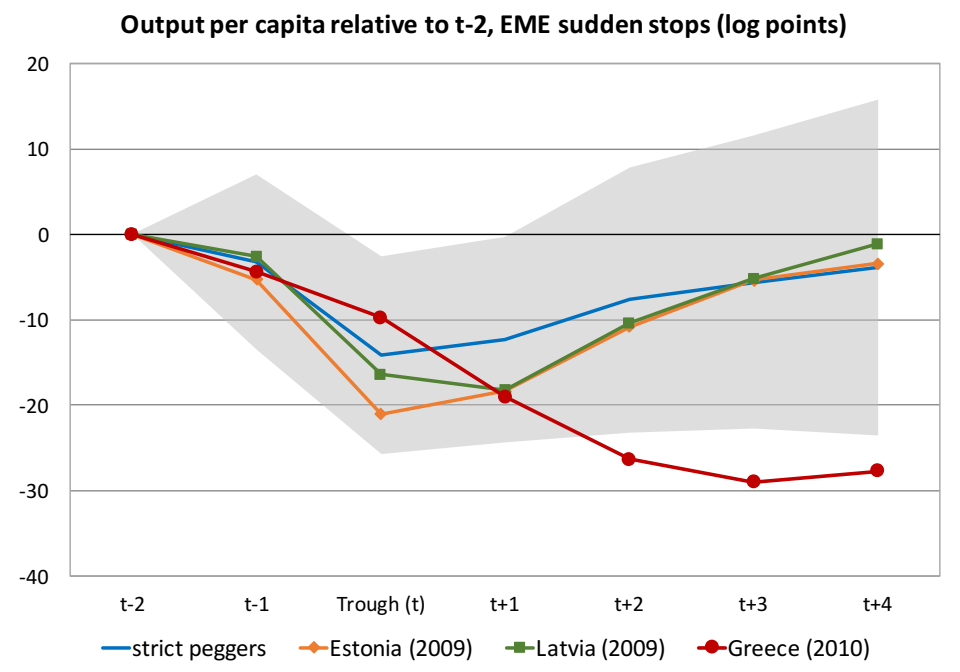

Figure 13: Output response for 'strict peggers'. The figure reports output per capita relative to period $t-2$, in 100 log-points for Emerging Market strict peggers, together with Estonia (2009), Latvia (2009) and Greece (2010). One-sided $10 \%$ point-wise confidence intervals for 'strict peggers'. See the appendix for data sources.

therefore interesting that the experience of Greece appears significantly worse than either country 22

Claim 4. The Greek crisis was significantly more severe than the typical emerging market sudden stop, even for countries such as Latvia or Estonia that maintained a fixed exchange rate in the aftermath of a sudden stop with large output collapse.

Figure 14 reports credit to the non financial sector (left panel) and public debt (right panel), relative to output. The credit-to-output ratio is measured in deviation from an hp-filter trend, while the debtto-output ratio is measured relative to the country mean. Each variable is expressed in percent of GDP. The left panel reports $10 \%$ one-sided point-wise confidence bands for lending boom/bust episodes, while the right panel reports similar confidence bands for 'Trifecta' episodes since these episodes witness the largest increase in public debt. Starting with the credit-to-output ratio, we see that the initial leverage was high, but not as high as in typical lending boom episodes, around $10 \%$ of GDP. The ratio of credit to GDP was gradually reduced, although at a more measured pace than in typical episodes. Overall,

\footnotetext{
${ }^{22}$ There are, of course, other differences between the Baltic countries and Greece and we want to acknowledge the limits of the comparison. For instance, price and wages adjusted more rapidly in Latvia than in Greece. Blanchard et al. (2013), in a case study of the Latvia boom, bust and recovery, argue that internal devaluation worked fast in part due to nominal wage cuts, but also to rapid productivity increases that fueled a solid supply response. We explore in section 6 what would have happened in Greece with more rapid price and wage adjustment.
} 

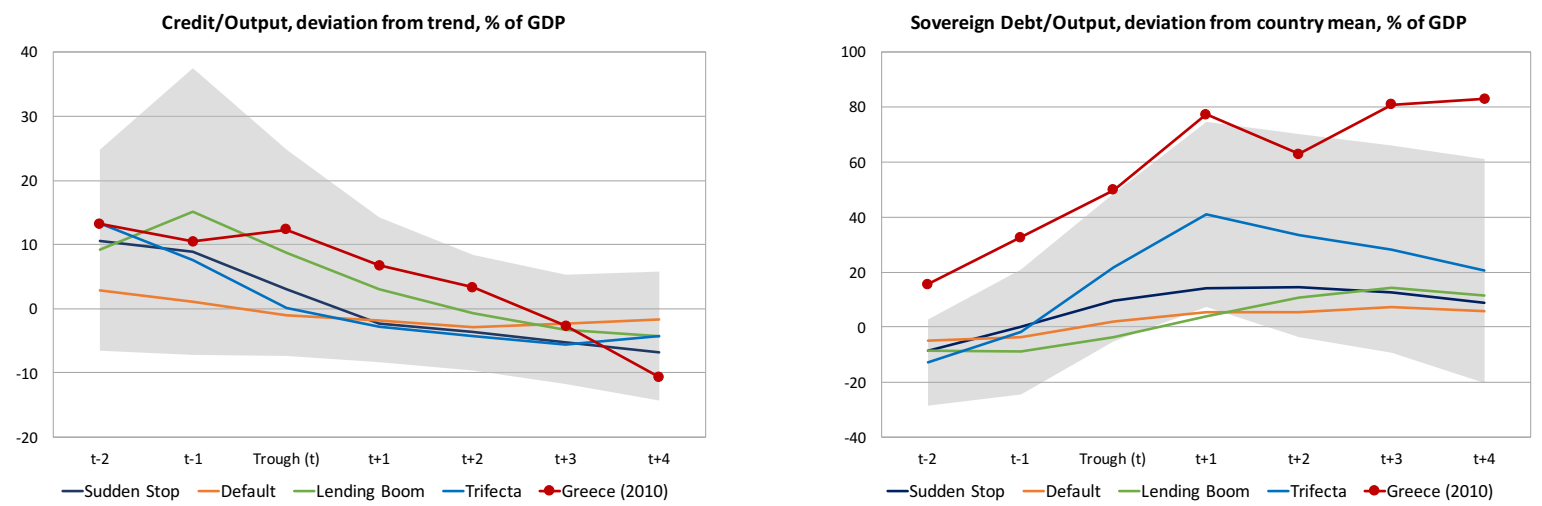

Figure 14: Credit and Government Debt The left panel reports the ratio of credit to the non financial sector to output, in deviation from a Hodrick-Prescott trend, in percent of GDP. The right panel reports the ratio of government debt to output, in deviation from a country mean, in percent of GDP. Both panels report the typical response over each type of episode, together with Greece in 2010 . One-sided $10 \%$ point-wise confidence intervals for lending boom (left panel) and Trifecta (right panel). See the appendix for data sources.

the contraction in credit to the economy is similar to what is observed in other countries. Confidence bands are quite large.

Turning to public debt, we observe an elevated level of public debt even before the crisis $(18 \%$ of GDP above mean in 2008), increasing rapidly and remaining significantly more elevated than in other episodes. We can see on the graph the effect of the 2012 debt restructuring (in $t+2$ ), reducing the debt-to-output ratio from $80 \%$ to $60 \%$ of GDP above its mean, but followed by a subsequent worsening, in part due to the collapse in economic activity in 2013 and 2014. Compared to 'Trifecta' or other episodes, levels of public debt remain extraordinarily high and it is clear from this figure that efforts to bring public debt back to sustainable levels have failed.

Claim 5. Domestic leverage in Greece was similar to other lending boom/bust episodes and evolved similarly. By contrast, public debt to output remained extremely elevated. Efforts to reduce the public debt burden mostly failed, despite a substantial debt restructuring in 2012.

Figure 15 reports the trade balance to output ratio as well as the CPI-based multilateral real exchange rate compiled by the IMF. As for domestic credit and public debt, the trade balance-tooutput ratio is measured in deviation from country means and expressed in percent of GDP. The multilateral real exchange rate is expressed in percentage deviation from its country mean. The figure also reports $10 \%$ point-wise one-sided confidence intervals for sudden stop episodes. The left panel 

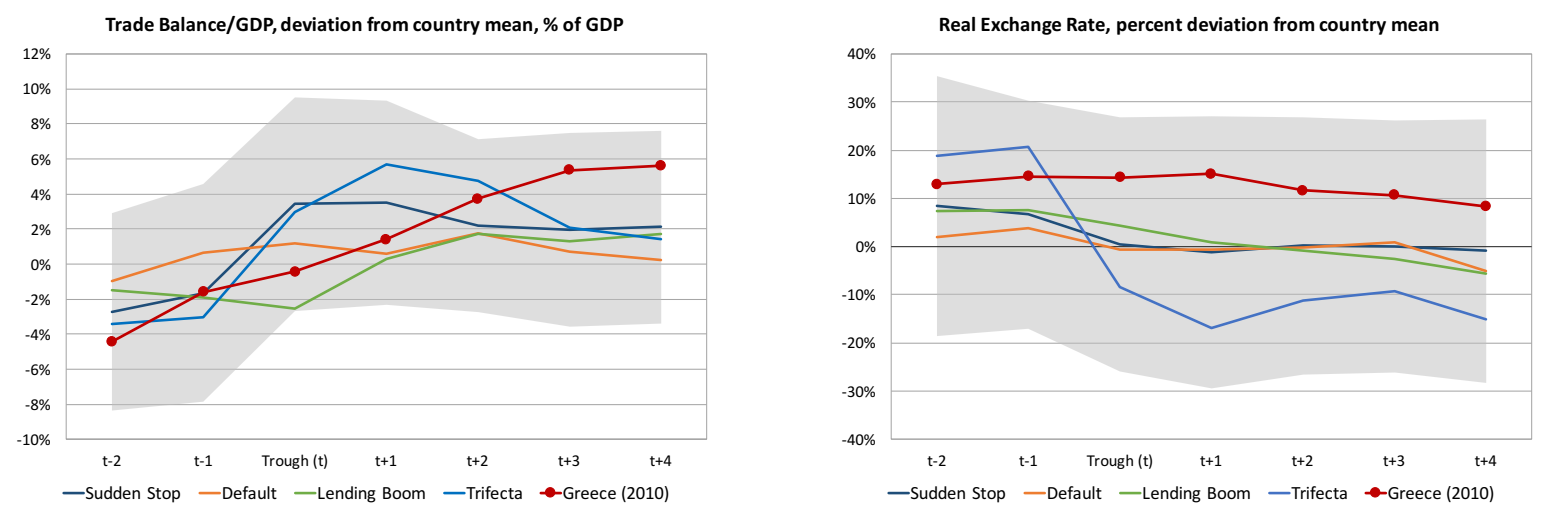

Figure 15: Net Exports and Real Exchange Rate The left panel reports the ratio of net exports on goods and services to output, in deviation from country mean, in percent of GDP. The right panel reports the multilateral real exchange rate, in percentage deviation from a country mean. Both panels report the typical response over each type of episode, together with Greece in 2010. One-sided point-wise confidence intervals for Trifecta episodes. See the appendix for data sources.

(trade balance) illustrates the gradual but large improvement of the Greek trade balance between 2008 and 2014, in excess of $10 \%$ of GDP, compared to the typical sudden stop episode. Unlike typical sudden stops, where loss of market access forces the trade balance and current account to improve overnight, the overall improvement in Greece was spread out gradually. The cumulated improvement in the trade balance in a typical sudden stop represents $6.2 \%$ of output, $5 \%$ of which occur in the year of the sudden stop itself. As discussed in the previous section, financial assistance and access to the liquidity facilities of the European Central Bank allowed Greece to spread out a massive and necessary adjustment in its trade balance. The right panel indicates that most of this adjustment occurred without major movements in the real exchange rate. Like other countries experiencing a sudden stop, Greece's real exchange rate was initially over-appreciated by about 13 percent. Yet, while the real exchange rate depreciates by $10 \%$ in the aftermath of a typical sudden stop (and a massive $35 \%$ following a 'Trifecta'), Greece's real exchange rate only depreciated by 4.5 percent between 2008 and 201423

Claim 6. The adjustment of external balances occurred more gradually but was nevertheless very significant in size. The improvement in external accounts occurred despite any significant movement in the real exchange rate.

\footnotetext{
${ }^{23}$ As pointed out to us by M. Obstfeld, the fall in spending required by the unavoidable fiscal consolidation required a large real depreciation, in order to maintain equilibrium on the market for non-traded goods. Absent an adjustment in the real exchange rate, the improvement in external balances must be associated with an output decline. See Corden and Neary (1982).
} 


\section{Model}

This section presents a stylized model of a small open economy in a currency union, with rich macrofinancial linkages. The model is designed to shed light on two sets of issues. First, we want a realistic enough model that allows us to understand which shocks were responsible for the performance of the Greek economy, both before and during of the crisis. Second, we want to use the model to perform some simple counterfactual exercises. To achieve these objectives, the model needs to remain stylized. In particular, while we introduce many macro-finance features, we abstract from a full micro-founded model of the banking sector that would put excessive constraints on the data. The model features eight exogenous stochastic processes. They are labelled $\zeta$ 's and each is assumed to follow an AR(1) process of the form:

$$
\zeta_{t}^{i}=\rho^{i} \zeta_{t-1}^{i}+\sigma^{i} \varepsilon_{t}^{i}
$$

where the persistence and volatility parameters $\left(\rho^{i}, \sigma^{i}\right)$ are estimated from the data, and the innovations $\varepsilon_{t}^{i}$ are i.i.d. with mean zero and unit variance, and $i=\{d g$, spend,... $\}$ is the name of the shock. We next specify the government, households, non-financial firms and the financial sector.

\subsection{Government}

Budget constraint. The government imposes a flat tax on income, spends $G_{t}$ on goods and services and makes social transfers $T_{t}$. Let $B_{\$, t-1}^{g}$ be the face value (in units of the common currency) of the debt issued at time $t-1$ and due at time $t$. The nominal budget constraint of the government, conditional on not defaulting, is

$$
\frac{B_{\$, t}^{g}}{R_{t}^{g}}+\tau_{t} P_{H, t} Y_{t}=P_{H, t}\left(G_{t}+T_{t}\right)+B_{\$, t-1}^{g},
$$

where $P_{H, t}$ is the price index of home goods (so $P_{H, t} Y_{t}$ is nominal GDP), $\tau_{t}$ is a time-varying tax rate, and $R_{t}^{g}$ is the gross interest rate on sovereign debt. It will be convenient to work with real variables.

We define real government debt $B_{t}^{g} \equiv \frac{B_{\Phi, t}^{g}}{P_{H, t}}$. We can then re-write the budget constraint (conditional on not defaulting) as

$$
\frac{B_{t}^{g}}{R_{t}^{g}}+\tau_{t} Y_{t}=G_{t}+T_{t}+\frac{B_{t-1}^{g}}{\Pi_{t}^{H}},
$$

where $\Pi_{t}^{H} \equiv \frac{P_{H, t}}{P_{H, t-1}}$ is the domestic (i.e. PPI) inflation rate from $t-1$ to $t$. This formula makes clear that unexpected inflation at time $t$ lowers the real debt burden. We use this convention for all other 
nominal assets.

Sovereign default. Sovereign risk plays an important role in the Greek crisis ${ }^{24}$ We do not model an optimal default decision by the government. Instead, we introduce a default shock $\tilde{\varepsilon}_{t}^{d g}$ and assume that the default happens when $\tilde{\varepsilon}_{t}^{d g}<F\left(\frac{B_{t-1}^{g}}{\Pi_{t}^{H}} ; Y_{t}\right)$. We assume that the function $F$ is increasing in the real debt burden $B_{t-1}^{g} / \Pi_{t}^{H}$ and decreasing in real GDP $Y_{t}$. For instance, $F$ could simply be the ratio of debt to GDP. The expected default rate is $\mathbb{E}_{t}\left[\tilde{d}_{t+1}\right]=\operatorname{Pr}\left(\tilde{\varepsilon}_{t+1}^{d g}<F\left(\frac{B_{t}^{g}}{\Pi_{t+1}^{H}} ; Y_{t+1}\right) \mid \mathcal{I}_{t}\right)$, where $\mathcal{I}_{t}$ is the information set of investors at time $t$. Notice that the distribution of $\tilde{\varepsilon}_{t+1}^{d g}$ can be time varying. What matters most in our model, however, are expected credit losses, which take into account the probability of default and expected loss given default. Upon default, government debt is reduced by some haircut and we let $d_{t}^{g}$ denote expected credit losses. In our quantitative analysis, we adopt the following log-linear specification for expected credit losses at time $t+1$ :

$$
d_{t}^{g}=\bar{d}_{g} \frac{B^{g}}{Y}\left(b_{t}^{g}-\mathbb{E}_{t}\left[y_{t+1}\right]-\mathbb{E}_{t}\left[\pi_{t+1}^{h}\right]+\zeta_{t}^{d g}\right),
$$

where $\frac{B^{g}}{Y}$ is the average debt-to-GDP ratio, $\bar{d}_{g}$ is a sensitivity parameter, and lowercase variables (e.g., $\left.b_{t}^{g}\right)$ represent log deviations from steady state values. The sovereign risk shock $\zeta_{t}^{d g}$ follows an $\mathrm{AR}(1)$ as postulated in equation (1), with persistence $\rho^{d g}$ and volatility $\sigma^{d g}$. Equation (4) states that expected default losses increase with the level of debt, decrease with the inflation rate -since the latter reduces the real debt burden, and increase with the sovereign default shock $\zeta_{t}^{d g}$. We will use data on sovereign yields to estimate the parameters $\left\{\bar{d}_{g}, \rho^{d g}, \sigma^{d g}\right\}$. The rate paid by the government on its debt is then (in log deviations)

$$
r_{t}^{g}=r_{t}+d_{t}^{g}
$$

where $r_{t}$ is the international interest rate.

Fiscal policy. The government's spending policy and its social transfer policy are represented by the same rule

$$
g_{t}=F_{l} g_{t-1}-F_{n} n_{t}-F_{r} r_{t}^{g}-F_{b} b_{t}^{g}+\zeta_{t}^{s p e n d},
$$

where $g_{t}$ is the log-deviation of spending, and $n_{t}, r_{t}^{g}$, and $b_{t}^{g}$ are log-deviations of employment $N_{t}$, government credit risk spread $R_{t}^{g}$, and government debt $B_{t}^{g}$ from their steady-state values, $F_{l}, F_{n}, F_{r}$,

\footnotetext{
${ }^{24}$ The literature on sovereign risk is large and we can only refer the reader to the classic contribution of Arellano (2008) and the recent survey by Aguiar and Amador (2014).
} 
and $F_{b}$ are fixed parameters, and $\zeta_{t}^{\text {spend }}$ is a spending shock that follows equation 11 with persistence $\rho^{\text {spend }}$ and volatility $\sigma^{\text {spend } 25}$ We have the same rule for transfers $t_{t}$. We allow spending itself to be auto-regressive (with $F_{l}>0$ ) to capture the fact that government programs are often scheduled of several years. This fiscal rule implies that the fiscal authorities respond to an increase in sovereign debt by tightening expenditures and reducing social transfers. The term $F_{n}$ captures automatic stabilizers: as the economy deteriorates, fiscal transfers and spending tends to increase. This formulation allows government expenditures and transfers to change both because of macro and financial channels, and also because of spending shocks. Lastly, we specify the following process for the tax rate:

$$
\tau_{t}=\bar{\tau}+\zeta_{t}^{t a x}
$$

where $\zeta^{\text {tax }}$ follows equation (1) with persistence $\rho^{\operatorname{tax}}$ and volatility $\sigma^{\operatorname{tax}}$ and $\bar{\tau}$ is calibrated to the steady state.

\subsection{Households}

Household debt dynamics play an important role during the Great Recession so we need to introduce borrowers and savers in the model. Households are heterogeneous in their time preferences, as in Eggertsson and Krugman (2012) and Martin and Philippon (2014) ${ }^{26}$ There are two types of households: a measure $1-\chi$ of patient households indexed by $i=s$ (who will be savers in equilibrium), and a measure $\chi$ of impatient households indexed by $i=b$ (who will be borrowers in equilibrium). These households have identical preferences over goods and hours worked, but differ in their discount factors: we assume that $\beta_{s}>\beta_{b}$. Household $i$ maximizes expected lifetime utility

$$
\mathbb{E}_{0} \sum_{t=0}^{\infty} \beta_{i}^{t}\left(\frac{\left(\mathbf{C}_{t}^{i}\right)^{1-\gamma}}{1-\gamma}-\frac{\left(N_{t}^{i}\right)^{1+\phi}}{1+\varphi}\right)
$$

where $\mathbf{C}_{i, t}$ is a bundle of home and foreign goods, defined as in Gali and Monacelli (2008) by

$$
\mathbf{C}_{t}^{i} \equiv\left[(1-\varpi)^{\frac{1}{\epsilon_{h}}} C_{H, t}^{i \frac{\epsilon_{h}-1}{\epsilon_{h}}}+\varpi^{\frac{1}{\epsilon_{h}}} C_{F, t}^{i \frac{\epsilon_{h}-1}{\epsilon_{h}}}\right]^{\frac{\epsilon_{h}}{\epsilon_{h}-1}}
$$

\footnotetext{
${ }^{25}$ The rate that enters $\sqrt{3}$ is not necessarily the same as the one in 5 because debt is long term and only a fraction is refinanced every period. During the crisis, Greek debt was refinanced by official creditors at low rates, in (3), while the secondary market rate was high. This secondary rate is the one that enters 5 .

${ }^{26}$ There are two types of models with heterogeneity: models where types are transient, as in Bewley models or Guerrieri and Lorenzoni (2010); and models where types are permanent, as in Campbell and Mankiw (1989), Mankiw (2000), Eggertsson and Krugman (2012), and Martin and Philippon (2014). Midrigan and Philippon (2010) propose an hybrid model that includes precautionary savings but is simple enough to incorporate in a standard macro model.
} 
where $\epsilon_{h}$ is the elasticity of substitution between home and foreign goods and $\varpi$ is the degree of openness of the economy. As usual, the home consumer price index (CPI) is

$$
\mathbf{P}_{t} \equiv\left[(1-\varpi) P_{H, t}^{1-\epsilon_{h}}+\varpi P_{F, t}^{1-\epsilon_{h}}\right]^{\frac{1}{1-\epsilon_{h}}}
$$

Household default. Households borrow at the rate $R_{t}^{h}$ and can default on their debts. Let $d_{t}^{h}$ be the credit loss rate on household loans. Default is a loss for the banks and a positive transfer to borrowers, similar to the financial shock described in Iacoviello (2015). The borrowers' budget constraint, following the same convention as with the government, is

$$
\mathbf{P}_{t} \mathbf{C}_{t}^{b}=\left(1-\tau_{t}\right) W_{t} N_{t}^{b}+\frac{P_{H, t} B_{t}^{h}}{R_{t}^{h}}-\left(1-d_{t}^{h}\right) P_{H, t-1} B_{t-1}^{h}+P_{H, t} T_{t}^{b}
$$

where $\left(1-\tau_{t}\right) W_{t} N_{t}^{b}$ denotes after tax labor income, $R_{t}^{h}$ the gross interest rate faced by borrowers, $B_{t}^{h}$ is the real face value of the household debt issued at $t$ and due at $t+1$, and $T_{t}^{b}$ the transfers received by borrowers. Borrowers are subject to the following borrowing limit:

$$
B_{t}^{h}<\frac{\bar{B}_{t}^{h}}{\chi}
$$

In our notations, $B_{t}^{h}$ is a per-capita measure while $\bar{B}_{t}^{h}$ denotes the aggregate lending capacity of the financial sector to households. We later derive this lending limit from the lender's problem, and we anticipate the result that only impatient households borrow in equilibrium. The credit loss rate is assumed to follow the process:

$$
d_{t}^{h}=-\bar{d}_{h y} y_{t}+\bar{d}_{h b} b_{t}^{h}+\zeta_{t}^{d h}
$$

where $\zeta_{t}^{d h}$ follows (1) with persistence $\rho^{d h}$ and volatility $\sigma^{d h}$. Equation (7) states that the credit loss rate on household loans increases with their debt level, decreases with output, and increases with a household default shock $\zeta^{d h}$. We will use data on non-performing loans to estimate $\left\{\bar{d}_{h y}, \bar{d}_{h b}, \rho_{d h}, \sigma_{d h}\right\}$. Note that $d_{t}^{h}$ are realized credit losses at time $t$, unlike $d_{t}^{g}$ which is an expected loss that may of may not materialize at $t+1$.

The savers' budget constraint is

$$
\mathbf{P}_{t} \mathbf{C}_{t}^{s}=\left(1-\tau_{t}\right) W_{t} N_{t}^{s}+\tilde{R}_{t} P_{H, t-1} S_{t-1}-P_{H, t} S_{t}+P_{H, t} T_{t}^{s}
$$


where $\tilde{R}_{t}$ is the nominal after-tax gross return on savings $P_{H, t-1} S_{t-1}$ at time $t$ and $T_{t}^{s}$ denotes real transfers to savers. This return is a complex object since savers are residual claimants: in equilibrium, they hold shares of firms and of banks, but also deposits, government bonds and potentially foreign assets. Notice however, that in equation (3) we have assumed a uniform tax rate on aggregate income, and this is what matters in the end. The savers' Euler equation is

$$
\mathbb{E}_{t}\left[\beta\left(\frac{\mathbf{C}_{t+1}^{s}}{\mathbf{C}_{t}^{s}}\right)^{-\gamma} \frac{\tilde{R}_{t+1}}{\Pi_{t+1}}\right]=1,
$$

where $\Pi_{t+1}=\mathbf{P}_{t+1} / \mathbf{P}_{t}$ denotes the gross CPI inflation rate from $t$ to $t+1$. Finally, in the aggregate, we have

$$
\begin{aligned}
C_{H, t} & =\chi C_{H, t}^{b}+(1-\chi) C_{H, t}^{s} \\
\mathbf{C}_{t} & =\chi \mathbf{C}_{t}^{b}+(1-\chi) \mathbf{C}_{t}^{s} .
\end{aligned}
$$

Nominal Wage Rigidity We assume a standard model of wage stickiness, with a representative union setting wages à la Calvo. The wage equations are standard and satisfy:

$$
\begin{aligned}
\pi_{t}^{w} & =\beta \mathbb{E}_{t} \pi_{t+1}^{w}-\lambda^{w}\left(w_{t}-\gamma c_{t}-\varphi n_{t}\right)+\zeta_{t}^{w}, \\
\pi_{t} & =(1-\varpi) \pi_{t}^{h}+\varpi \pi_{t}^{f}, \\
w_{t} & =w_{t-1}+\pi_{t}^{w}-\pi_{t}^{h},
\end{aligned}
$$

where $\pi_{t}^{w}$ denotes wage inflation, $w_{t}$ is the real wage in terms of the CPI $\left(\ln \left(W_{t} / \mathbf{P}_{t}\right)\right), \zeta_{t}^{w}$ is a wagemarkup shock that follows 11 with persistence $\rho^{w}$ and volatility $\sigma^{w} \cdot \pi_{t}$ denotes CPI inflation, $\pi_{t}^{h}$ is home inflation, $\pi_{t}^{f}$ is foreign inflation, and $\lambda^{w}$ is derived from the Calvo wage setting process. The first equation is a forward looking wage Phillips curve. Wage inflation depends on expected future wage inflation, on the marginal rate of substitution between consumption and leisure, and on the wage markup shock $\zeta^{w}$.

\subsection{Non Financial Firms}

We separate firms into goods producing and capital producing firms in order to simplify the derivation of the price setting equation on the one hand, and the investment/Q equation on the other hand. 


\subsubsection{Capital Producing Firms}

Capital firms convert consumption goods into capital through investment, and rent this capital to goods producing firms for a rental rate $Z_{k, t}$. The capital stock evolves according to

$$
K_{t}=(1-\delta) K_{t-1}+I_{t}
$$

and real period profits (i.e., scaled by $P_{H, t}$ ) for these firms are given by

$$
\operatorname{Div}_{t}=Z_{k, t} K_{t-1}-I_{t}-\frac{\varphi_{k}}{2} K_{t-1}\left(\frac{I_{t}}{K_{t-1}}-\delta\right)^{2}
$$

where the last term captures adjustment costs to physical capital. Let $R_{t}^{k}$ be the firm's funding cost. The real value of capital producing firms is $V\left(K_{t-1}\right)$ and satisfies the following Bellman equation

$$
V\left(K_{t-1}\right)=\max _{I_{t}, K_{t}}\left\{Z_{k, t} K_{t-1}-I_{t}-\frac{\varphi_{k}}{2} K_{t-1}\left(\frac{I_{t}}{K_{t-1}}-\delta\right)^{2}+\mathbb{E}_{t}\left[\frac{\Pi_{H, t+1}}{R_{t}^{k}} V\left(K_{t}\right)\right]\right\}
$$

subject to $(9)$.

Let $x_{t} \equiv \frac{K_{t}-K_{t-1}}{K_{t-1}}$ be the net investment rate. Given our homotheticity assumptions, we guess and verify that the value function can be written as

$$
V\left(K_{t-1}\right)=\mathcal{V}_{t} K_{t-1}
$$

where

$$
\mathcal{V}_{t}=\max _{x_{t}}\left\{Z_{k, t}-x_{t}-\delta-\frac{\varphi_{k}}{2} x_{t}^{2}+\left(1+x_{t}\right) \mathbb{E}_{t}\left[\frac{\Pi_{H, t+1}}{R_{t}^{k}} \mathcal{V}_{t+1}\right]\right\}
$$

Define Tobin's Q as the end of period value of assets divided by the end of period replacement cost of capital

$$
Q_{t} \equiv \mathbb{E}_{t}\left[\frac{\Pi_{H, t+1}}{R_{t}^{k}} \mathcal{V}_{t+1}\right]
$$

Optimal investment yields the standard Q-equation:

$$
x_{t}=\frac{Q_{t}-1}{\varphi_{k}} .
$$




\subsubsection{Goods Producing Firms}

Goods producing firms produce differentiated varieties of a domestic good using capital and labor. The production function for a producer of good $j$ is

$$
Y_{t}(j)=A K_{t}(j)^{\alpha} N_{t}(j)^{1-\alpha}
$$

where labor costs wage $A$ is aggregate total factor productivity (TFP). We focus here on the case where TFP is constant because the model is simpler to present and fits the data quite well. Goods producing firms are subject to a financial friction that requires them to pay part of their operating costs in advance, before production is undertaken as in Christiano et al. (2005) or Jermann and Quadrini (2012) ${ }^{27}$ Let $\psi_{s k}$ denote the fraction of input cost that needs to be financed by working capital loans.

Profits are given by

$$
\text { Profits }_{t}=\text { Revenues }_{t}-\text { Costs }_{t}\left[1+\psi_{s k}\left(R_{t}^{k}-1\right)\right]
$$

Standard cost minimization yields an expression for the nominal marginal cost,

$$
\mathrm{MC}_{t}^{\$}=\frac{\left[1+\psi_{s k}\left(R_{t}^{k}-1\right)\right]}{A}\left(\frac{P_{H, t} Z_{k, t}}{\alpha}\right)^{\alpha}\left(\frac{W_{t}}{1-\alpha}\right)^{1-\alpha}
$$

Notice that the working capital friction can be represented by an incremental marginal cost for the firm. This will be an important property, as it allows financial frictions to pass through to inflation. Differentiated goods producers solve a standard Calvo problem, given factor demands. Given real marginal $\operatorname{cost} \mathrm{MC}_{t} \equiv \frac{\mathrm{MC}_{t}^{\mathbb{S}}}{P_{H, t}}$, we can write the (log-linear) Phillips Curve as

$$
\pi_{h, t}=\lambda_{p} \mathrm{mc}_{t}+\beta \mathbb{E}_{t} \pi_{h, t+1}+\zeta_{t}^{\pi h},
$$

where $\lambda_{p}$ is derived from the Calvo price setting process, $\beta$ is the discount factor of savers, and the $(\log )$ real marginal cost is

$$
\mathrm{mc}_{t}=\frac{\psi_{s k} R^{k}}{1+\psi_{s k}\left(R^{k}-1\right)} r_{t}^{k}+\alpha z_{k, t}+(1-\alpha)\left(w_{t}+\varpi t o t_{t}\right) .
$$

\footnotetext{
${ }^{27}$ The assumption that this loan is intra-period is made for simplicity. The fact that the loan is made by the bank allows for financial shocks to pass through to the production sector, with the added advantages that: (i) we do not need to keep track of an extra state variable, and (ii) we avoid any complications arising from the interaction of two dynamic frictions: nominal rigidities and financial frictions. If debt were inter-temporal, we would have to keep track of the joint distribution of prices and debt, as firms with different preset prices would produce different quantities and thus borrow different amounts. Intra-period loans allow us to introduce a financial friction that is static from the firm's point of view.
} 
$\zeta_{t}^{\pi h}$ is an $\mathrm{AR}(1)$ price markup shock that satisfies equation 11 with persistence $\rho^{\pi h}$ and volatility $\sigma^{\pi h}$. Notice that marginal costs are deflated in terms of the price of home produced goods, hence the terms-of-trade adjustment for the real wage, which reflects the term $\frac{\mathbf{P}_{t}}{P_{H, t}}$. Finally, we have the usual static optimality condition for labor demand:

$$
\frac{K_{t-1}}{N_{t}}=\frac{\alpha}{1-\alpha} \frac{W_{t}}{P_{H, t} Z_{k, t}}
$$

\subsection{Banks, Sudden Stop, and Funding Cost}

A fully specified model of banking intermediation as in Gertler and Kiyotaki (2010) is beyond the scope of this paper. Moreover, the financial sector data necessary to estimate the restrictions of such a model, such as the balance sheet of banks and its components are not available (see Faria-e-Castro (2016) for a more ambitious estimation). There is, however, one fundamental insight from the models of banking intermediation that is theoretically straightforward and, as we show later, empirically relevant. At the heart of many banking models is a capital requirement of the type

$$
V_{t}^{\text {bank }} \geq \kappa\left(\frac{B_{t}^{k}}{R_{t}^{k}}+\frac{B_{t}^{h}}{R_{t}^{h}}\right)
$$

where $V_{t}^{\text {bank }}$ is the franchise value of the banking sector and $B_{t}^{k}$ and $B_{t}^{h}$ denote the outstanding loans to the corporate non-financial and household sectors respectively, both measured at the end of period $t$. This equation assumes that there is no capital requirement for sovereign exposure, as was the case in Europe at the time. Equation 13 says that bank equity $V_{t}^{\text {bank }}$ must cover a fraction $\kappa$ of the total credit exposure to firms and to households. The second important equation is the current account of the banking sector:

$$
\Pi_{H, t+1} E_{t+1}=\left(1-d_{t+1}^{k}\right) B_{t}^{k}+\left(1-d_{t+1}^{h}\right) B_{t}^{h}-D_{t}
$$

Equation (14) states that nominal bank earnings $\Pi_{H, t+1} E_{t+1}$ consist of repayment from firms and households net of default losses, minus the repayment of banks' liabilities $D_{t}$. Finally, bank value solves a Bellman equation

$$
V_{t}^{\text {bank }}=\max _{\left\{B_{t}\right\}, D_{t}} D_{i v_{t}}+\mathbb{E}_{t}\left[\frac{\Lambda_{t+1}}{\Pi_{t+1}} \Pi_{H, t+1}\left((1-\sigma) E_{t+1}+\sigma V_{t+1}^{\text {bank }}\right)\right]
$$


where $\sigma$ is an exogenous exit rate, $\Lambda_{t+1}$ is the pricing kernel of savers, and dividends Div $v_{t}$ are assumed to be a fixed fraction of earnings $E_{t}$. This captures the assumption that banks cannot raise equity very quickly, and it implies that capital losses lead to tighter lending constraints, as least in the short run.

Equations (13), 14 and (15) capture the fundamental credit channel in the economy. Credit losses reduce banks' earnings (14), lower bank value (15) and tighten capital requirement (13). This leads to an increase in the economy's funding cost. All else equal, this channel is stronger the higher is bank leverage. We capture this idea in two steps. First, we model the banks' (log) funding cost $r_{t}^{d}$ as

$$
r_{t}^{d}=r_{t}+\zeta_{t}^{r}+\xi^{d} L \mathbb{E}_{t}\left[d_{t+1}^{p}\right]
$$

where $L$ is bank leverage (assets over equity capital) in steady state, $\xi^{d}$ is a sensitivity parameter to be estimated, $d_{t+1}^{p}$ measures losses on private credit portfolio (households and firms' loans), and $\zeta_{t}^{r}$ is a 'sudden stop' shock that increases funding costs to banks. $\zeta^{r}$ satisfies equation (1) with persistence $\rho^{r}$ and volatility $\sigma^{r}$. Since we only have data on total non-performing loans, we will assume that loss rates on households' and firms' credit are identical: $d_{t}^{h}=d_{t}^{k} \equiv d_{t}^{p}$.

Second we assume that banks' funding costs are passed on to banks' customers (with a constant margin that drops out in logs), therefore

$$
r_{t}^{k}=r_{t}^{d}
$$

Note that in our notations above, $r_{t}^{k}$ is the funding cost of firms, which enters directly the Q equations 10 and 11. For households, we had defined $r_{t}^{h}$ as the interest rate on loans, gross of expected losses, that enters the budget constraint (6). If we were to quote an interest rate for corporate loans, it would be $r_{t}^{d}+\mathbb{E}_{t}\left[d_{t+1}^{k}\right]$, and the expected return would be $r_{t}^{d}$. With our assumptions, the sudden stop shock is an increase in the country's funding cost above and beyond what can be explained by domestic intermediation spreads. 


\subsection{Equilibrium}

All transactions with the rest of the world happen at rate rate $R_{t}$. Let $N F A_{t}$ denote the net foreign assets of the country (in units of domestic goods). By definition, NFA evolves as

$$
\frac{N F A_{t}}{R_{t}}=N F A_{t-1}-\mathbf{P}_{t} \mathbf{C}_{t}+P_{H, t}\left(Y_{t}-G_{t}-I_{t}-\frac{\varphi_{k}}{2} K_{t-1}\left(\frac{K_{t}}{K_{t-1}}-1\right)^{2}\right) .
$$

As is common in the literature, we make a technical assumption to ensure stationarity of NFA $28 \mathrm{We}$ assume that there is a (small) price impact of $N F A$ on the country's borrowing (or saving) rate

$$
\frac{\partial \log R_{t}}{\partial \log N F A_{t}}=-\epsilon_{r}
$$

where $\epsilon_{r}$ is a small but strictly positive number. Clearing in the market for domestic goods requires

$$
Y_{t}=C_{H t}+\left(\frac{P_{H t}}{\mathbf{P}_{t}^{F}}\right)^{-\epsilon_{f}} \mathbf{C}_{t}^{F}+G_{t}+I_{t}+\frac{\varphi_{k}}{2} K_{t-1}\left(\frac{K_{t}}{K_{t-1}}-1\right)^{2}
$$

where $\mathbf{C}_{t}^{F}$ represents aggregate foreign consumption and $\mathbf{P}_{t}^{F}$ the foreign CPI. $\epsilon_{f}$ is the demand elasticity.

Household Debt. Banks lend to domestic households. We assume that borrowers are impatient enough to hit their borrowing limits, so

$$
\chi B_{t}^{h}=\bar{B}_{t}^{h} .
$$

The basic model does not pin down a unique borrowing rate $R_{t}^{h}$. As long as $R_{t}^{h}>R_{t}^{d}$, banks are willing to lend more. As long as $\beta_{b} \mathbb{E}_{t}\left[\frac{R_{t}^{h}}{\Pi_{t+1}} u^{\prime}\left(c_{t+1}\right)\right]<u^{\prime}\left(c_{t}\right)$ borrowers want to borrow more. In steady state, any $R^{h} \in\left(\beta_{s}^{-1}, \beta_{b}^{-1}\right)$ is potentially an equilibrium 29 This issue is present in and out of steady state. For the steady state, however, a reasonable assumption is that the lending spread is pinned down by free entry into banking. We will directly calibrate the steady state spread $\Delta_{t} \equiv \frac{R_{t}^{h}}{R_{t}}$ using empirical studies of financial intermediation: Philippon (2011) shows that the spread is remarkably

\footnotetext{
${ }^{28}$ See Schmitt-Grohe and Uribe $(2003)$.

${ }^{29}$ To see why simply pick some $R^{h} \in\left(\beta_{s}^{-1}, \beta_{b}^{-1}\right)$. Given this rate and the other parameters, there is a unique steady state for bank equity, bank size, etc. Hence there is a unique value for $B^{h}$. Now, as long as interest payments do not violate the non-negativity constraint on consumption (which never happens for reasonable values), then this level of $B^{h}$ also satisfies the households' problem since for them $B^{h}$ is a constraint. This shows that any $R^{h} \in\left(\beta_{s}^{-1}, \beta_{b}^{-1}\right)$ is potentially an equilibrium, corresponding to different values of $B^{h}$.
} 
stable in the long run at $\Delta=1.02$. Out of steady state, we expect both loan supply and loan demand to decrease in response to an increase in bank's funding cost, so we specify, in log deviations from steady-state values

$$
b_{t}^{h}=\psi_{b h} b_{t-1}^{h}-\xi^{b h} r_{t}^{d}+\zeta_{t}^{b h}
$$

where $\zeta_{t}^{b h}$ is an $\operatorname{AR}(1)$ shock that satisfies (1) with persistence $\rho^{b h}$ and volatility $\sigma^{b h}$.

Interest Rates and Funding Costs in the Model. There are four interest rates in the model, so it is useful to summarize them here. First of all, there is the baseline interest rate $r_{t}$ that enters the NFA and the Euler equation of savers. Above and beyond this rate there are spreads and expected losses, so that

$$
\begin{aligned}
r_{t}^{d} & =r_{t}+\zeta_{t}^{r}+\xi^{d} L \mathbb{E}_{t}\left[d_{t+1}^{p}\right] \\
d_{t}^{p} & =-\bar{d}_{y} y_{t}+\bar{d}_{b} b_{t-1}+\zeta_{t}^{d e f} \\
r_{t}^{k} & =r_{t}^{d} \\
r_{t}^{h} & =r_{t}^{d}+\mathbb{E}_{t}\left[d_{t+1}^{p}\right] \\
r_{t}^{g} & =r_{t}+d_{t}^{g} \\
d_{t}^{g} & =\bar{d}_{g} \frac{B^{g}}{Y}\left(b_{t}^{g}-\mathbb{E}_{t}\left[y_{t+1}\right]-\mathbb{E}_{t}\left[\pi_{t+1}^{h}\right]+\zeta_{t}^{d g}\right)
\end{aligned}
$$

Notice our assumptions here. First, domestic savers do not earn higher expected returns when there is a sudden stop. They earn $r$, which remains essentially constant and equal to the rate in the eurozone. Second, the banks are sensitive to the sudden stop and to credit losses. The sudden stop $\zeta_{t}^{r}$ enters the economy via the banks, which then pass it on to their customers. Non-performing loans $d_{t+1}^{p}$ hurt banks and increase the funding costs of all private agents. We only have data on total non-performing loans, so we do not model separately firm and household defaults. We assume that they move together and we estimate only one equation for $d_{t}^{p}$. The shock $\zeta_{t}^{\text {def }}$ captures the evolution of NPLs that is not predicted by macroeconomic fundamentals.

Fourth, the government is not necessarily affected by the same sudden stop as the private sector. The shock $\zeta_{t}^{d g}$ raises the cost of funds for the government. It captures pessimism by investors about the creditworthiness of the government, whether or not this pessimism is borne out in equilibrium. There are many reasons why $\zeta_{t}^{d g}$ and $\zeta_{t}^{r}$ are different, but let us just mention two. First as we discussed, the ECB provided funding to Greek banks both directly and indirectly via Emergency Liquidity Assistance, 
insulating them from sovereign risk, in particular during the sovereign debt restructuring. Second government debt is now largely held by official creditors, rather than domestic banks, attenuating the link between sovereign and banking risks.

Finally, while the two shocks $\zeta^{r}$ and $\zeta^{d g}$ are conceptually distinct, the model features important feedback loops between the sovereign and the banks. This 'doom loop' has been extensively discussed in policy circles and analyzed in stylized models (see Brunnermeier et al. (2016) and Farhi and Tirole (2016)). The impact of banks on the sovereign is always present via general equilibrium effects and tax revenues. If banks experience a sudden stop, the economy contracts and credit risk, both private and sovereign, increases. Conversely, if sovereign risk increases, the worsening of economic outcomes increases default in the private sector, affecting bank values. Hence, our model features rich and complex interactions between the financial and public sectors.

\section{Estimation}

In this section, we describe the estimation of the model. We combine the Kalman Filter with Bayesian techniques, which allow us to recover estimates for the structural shocks that affected Greece during the 2000's. These estimated shocks can then be used to conduct counterfactual exercises.

\subsection{Data, Observables and Calibration}

The sample is annual, from 1999 to 2015. Figure 16 shows the eight series that we feed into the model, all measured in $\log$ deviations from steady-state. For interest rates and inflation, we also take the difference from the Eurozone average series.

The model features as many shocks as observables, which are described in Table $4{ }^{30}$ In addition, we allow for measurement error to domestic inflation, wage inflation, and the measure of non-performing loans since these variables are quite noisy and or measured imprecisely. Specifically, we assume that we observe $\tilde{x}_{t}$, where

$$
\tilde{x}_{t}=x_{t}+\varepsilon_{t}^{\text {error }}
$$

and $\varepsilon_{t}^{\text {error }}$ is a measurement error term ${ }^{31}$ For household debt, we take as a proxy the series for total

\footnotetext{
${ }^{30}$ We treat the sovereign spread as a secondary market price that contains information about sovereign risk. On the other hand, it does not enter the government budget constraint since Greece did not refinance its stock of debt at that price. In the budget constraint we scale down the spread by a factor of 5 so that it is in line with the data.

${ }^{31}$ In practice, as we will see, domestic inflation deviates most from the model in 2010. According to the Bank of Greece, that year saw a surge in inflation due to a significant rise in oil prices and an increase in indirect taxes, in particular VAT.
} 

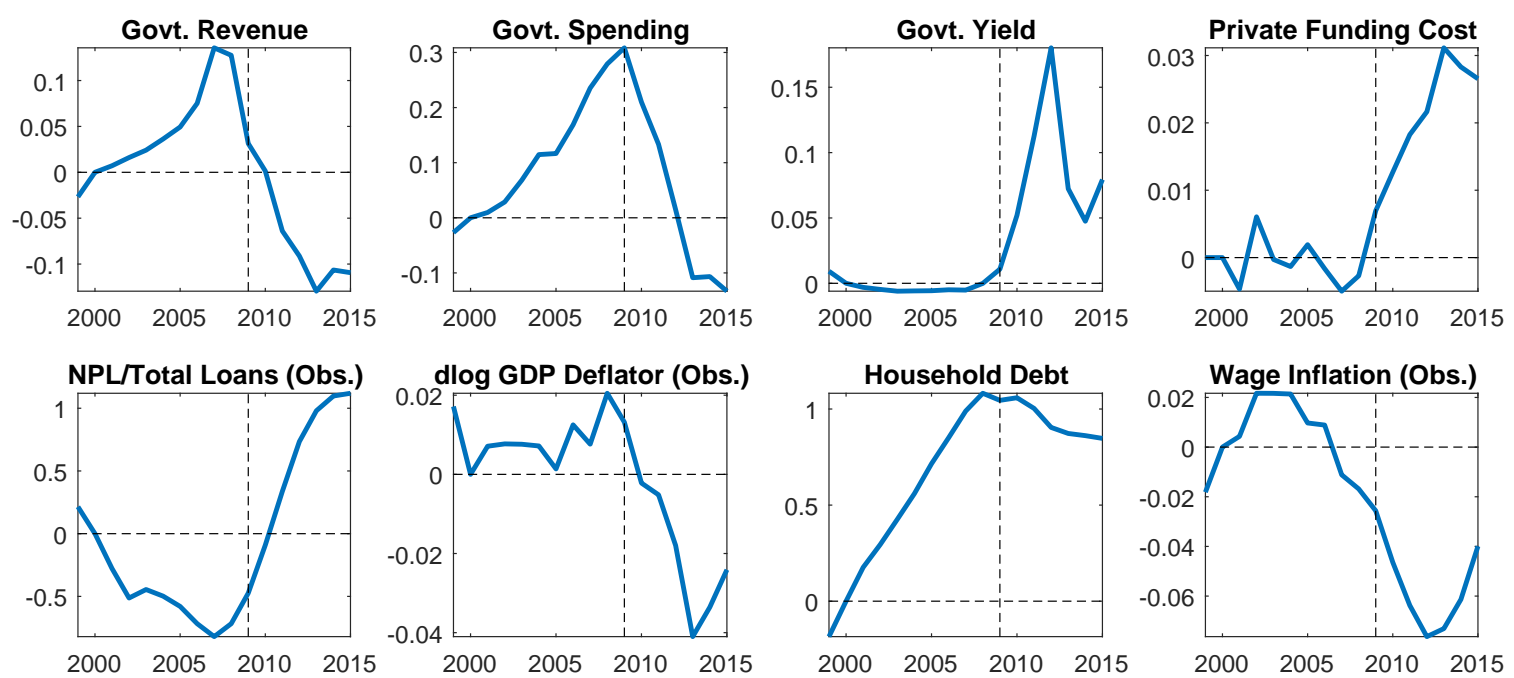

Figure 16: Observables: Filtered Data. Notes: All series are in log deviations from steady state. Interest rates and inflation rates are also in deviation from the Eurozone average. NPL, GDP deflator and wages are assumed to be measured with errors.

\begin{tabular}{cccc}
\hline Observable & Description & Shock & Shock Description \\
\hline$G_{t}+T_{t}$ & Government spending & $\zeta_{t}^{s p e n d}$ & Govt. spending shock \\
$\tau_{t} Y_{t}$ & Government revenues & $\zeta_{t}^{t a x}$ & Tax rate shock \\
$R_{t}^{g}$ & Greek government spread over EZ average & $\zeta_{t}^{d g}$ & Sovereign risk shock \\
$R_{t}^{k}$ & SME spread over EZ average & $\zeta_{t}^{r}$ & Funding cost shock \\
$\exp \left(d_{t}^{p}\right)$ & Non-performing loans/total loans, def $=n p l$ & $\zeta^{d e f}$ & Private default shock \\
$\Pi_{t}$ & Greece CPI - EZ CPI & $\zeta^{\pi h}$ & PPI cost push shock \\
$B_{t}^{h}$ & Household debt & $\zeta_{t}^{b h}$ & Household credit shock \\
$\Pi_{t}^{w}$ & Greek Wage Inflation - EZ Wage Inflation & $\zeta^{w}$ & Wage inflation shock \\
\hline
\end{tabular}

Table 4: Observables and Shocks

credit to the private non financial sector for Greece.

We use a combination of calibration and estimation. We calibrate parameters that affect steady state variables. Most of the calibrated parameters take standard values for small open economies and are reported in Tables 10, 11 and 12 in the appendix.

We estimate the remaining "dynamic" parameters using standard Bayesian estimation techniques following An and Schorfheide (2007) ${ }^{32}$ We estimate a total of 25 parameters: the persistence and volatility of the eight structural shocks, the variance of the three measurement errors, as well as six other dynamic parameters: the elasticity of expected sovereign default losses with respect to debt to GDP, the elasticities of private default with respect to GDP and debt, the persistence of the household

\footnotetext{
${ }^{32}$ The "dynamic" parameters are those parameters that are not required to compute the steady state and that only affect the dynamics of the model, such as the pass-through elasticities and the persistence as well as the standard deviation of the exogenous shocks $\left(\rho^{i}, \sigma^{i}\right)$.
} 
credit equation, the elasticity of household credit with respect to the cost of funds, and the passthrough of future default to current lending rates. The estimation results, along with our choice of priors, are described in Table 14 in the Appendix.

\subsection{Results}

Smoothed Variables The smoothed shocks are reported in Figure 32 in the Appendix. We also use the Kalman Filter to extract the sequences implied by the model for the remaining endogenous variables. This provides a good way of gauging the fit of the model. We present the most important series in Figure 17, where we plot the data and model-implied paths for GDP, Corporate Investment, PPI Inflation and Current Account-to-GDP ratio.

The main point to take away from Figure 17 is that the model's predictions for output and investment are good, even though we did not use any data on output or investment in the estimation. This means that our fiscal and financial multipliers are consistent with the data. For domestic price inflation, whose measurement is imperfect, we plot the observed raw data series against the model-based series that filters out the noise ${ }^{33}$ For wage inflation, on the other hand, measurement errors appear small.

Figures $18 \mid 21$ are the first main findings of the model. In each case, the black line is the smoothed value of the corresponding endogenous variable, in percent deviations from steady state. Each colored bar represents the contribution of a corresponding shock and its lagged values to the predicted value of the corresponding variable at each point in time 34

GDP The GDP series in Figure 18 shows how our model interprets the Greek crisis. Around 2000, credit demand is high and credit risk is low, so households borrow and consume. During that period, government spending increases more than predicted by our fiscal rule, as captured by the positive spending shocks. This is the same finding as in Martin and Philippon (2014). This massive fiscal expansion explains most of the output gap, which is around $+15 \%$ in 2007 . The recessionary shocks arrive in sequence. The model finds that the sudden stop starts in 2009 and remains very significant

\footnotetext{
${ }^{33}$ As discussed earlier, the model implies that domestic inflation starts declining as early as 2008 . In the data, we observe a spike in domestic inflation in 2009 and 2010, most likely due to the impact of oil prices (not modeled) and changes in the VAT rate (not modeled).

${ }^{34}$ Knowledge of the structural shocks and the structural matrices that describe the law of motion for the endogenous variables as functions of the states allows us to estimate the contribution of each shock to the observed behavior of each variable in the model. This can be done for any endogenous variable, observed or not. Note that the plotted contributions of the shocks do not need to add up to the value of the variable due to initial conditions estimated by the Kalman filter.
} 

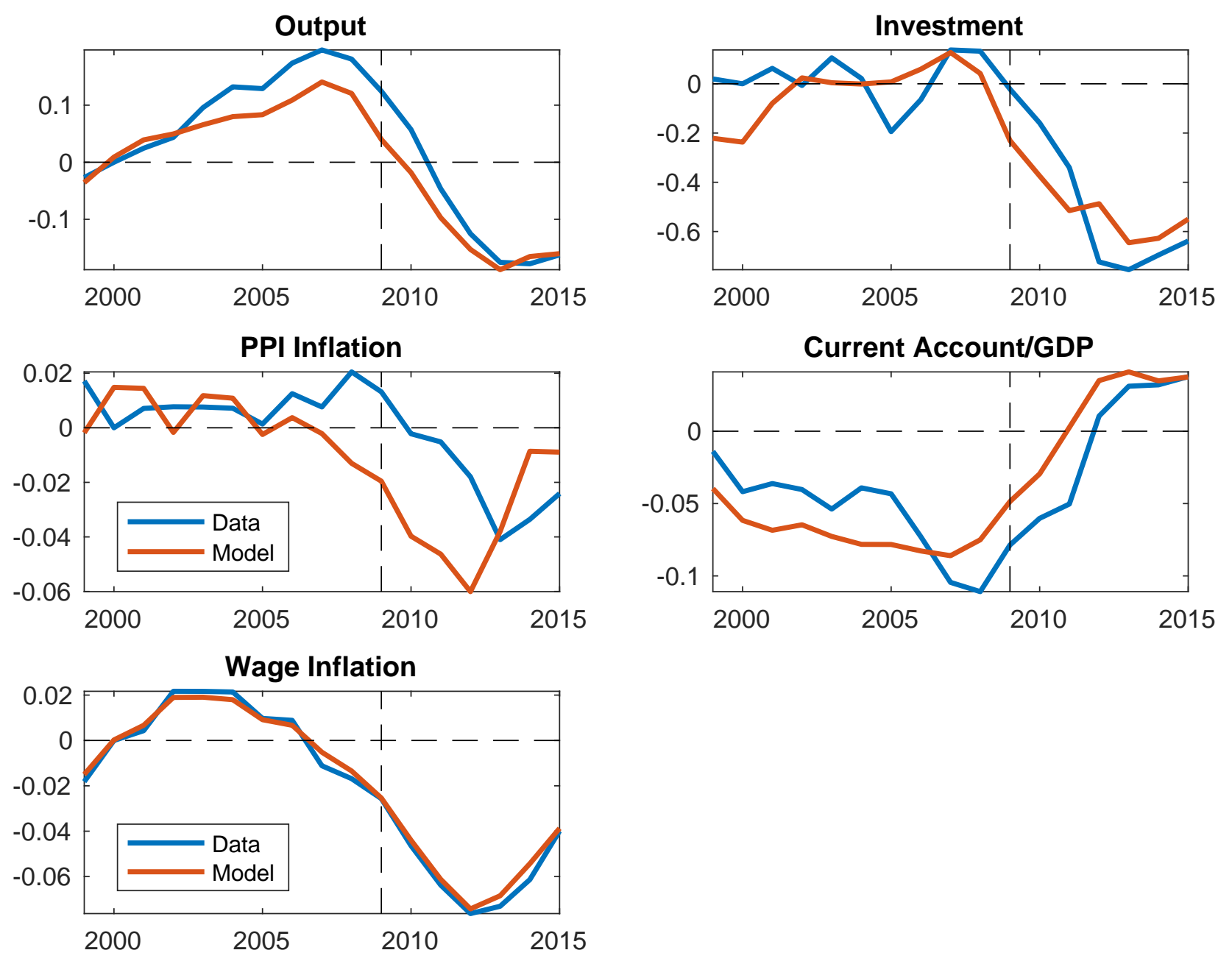

Figure 17: Smoothed Variables. Note: The figure reports the model estimated values of output, investment, inflation (price and wage) and next exports to GDP ratio. Both inflation series are part of the estimation but are assumed to be measured with error.

until 2013, depressing output by $5 \%$ to $10 \%$. It is important to keep in mind that this is a decomposition with respect to shocks, not propagation mechanisms. For example, the sudden stop shock appears first in the funding cost of the private sector. But its effects propagate via several mechanisms: lower credit, lower demand, more private and sovereign default risk, etc. The effect of all of these mechanisms is aggregated into the bar corresponding to the sudden stop shock (green bar).

Role of Government Spending It is important to understand how exactly the model interprets fiscal policy shocks. We feed in actual government spending in our calibration, and since the model implies significant fiscal multipliers (around 1.5), fiscal dynamics "accounts" for much of GDP dynamics. But that is not how the model computes the contribution of each shock. The model seeks to understand 

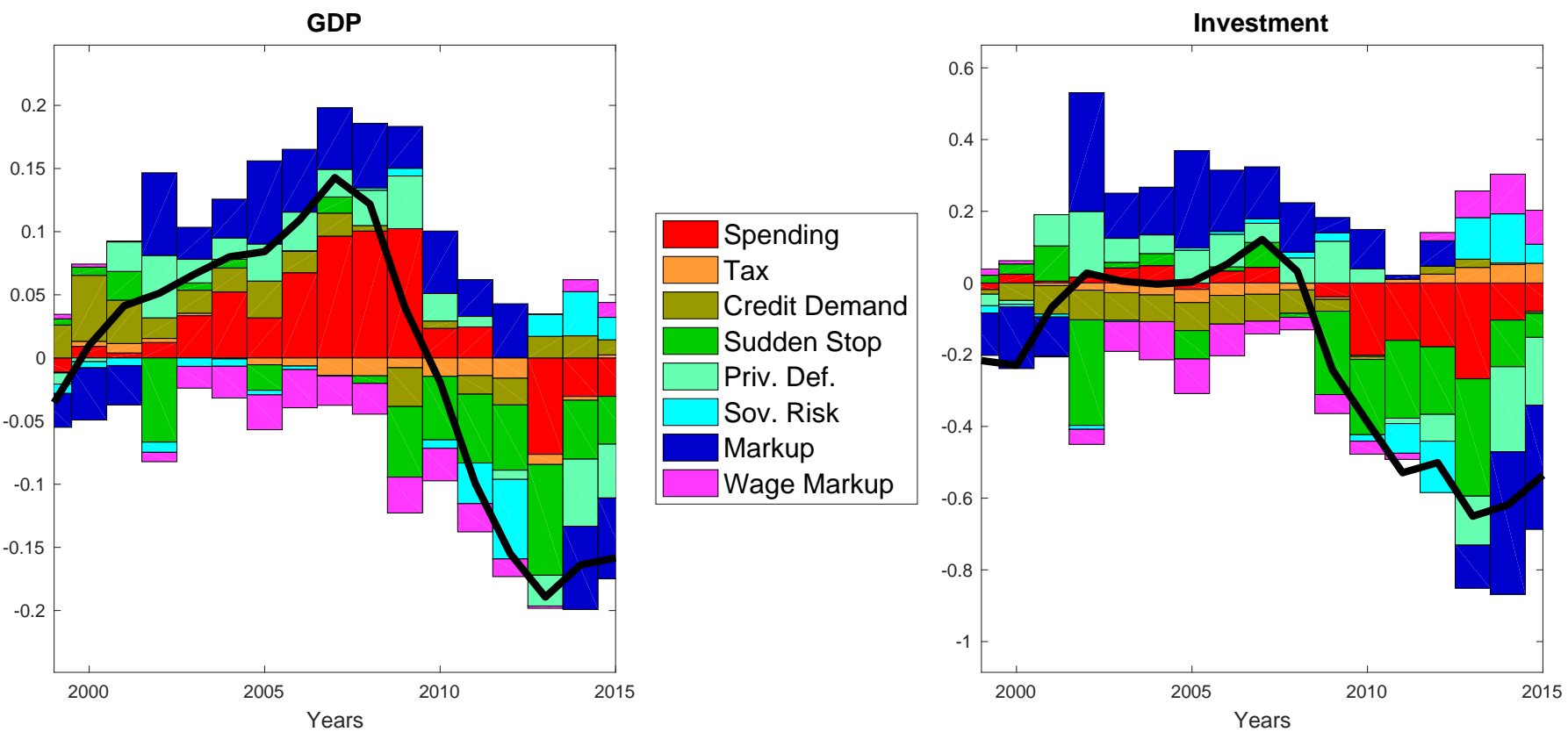

Figure 18: Decomposition of GDP and Investment. Note: The figure reports the decomposition of the predicted path for output (left panel) and investment (right panel) into the contribution of each of the eight shocks.

why government spending moves using the fiscal rule (5). Government default risk increases in 2011 and especially in 2012, the year of the sovereign default. From 2010 to 2012, there is no autonomous negative spending shock. In other words, the observed path of government spending can be explained by our fiscal rule, given the increase in funding costs ${ }^{35}$ In reality, spending was largely determined by official financing. Under the 2010 program, the Greek government received 110 billion Euros. Another 130 billion Euros became available as part of the 2012 program and debt restructuring. What the model says is that the size of the program (and the implied path of spending and taxes) was consistent with a fiscal rule such as (5).

Autonomous (negative) spending shocks emerge in 2013 and to a lesser extent 2014 because sovereign spreads decrease and spending does not increase (or even decrease). This coincides with the implementation of the 2012 IMF and Eurogroup program.

Figure 19 reports the decomposition for government debt (left panel) and its yield (right panel). Both variables are part of the estimation. We see that the accumulation of government debt is mostly the consequence of past spending decisions. Fiscal expansions do not increase debt much in the short run because GDP and revenues increase. In the long run however they increase debt. The debt

\footnotetext{
${ }^{35}$ Remember that we do not assume that the Greek government actually borrowed at these rates. In equation 3 . the cash flows are much more stable.
} 

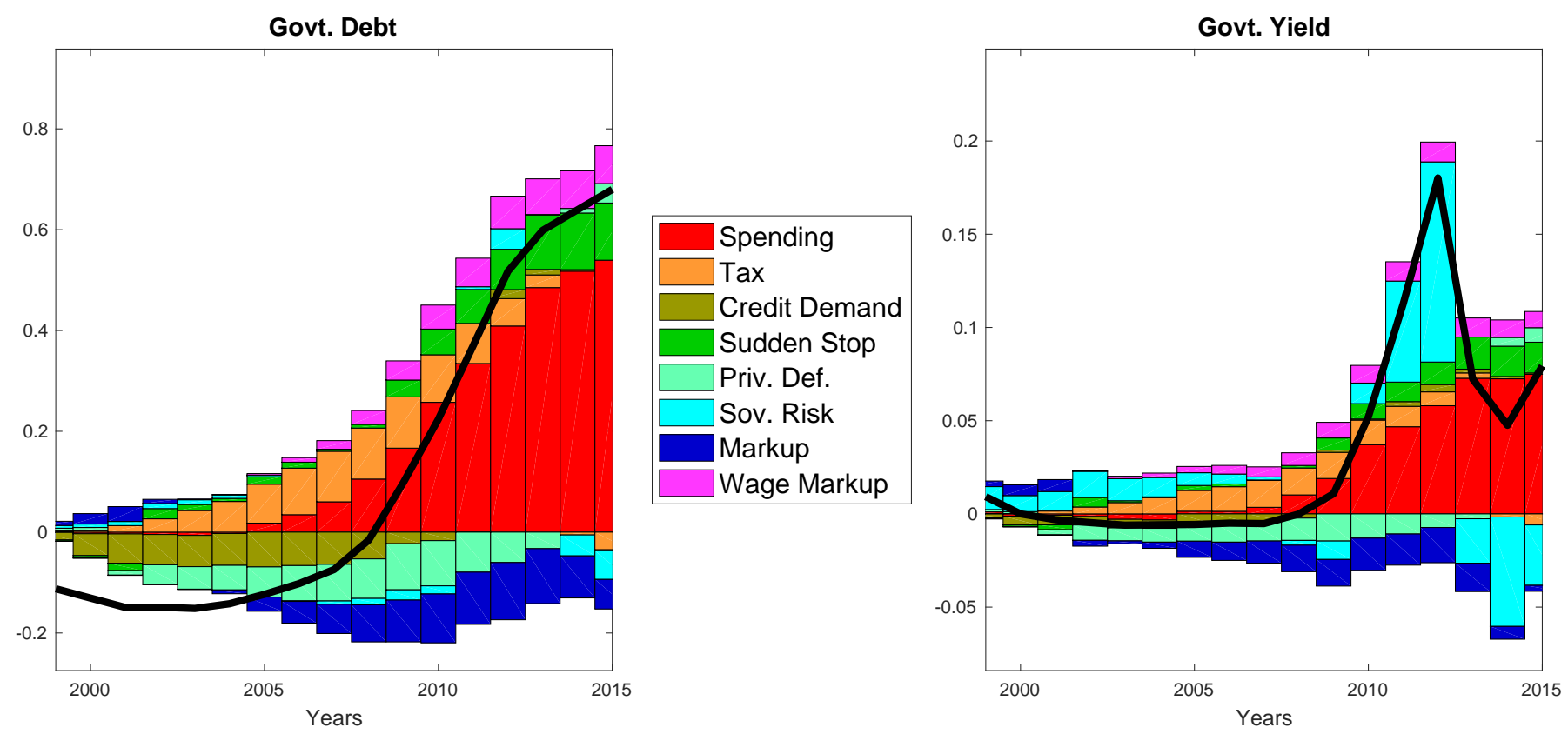

Figure 19: Decomposition of Govt. Debt and Yield. Note: The figure reports the decomposition of the predicted path for sovereign debt (left panel) and the yield on sovereign debt (right panel) into the contribution of each of the eight shocks.

accumulation after the crisis in Figure 19 is mostly due to spending shocks that happened before the crisis. The yield on sovereign debt is also mostly affected by the fiscal shock, and also by by sovereign risk. We observe a sharp decline in sovereign risk following the 2012 debt restructuring.

Markups and Non-performing loans Finally, starting in 2013, two important factors dragging down the Greek economy are the rise in non-performing loans, and the increase in price markups. As in Agatha Christie's 'Murder on the Orient Express', the boom and bust in Greek output per capita cannot be attributed to a single cause: over time, different shocks played a role. This decomposition also indicates that, by 2015, the external drags on the Greek economy due to the sudden stop and the sovereign debt crisis have subsided. What remains are mostly domestic factors: some fiscal austerity, mounting losses on private loans, and the relative lack of adjustment in Greek prices relative to wages.

Investment (figure 18, right panel) is mostly affected by the increase in funding costs due to the sudden stop in 2009-2013. In 2014 and 2015, investment remains subdued largely because of private sector credit risk, fiscal austerity and especially price markup shocks.

Figure 20 reports both expected private defaults (left panel) and the funding cost of the private sector (right panel). Both variables are also perfectly predicted by the model, by construction. Private 

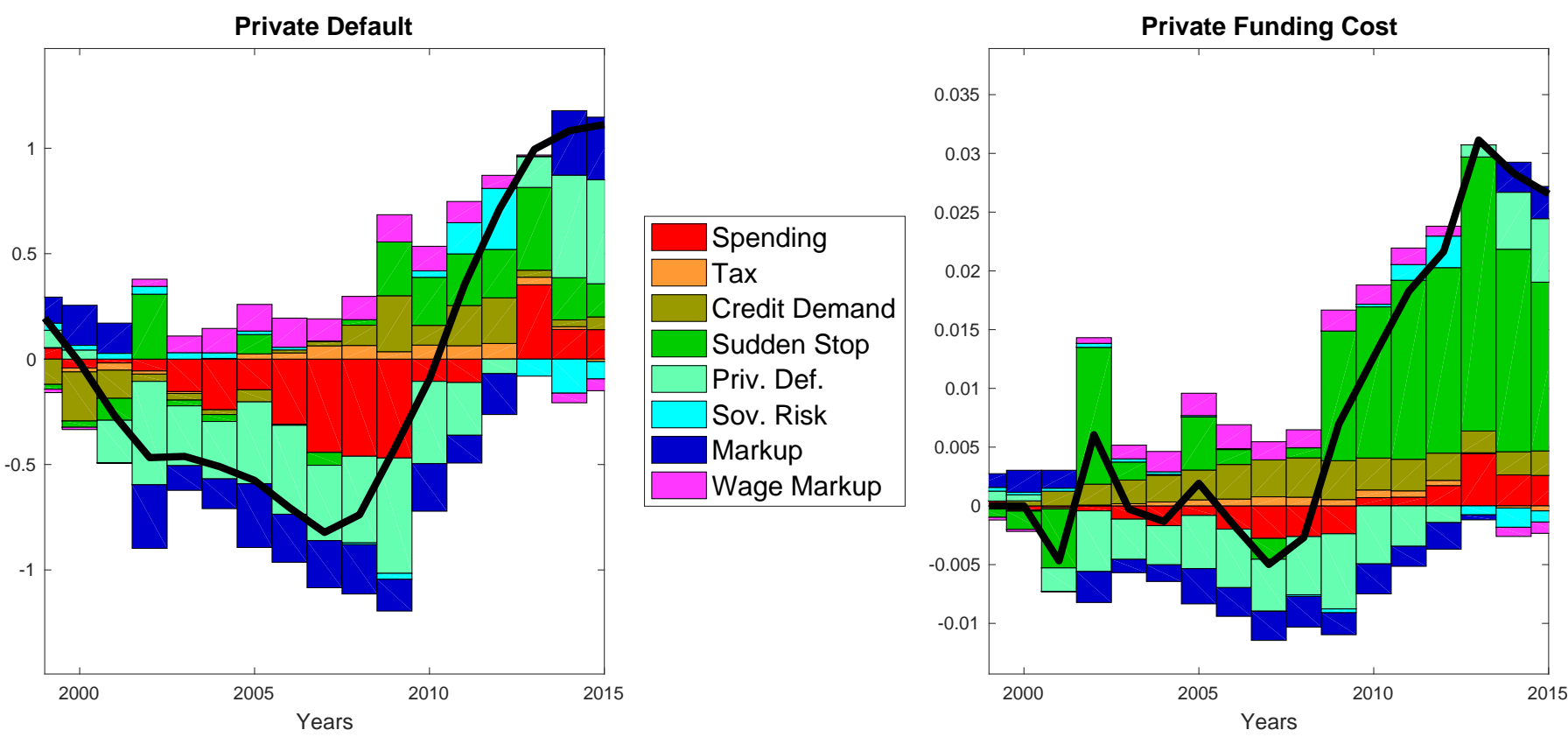

Figure 20: Decomposition of Private Default and Funding Cost. Note: The figure reports the decomposition of the predicted path for household credit losses (left panel) and the borrowing rate (right panel) into the contribution of each of the eight shocks.

credit losses were low early in the sample because of low private default risk, and the strong stimulus coming from government spending. After 2007, private credit losses mount rapidly, mostly as a consequence of macro dynamics. The increase in funding costs due to the sudden stop, the collapse in credit demand, fiscal austerity and the increase in private default risk all contribute to raise private credit losses. The right panel illustrates that the main driver of private sector cost of funds was the sudden stop 36

Figure 21 reports government spending (left panel) and revenues (right panel). Government spending is largely autonomous in the boom, a finding consistent with Martin and Philippon (2014). In the bust, it is explained by the funding constraint, and then by restrictions consistent with the IMF/Eurogroup program. Government revenues are dominated by macro dynamics. While tax shocks move from negative to positive, revenues decline overall due to the sudden stop and its effect on output and investment, the impact of spending cuts on output, and mounting non-performing loans.

Finally, Figure 22 decomposes domestic price (left panel) and wage inflation (right panel). Fiscal austerity, private sector default and wage compression (negative wage markup shocks) contribute to

\footnotetext{
${ }^{36} \mathrm{As}$ in the case of sovereign yields, one may argue that the borrowing rate for Small and Medium Enterprises may not have been allocative at that time. However, recall that Greek banks could obtain liquidity at the ECB and the Bank of Greece against eligible collateral. Hence the supply of loanable funds to the private sector was presumably not vertical.
} 

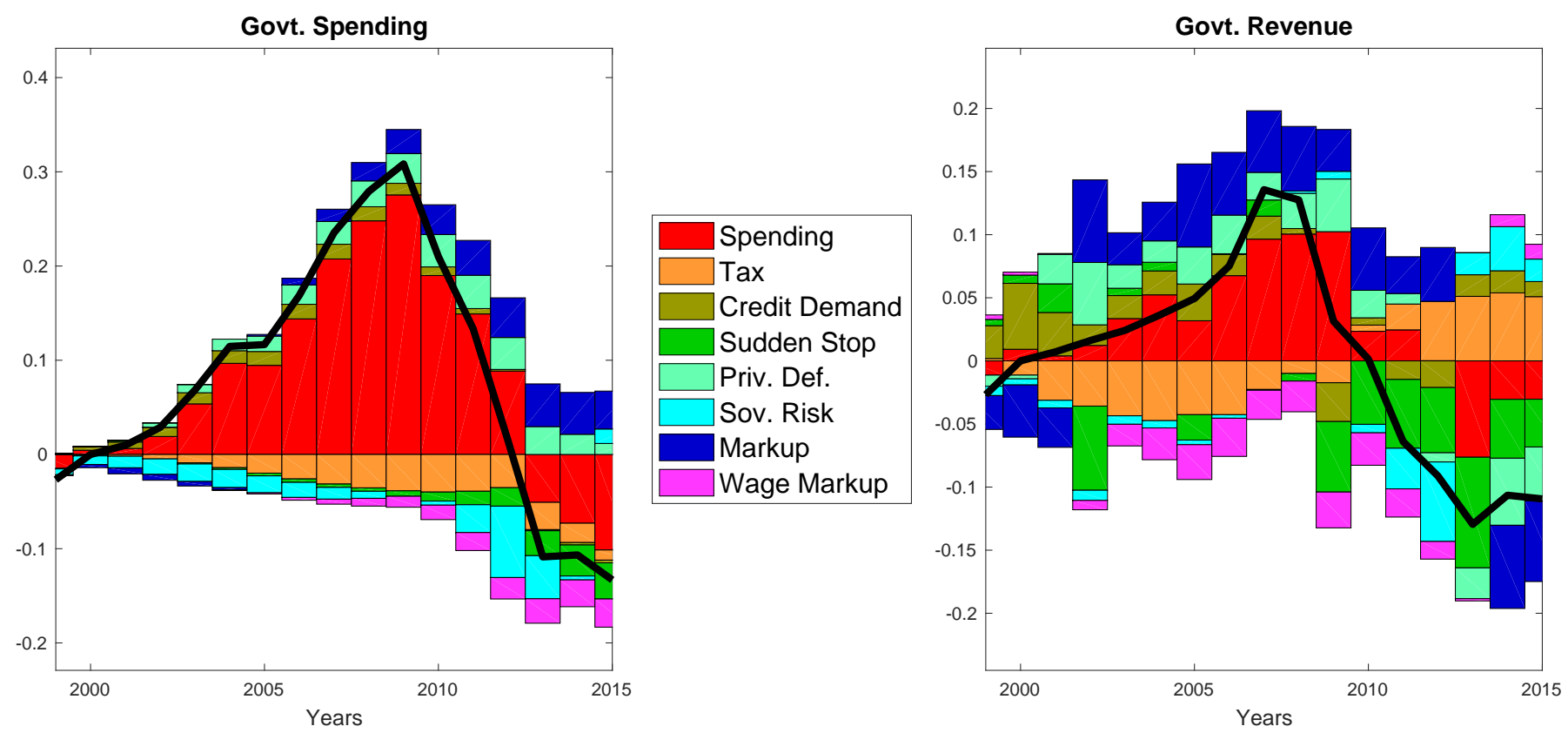

Figure 21: Decomposition of Govt. Spending and Revenues. Note: The figure reports the decomposition of the predicted path for government spending (left panel) and government revenues (right panel) into the contribution of each of the eight shocks.

deflationary price and wages forces. Yet wage adjustment is significantly larger than price adjustment, and the difference can largely be attributed to price markup shocks $\zeta^{\pi h}$.

\subsection{Impulse Responses}

We next explore the internal mechanics of the model by plotting some impulse response functions, estimated at the posterior mean of the parameters. Each impulse response reports the effect of a one standard deviation shock on the variables of the model, expressed in percent deviation from their steady state. We present here only a few impulse responses. Other figures are in the Appendix.

Figure 23 shows the response to a transfer shock, $\varepsilon_{t}^{\text {spend }}$. Our model is not Ricardian. An increase in government spending raises the consumption of borrowers, as well as output, employment, investment and inflation. As the economy expands, non-performing loans decline. Over time, public debt gradually increases, which pushes up sovereign yields. The model thus features a significant but temporary effect of a fiscal expansion on output, and a long lasting effect on the level of public debt.

Figure 24 shows the response to a sovereign risk shock, $\varepsilon_{t}^{d g}$. The fiscal rule forces a cut in spending that leads to a drop in output, employment and inflation. The decline in output increases private credit risk which feeds back into funding costs and curtails investment. Figure 24 (and Figure 33 

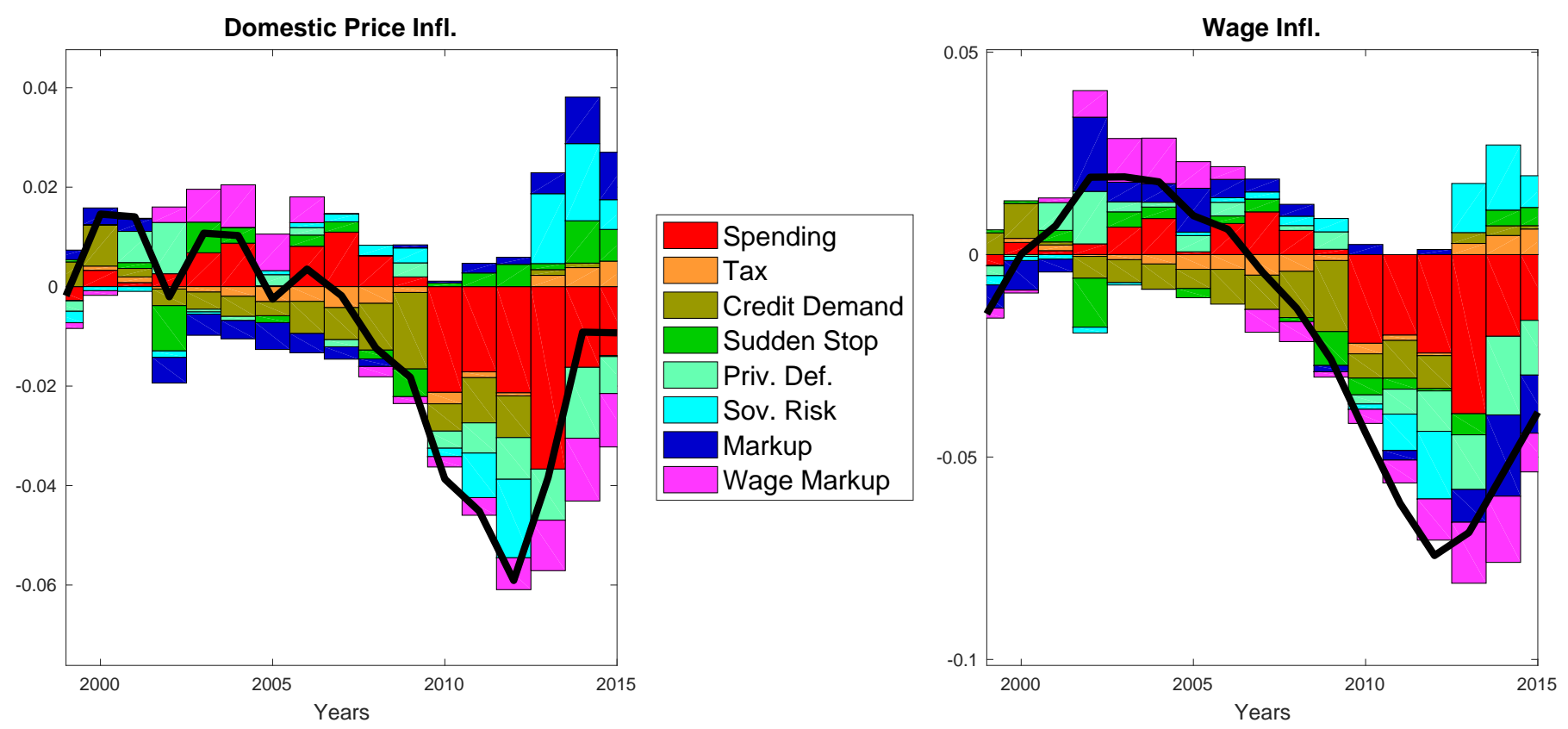

Figure 22: Decomposition of Domestic Price and Wage Inflation. Note: The figure reports the decomposition of the predicted path for domestic price and wage inflation into the contribution of each of the eight shocks.

Spending
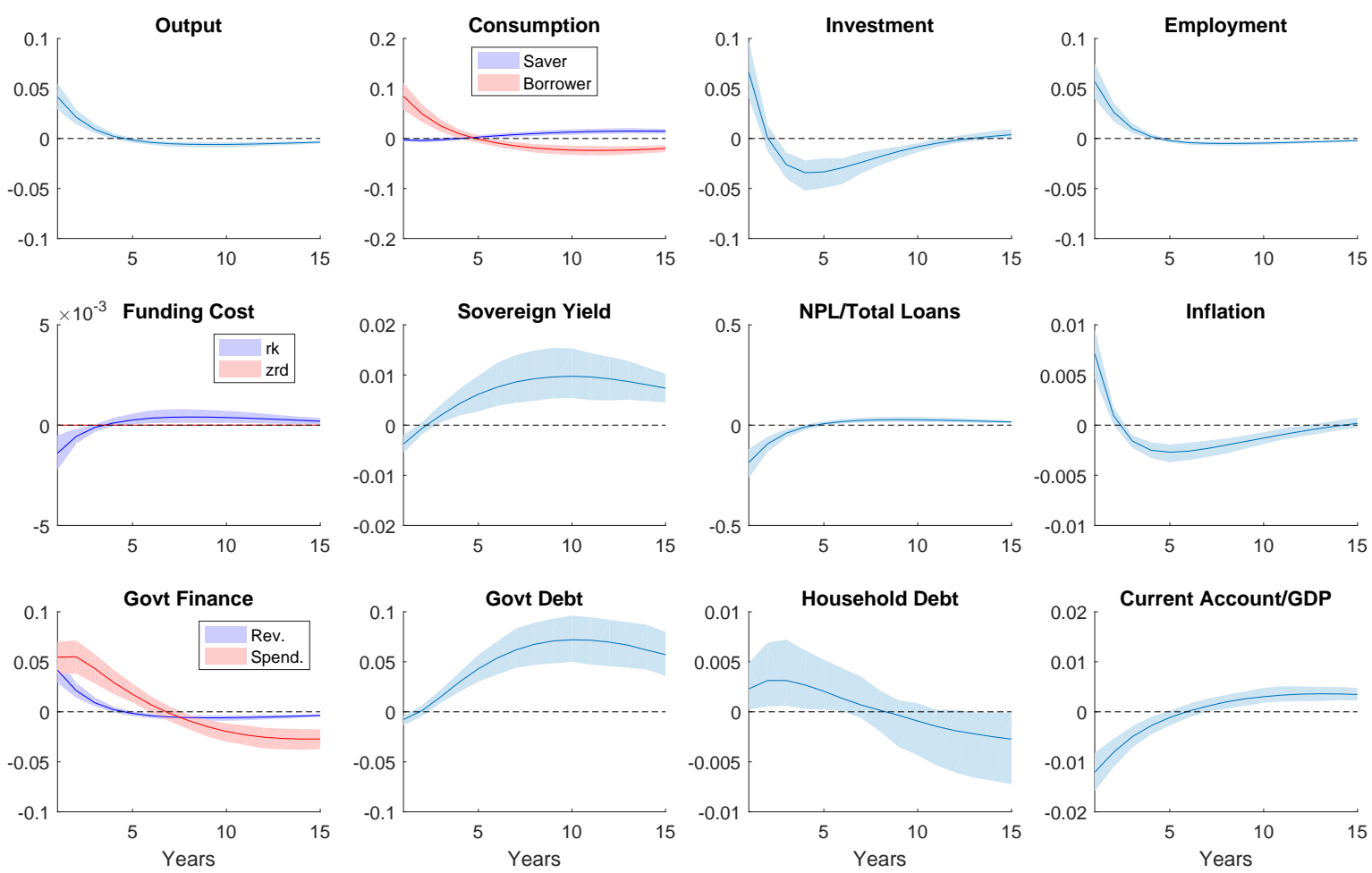

Figure 23: Fiscal Expansion Shock. Note: The figure reports $90 \%$ Bayesian confidence bands. 
Sov Risk
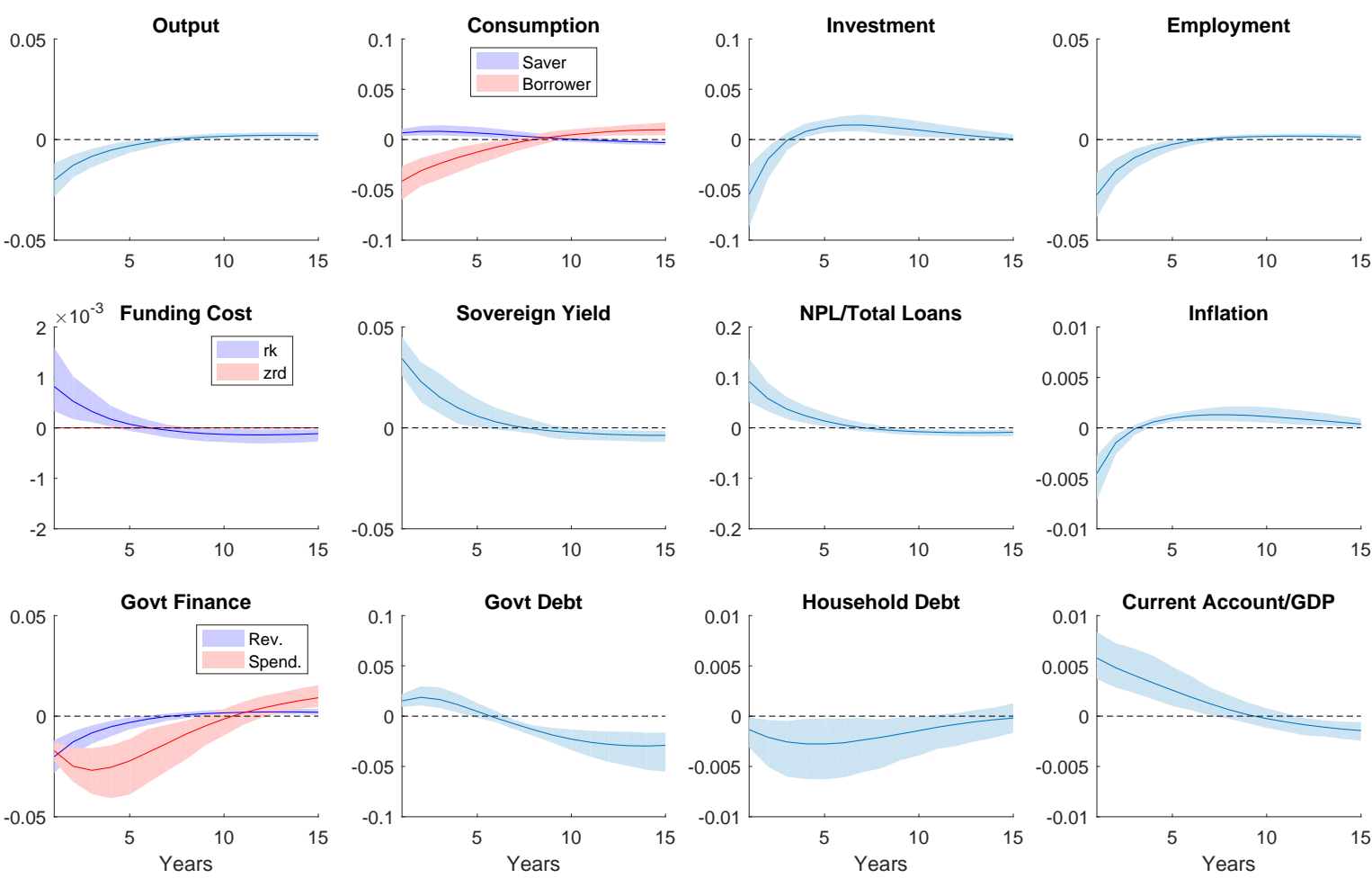

Figure 24: Sovereign Risk Shock. Note: The figure reports 90\% Bayesian confidence bands.

in the appendix which looks at the response to a private default shock) illustrate the sovereign/bank interactions: as sovereign risk increases, the funding costs of the private sector are affected. Conversely, as private default risk increases, sovereign risk increases as well. In our model, these effects work via general equilibrium effects.

Finally, Figure 25 shows the response to a sudden stop, $\varepsilon^{r}$. An increase in the country's funding cost causes corporate investment to decline. Impatient household debt declines as well, and so does borrower consumption. The decline in consumption and investment drives output, employment and inflation down. The interest rate on government debt increases because the decline in economic activity heightens sovereign risks.

\section{Counterfactuals}

In this section, we run five counterfactual exercises. To understand our counterfactual exercises, let $y_{i t}$ denote the observation of variable $i$ at date $t$, and let $\hat{x}_{i t}$ denote the smoothed value for variable $i$ at 


\section{Sudden Stop}
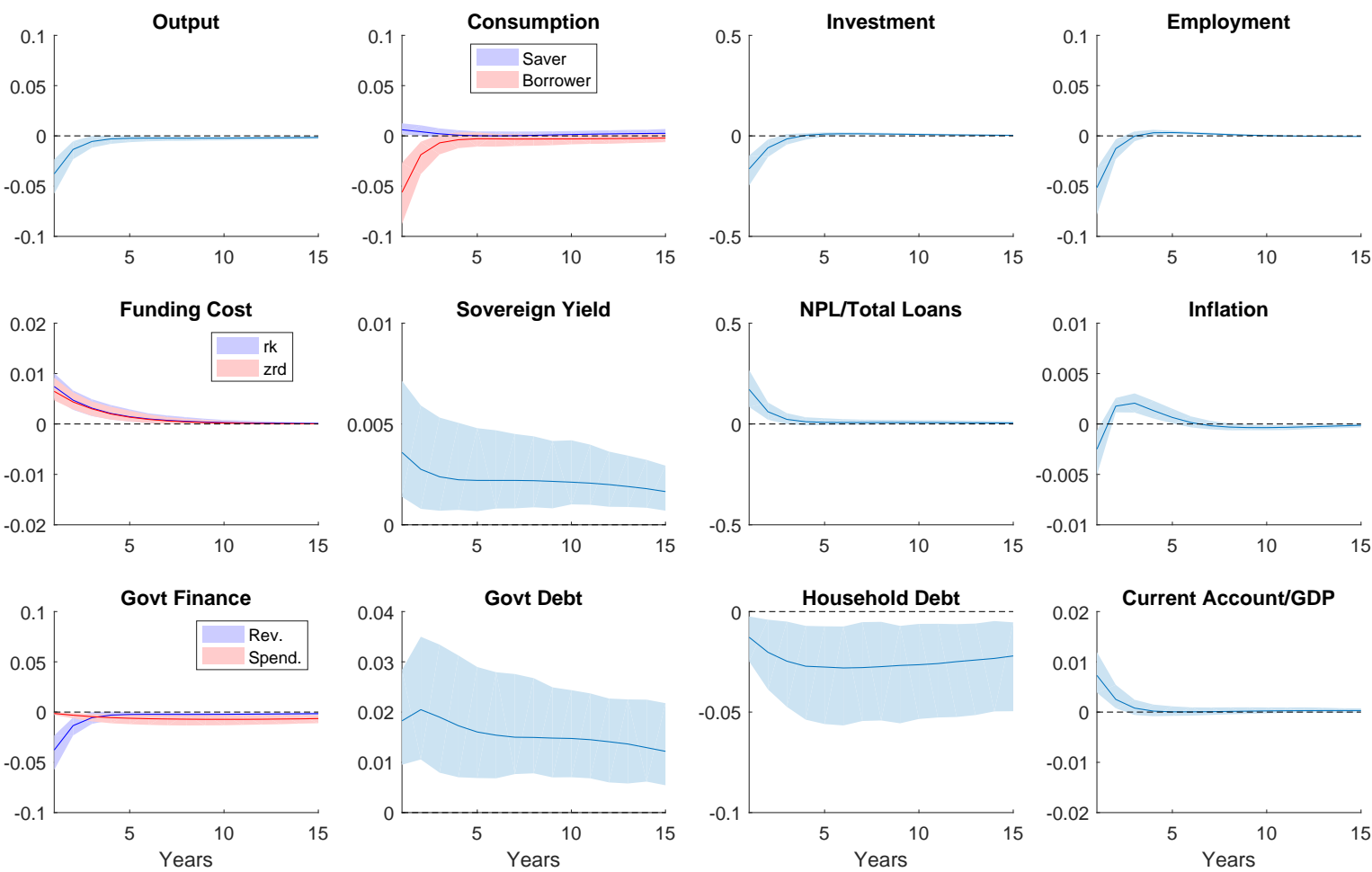

Figure 25: Sudden Stop. Note: The figure reports 90\% Bayesian confidence bands.

date $t$. Let $\hat{x}_{i}^{T} \equiv\left\{\hat{x}_{i, t}\right\}_{t=0}^{T}$ denote the estimated smoothed sequence for variable $i$ in our sample period for $t=0, \ldots, T$ and denote $\hat{x}^{T}$ the sequence of all smoothed variables: $\hat{x}^{T} \equiv\left\{\hat{x}_{i}^{T}\right\}$. Every estimated sequence can be written as a mapping $\Gamma($.$) from the estimated parameters \hat{\Theta}$ and the sequences of smoothed shocks, $\left\{\hat{\varepsilon}_{k}^{T}\right\}_{k=1}^{K} \equiv\left\{\hat{\varepsilon}_{k, t}\right\}_{k=1, t=0}^{K, T}$, where $K$ is the number of shocks in our model:

$$
\hat{x}^{T}=\Gamma\left(\hat{\Theta},\left\{\hat{\varepsilon}_{k}^{T}\right\}_{k=1}^{K}\right) .
$$

A counterfactual exercise consists in postulating an alternate choice for $\hat{\Theta}$ and $\left\{\hat{\varepsilon}_{k}^{T}\right\}_{k=1}^{K}$, denoted $\tilde{\Theta}$ and $\left\{\tilde{\varepsilon}_{k}^{T}\right\}_{k=1}^{K}$ and then compute the counterfactual $\tilde{x}^{T}$ as:

$$
\tilde{x}^{T}=\Gamma\left(\tilde{\Theta},\left\{\tilde{\varepsilon}_{k}^{T}\right\}_{k=1}^{K}\right) .
$$

Based on our the empirical analysis of section 3 and the analytical results of section 5 , we begin with a 'low leverage' counterfactual. In that exercise, we ask what would have happened, through the lens of our model, if Greece's external and internal leverage had been similar to that of emerging market 
economies about to experience a sudden stop. This counterfactual is motivated by the evidence from section 3 that documents the severity and persistence of the Greek crisis when compared to many other - especially Emerging Market economies crises. In our second counterfactual we ask: what would Greece have looked like without a "sudden stop" for private capital? Setting $\varepsilon_{t}^{r}=0$ for all $t$ represents the situation that would have prevailed with a well-functioning European Banking Union 37 The third counterfactual asks what would have happened if Greece had maintained fiscal discipline

before 2007. In that counterfactual, we set $\varepsilon_{t}^{\text {spend }}=0$ for all $t$. The fourth counterfactual explores the role of price markups and sets $\varepsilon_{t}^{\pi h}=0$ for all $t$. This is an important exercise since the analytical decomposition of section 5 indicates that price markup shocks are an important drag on output and investment in 2014 and 2015. Our last counterfactual considers the role of price and wage stickiness in the adjustment path of Greece. As discussed in section 3 other countries such as Latvia or Estonia that maintained their peg in the face of a sudden stop and output collapse experienced a much faster recovery. We ask how much a lack of price flexibility may be responsible for this outcome. To do this, we reduce the calibrated price stickiness parameters $\lambda_{p}$ and $\lambda_{w}$ while keeping the sequence of shocks unchanged.

\subsection{Low Leverage Economy}

For our first counterfactual exercise, we calibrate the Greek economy to the level of government, private and banking leverage observed in the typical emerging market economy just prior to a sudden stop.

\begin{tabular}{ccccc} 
& Greece & Typical EME & Min & Max \\
\hline Credit / GDP & 1.01 & 0.46 & 0.025 & 1.46 \\
Sovereign Debt / GDP & 1.38 & 0.343 & 0.063 & 0.68 \\
Current Account /GDP & -0.083 & -0.039 & -0.10 & +0.17 \\
\hline
\end{tabular}

Table 5: Leverage and Imbalances Before Sudden Stop

Notes: Average from t-6 to t- 2 where t is the year of the sudden stop. Credit refers to domestic credit to non-financial institutions.

Table 5 compares the leverage of Greece to the leverage of other EMs that have experienced a sudden stop as described in section 3 . It is clear that leverage is much higher in Greece along all dimensions and in particular with respect to sovereign debt. Typically, leverage in EMs prior to sudden stops is roughly half of that of Greece prior to the 2010 crisis. Accordingly, we reduce $\frac{B^{h}}{Y}, \frac{B^{g}}{Y}, \frac{G}{Y}, \frac{T}{Y}$ and bank

\footnotetext{
${ }^{37}$ We also performed another counterfactual where we remove the sudden stop on public capital by setting $\varepsilon_{t}^{d g}=0$. This corresponds to the situation that would have prevailed in the presence of a sovereign debt 'backstop' in the form of ECB or bailout guaranties. These results are available upon request.
} 

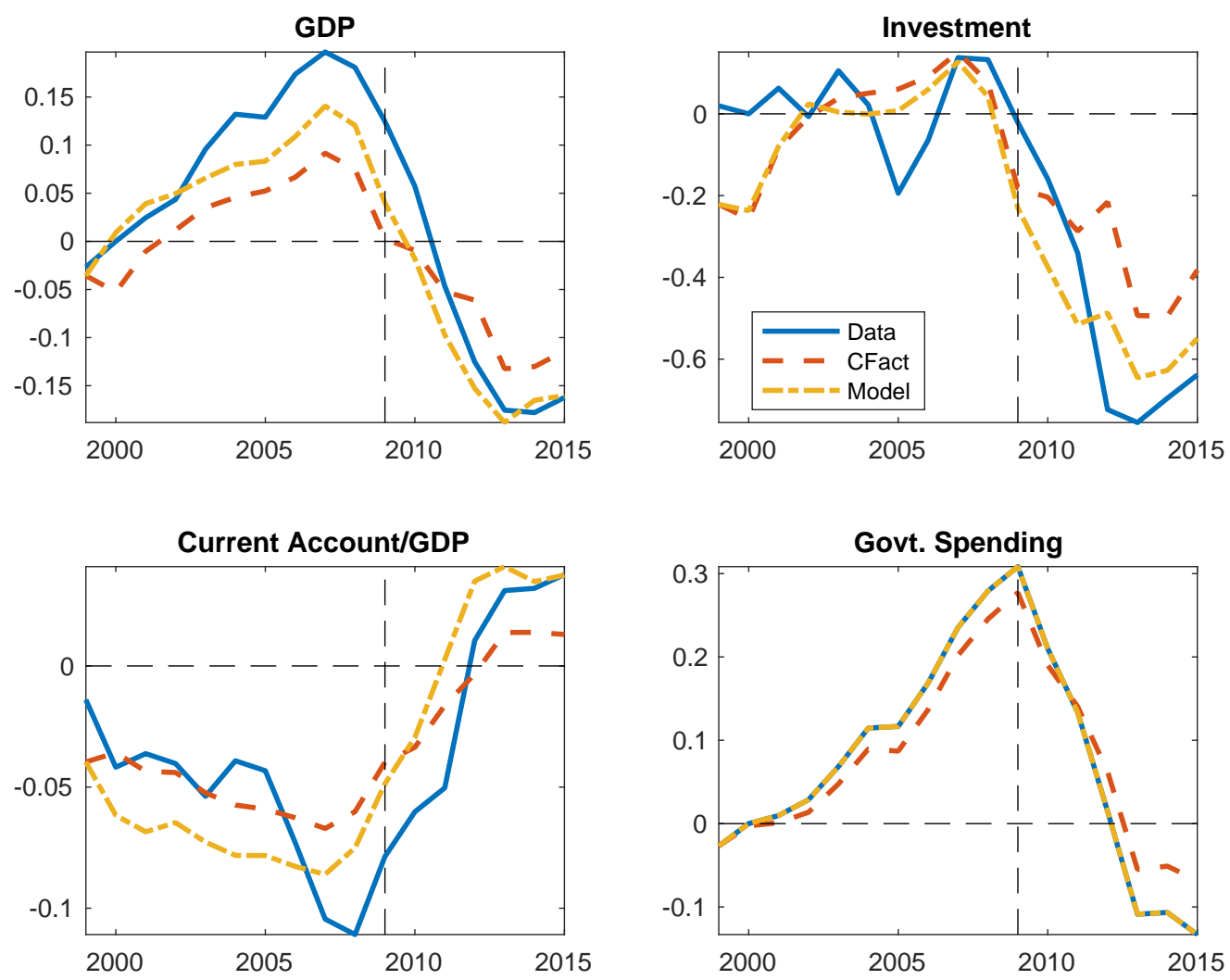

Figure 26: Counterfactual: Low Leverage. Note: The figure reports the counterfactual when we the government, private and banking leverage to the value for EM economies prior to a sudden stop.

leverage at the steady state by half. With these alternate parameters $\tilde{\Theta}$, and the same sequence of smoothed shocks $\left\{\hat{\varepsilon}_{k}^{T}\right\}_{k=1}^{K}$ we recompute the path of the endogenous variables, $\tilde{x}^{T}$.

Figure 26 reports the path for the actual data (in blue), the smoothed original estimates (in yellow) and the counterfactual (in orange). In this counterfactual, Greece would have been much more constrained in the build up phase of the crisis. The smaller size of its government sector would have prevented it from excessively stimulating its economy, reducing the output gap from $+14.1 \%$ in 2007 in the smoothed estimates to $+9.2 \%$ (top left panel). Once the fiscal contraction, sudden stop and sovereign risk materialize, we find that they would have had a substantially more muted impact on the economy. For instance, the peak to trough decline in output is now only $22 \%$ instead of $33 \%$. The decline in investment is also more muted, around $64 \%$ instead of $77 \%$. Hence some of the excess drop in investment observed in figure 9 can be attributed to the exceptional leverage of the Greek economy relative to other emerging economies. Were it not for its elevated exposure levels, Greece would have experienced a more typical emerging market 'Trifecta' crisis. Similarly, limited external 

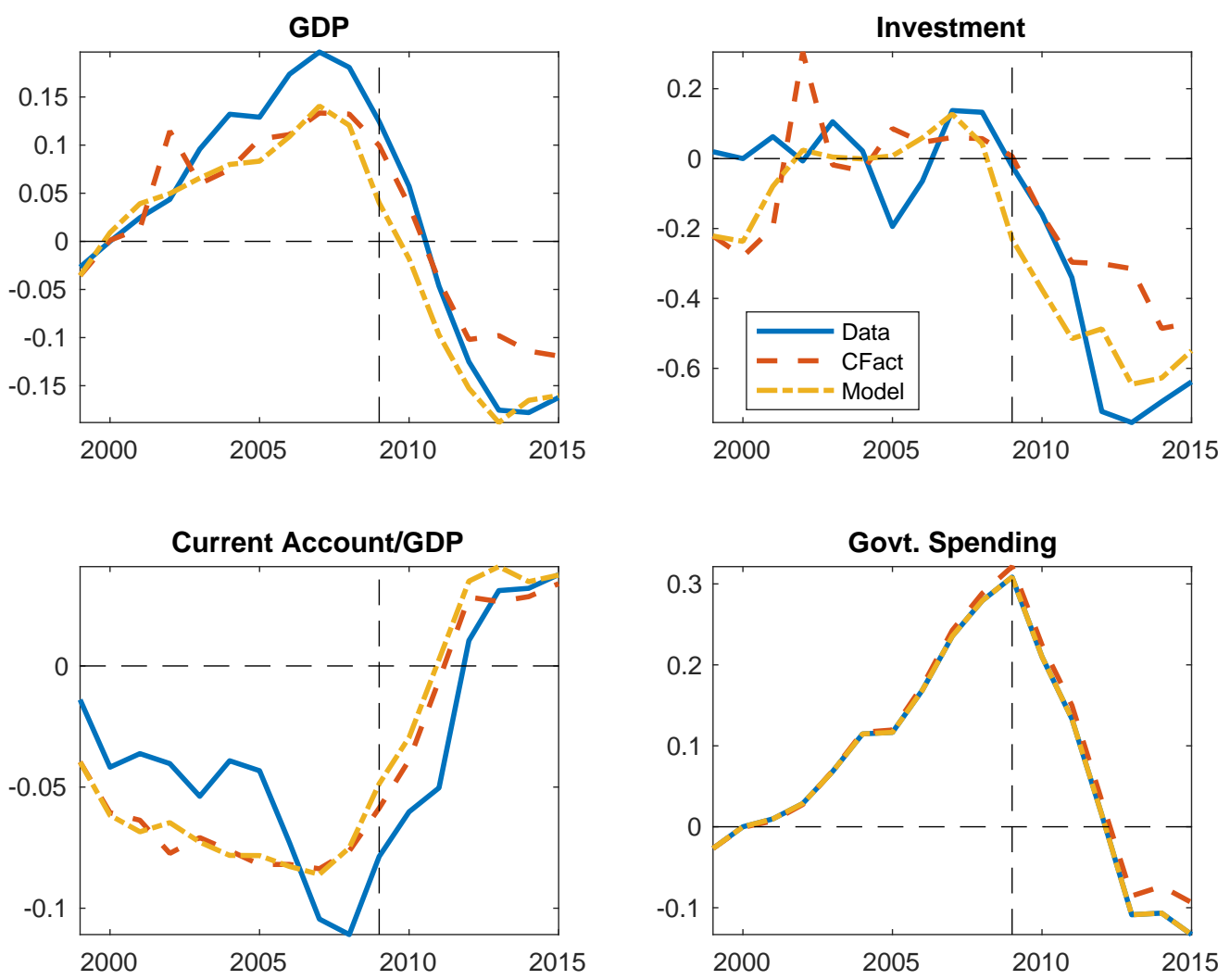

Figure 27: Counterfactual: No Private Sudden Stop . Note: The figure reports the counterfactual when we set the private sudden stop shock $\tilde{\varepsilon}_{t}^{r}=0$.

exposure would have reduced the build up in external deficits, to $-6.7 \%$ of GDP instead of $-8.6 \%$, and consequently imposed a smaller turnaround in the current account $(+8 \%$ instead of $+12.7 \%)$.

\subsection{No Sudden Stop Shocks}

For our second counterfactual exercise, we keep our vector of estimated and calibrated parameters

fixed, $\hat{\Theta}$, and we recompute $\tilde{x}^{T}$ based on a new sequence of smoothed shocks. This new sequence is identical to the one that we estimated, with the exception that we set the private sudden stop shock to zero, $\hat{\varepsilon}_{t}^{r}=0$. Figures 27 reports the results with the same convention as the previous counterfactual.

The absence of a private sudden stop can be interpreted as the outcome in presence of a wellfunctioning banking union. With a European level resolution and supervision authority, foreign and domestic creditors would have no incentive to run. The counterfactual reveals that a banking union would have had almost no impact on the path of output during the build-up (Figure 27, top left panel). Recall that the path for output prior to 2007 was largely driven by high credit demand, as well as by 
the stimulative effect of expansionary fiscal policies. The eventual consolidation of fiscal accounts was unavoidable, with or without a private sudden stop. In other words, a banking union would not have insulated Greece from the consequences of its past unsustainable fiscal policies. However, the sudden stop did contribute to worsen the output response once the crisis got under way. By 2013, we find that output would have been higher by 9 percentage points in the absence of sudden stop, although the difference would have subsequently declined. Much of the effect of the sudden stop was on investment (top right panel), which would have been higher by 33 percentage points otherwise in 2013.

\subsection{Fiscal Discipline}

As mentioned already many times, it is perhaps not entirely surprising that Greece would experience a serious downturn given the size of the needed fiscal consolidation. What would have happened if instead Greece had followed a virtuous fiscal path since 2000? We consider this counterfactual

by setting $\tilde{\varepsilon}_{t}^{\text {spend }}=0$, i.e. assuming away both the fiscal excesses of the 2000-2007 period and the subsequent required fiscal consolidation. Figure 28 reports the results. Not surprisingly, the crisis would have been much more muted, especially for output, government spending and net exports. Output (top left panel) would have declined by around 16\% instead of 33\% between 2007 and 2013 . Government spending (bottom right panel) would have barely increased between 2000 and 2010, then declined a modest $8 \%$ instead of $34 \%$ relative to steady state. Finally the current account would have started to improve as early as $2006{ }^{38}$

\subsection{No Markup Shocks}

Next, we consider the relative contribution of price mark-up shocks, by studying the paths of the variables of the model while turning shocks to domestic inflation $\hat{\varepsilon}_{t}^{\pi h}=0$.

Figure 29 reports the results. The figure suggests that price markup shocks play an important role in the analysis. Perhaps surprisingly, in the absence of price markup shocks Greece would have experienced no boom (top left panel) but a bust of a similar magnitude. Most importantly, this counterfactual reveals that the increase in price markups has become a significant force hindering the recovery of the Greek economy: without markup shocks, investment would have recovered to $18 \%$

\footnotetext{
${ }^{38}$ In our model, eliminating fiscal profligacy would not have eliminated the Greek crisis altogether because we are still keeping the sudden stop and sovereign risk shocks. Our estimates of the benefit of fiscal discipline are only a lower bound. This is the main difference with Martin and Philippon (2014) who estimate the impact of sovereign debt on the sudden stop itself. Martin and Philippon (2014) find much larger benefits of fiscal discipline, but their estimation requires cross-sectional information from different countries and is not feasible here.
} 

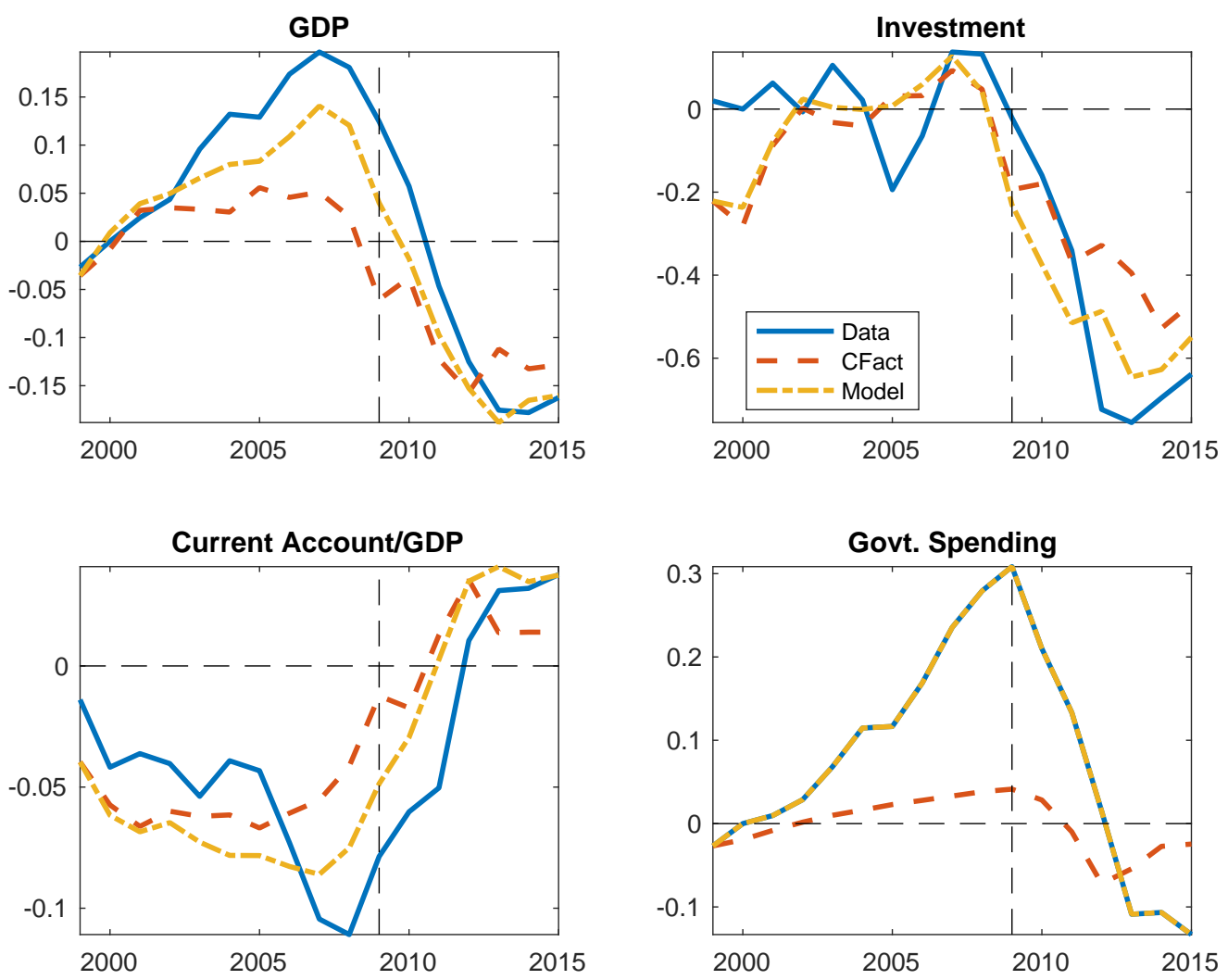

Figure 28: Counterfactual: Fiscal Discipline . Note: The figure reports the counterfactual when we set the spending shocks $\tilde{\varepsilon}_{t}^{\text {spend }}=0$

of its steady state value (top right panel) by 2015 , while output would have rebounded by $11 \%$ of its steady state value since the trough. Interestingly, lower markups would translate into stronger deflation, which would have adversely affected government debt dynamics, triggering further declines in government spending (bottom right panel). We infer from this counterfactual analysis that price dynamics are crucial to the recovery of the Greek's economy. Recall that in our model marginal costs include a financial component due to working capital. The increase in price-marginal costs markups cannot, therefore, be attributed to an increase in financial frictions that raise the non-wage components of the marginal costs. Instead, our estimates indicate that lack of entry and competition in product markets, as well as a rise in firms' costs stemming from factors such as the uncertainty about EZ exit and higher taxes on key inputs may be responsible for a very sluggish recovery. 

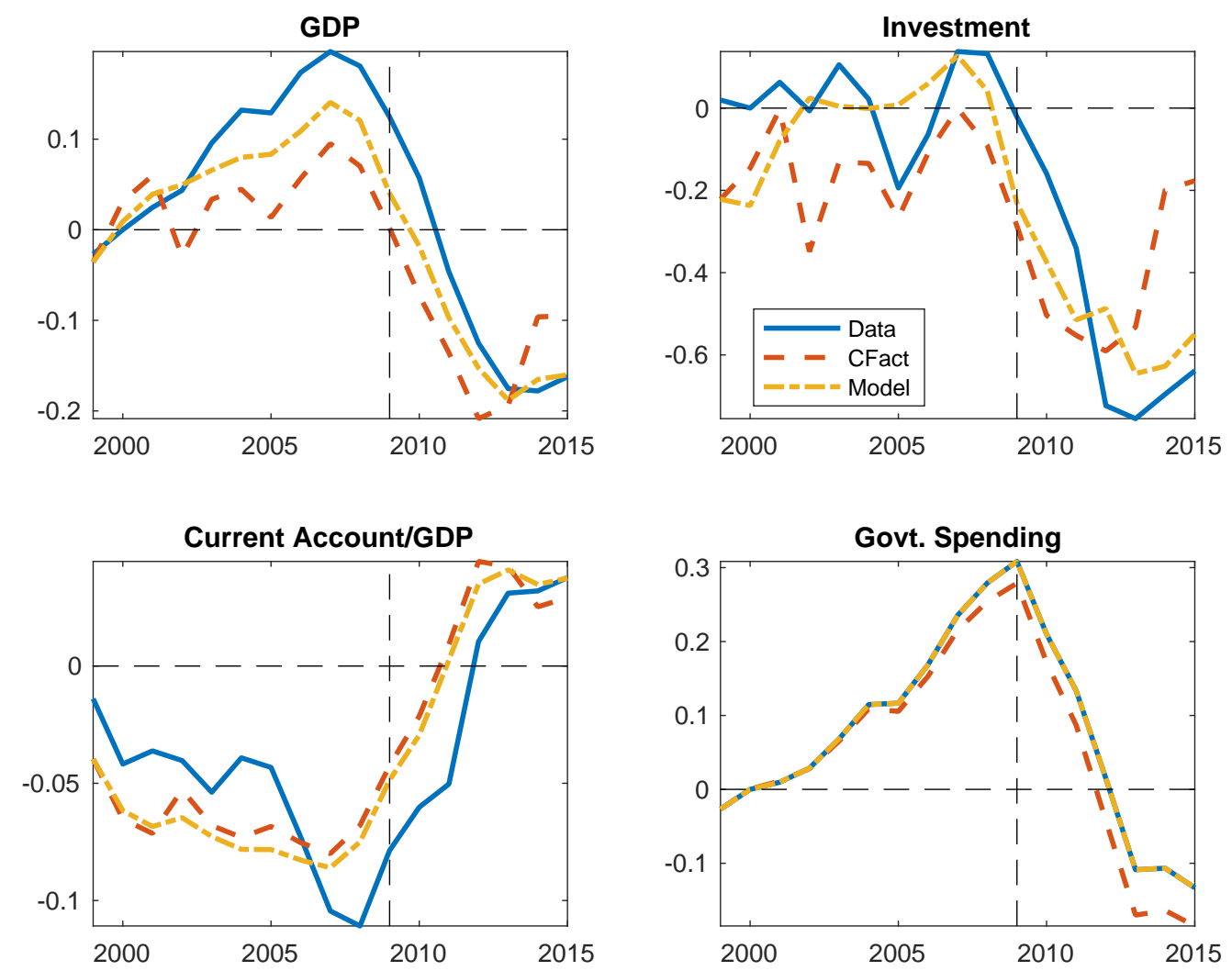

Figure 29: Counterfactual: No Domestic Price Markup Shocks . Note: The figure reports the counterfactual when we set price markup shocks $\tilde{\varepsilon}_{t}^{\pi h}=0$

\subsection{Latvia: Low Price Stickiness}

Our final counterfactual aims to explore the role of price and wage rigidities more closely. Ideally, one would like to analyze how the Greek economy would have performed had it left the Euro and been able to depreciate its own currency. Yet this is not a counterfactual that we can easily analyze, at least without auxiliary assumptions. For instance, under a 'Grexit' scenario, one needs to specify what would happen to euro denominated liabilities. Instead, we ask the converse -and easier- question: what would have happened if prices had been more flexible in Greece? In the limit where prices are perfectly flexible, the nominal exchange rate regime becomes irrelevant. It is well known also that price and wage flexibility may work perversely, aggravating Fisherian debt-deflation dynamics either at the zero lower bound, or under a fixed exchange rate. Nevertheless, the evidence of Latvia and Estonia discussed in section 3 suggests that countries with more flexible wages and prices may experience shorter recessions. To investigate these questions, we keep the sequence of shocks fixed, and reduce the calibrated price stickiness parameters $\lambda_{p}$ and $\lambda_{w}$, to half of their original values. 

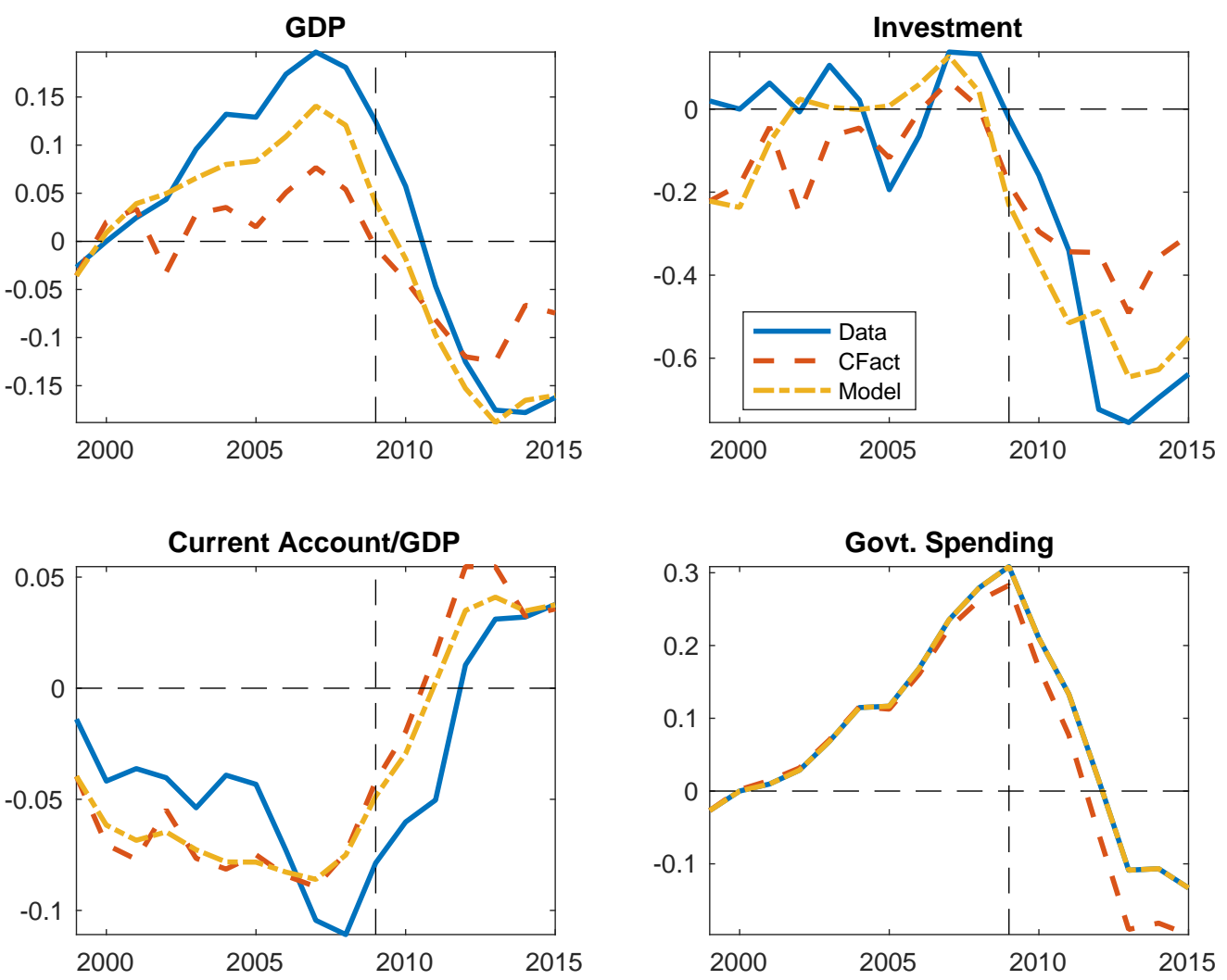

Figure 30: Counterfactual: Low Price Stickiness . Note: The figure reports the counterfactual when we set wage and price stickiness $\lambda_{p}$ and $\lambda_{w}$ to half their calibrated values

Figure 30 reports the results. The figure indicates that Greece would have avoided a significant share of the boom bust cycle, with a peak to trough decline in output of $20 \%$ instead of $33 \%$. Similarly, investment would have declined by only $55 \%$ instead of $77 \%$. The recovery in output would also have been sharper, with output in 20158 percentage points above the baseline estimates. We conclude that faster price and wage adjustment would have dampened the boom bust cycle and accelerated the recovery.

\section{Conclusion}

In this paper we analyze the macroeconomic dynamics of Greece before and during the crisis that it has been experiencing since 2008. This is only an interim report since, six years down the road, the crisis is still playing out, and the Greek economy is still very much on life support. Nevertheless, we believe that enough time has elapsed to make it possible to provide preliminary answers. We put Greek macroeconomic dynamics in perspective by comparing with crisis episodes in other countries, 
including sudden stops, sovereign defaults, lending booms and busts, and combinations of the above. We also interpret Greece's crisis dynamics through the lens of a DSGE model that incorporates key features of the crisis such as sovereign default and financial frictions. Using the model, we decompose the movements of macroeconomic variables such as output and investment, into the contributions of different types of shocks, including fiscal shocks and shocks to the financial sector. We also perform counterfactuals to examine how factors such as debt levels, fiscal policy, and price rigidities may have contributed to the severity of the crisis.

Our main findings are as follows. First, Greece's drop in output was significantly more severe and protracted than in the average crisis episode. Second, the unusually large drop in output was accompanied by an unusually large drop in the investment-to-output ratio. Third, much of the discrepancy can be accounted for by the higher levels of debt - government, private, and foreign - that Greece entered the crisis with. Fourth, Greece's output drop at the early stages of the crisis appears to have been driven mainly by fiscal shocks and by the sudden stop (which raised funding costs). At the later stages of the crisis, however, the effects of these shocks appear to have subsided, and the shocks that account for protracted drop in output appear to be the slow resolution of non-performing loans and price rigidities in product markets. Hence the micro dimension of the crisis may now have taken precedence over macroeconomic forces.

While our model captures a rich set of dynamics, it undoubtedly leaves aside many factors that may prove to be important when the final account will be written. One such factor is the uncertainty about EZ exit (Grexit). That uncertainty hampered investment and contributed to the liquidity problems of Greek banks. Retail deposits in Greek banks dropped by about $50 \%$ between 2009 and 2015, while they remained stable or even increased in Irish, Italian, Portuguese, and Spanish banks. Hence, uncertainty about EZ exit seems to have been much larger in Greece than in the other countries. Some of the effects of Grexit may be 'relabeled' under other shocks in our model, such as the sudden stops, but introducing a more primitive shock may give a more accurate decomposition. Another factor that relates to the uncertainty is the political response to the crisis: domestic consensus on a strategy to exit the crisis was lacking in Greece, while it was present to a larger extent in other crisis-hit EZ countries such as Ireland and Portugal. 


\section{References}

Adalet, M. and B. Eichengreen (2007, March). Current Account Reversals: Always a Problem? In G7 Current Account Imbalances: Sustainability and Adjustment, NBER Chapters, pp. 205-246. National Bureau of Economic Research, Inc.

Aguiar, M. and M. Amador (2014). Sovereign debt. Handbook of International Economics 4.

An, S. and F. Schorfheide (2007). Bayesian Analysis of DSGE Models. Econometric Reviews 26(2-4), $113-172$.

Arellano, C. (2008). Default risk and income fluctuations in emerging economies. American Economic Review.

Blanchard, O. J. and F. Giavazzi (2002). Current Account Deficits in the Euro Area: The End of the Feldstein Horioka Puzzle? Brookings Papers on Economic Activity 33(2), 147-210.

Blanchard, O. J., M. Griffiths, and G. Bertrand (2013). Boom, bust, recovery: Forensics of the latvia crisis. Brookings Papers on Economic Activity, 325-371.

Brunnermeier, M., L. Garicano, P. Lane, M. Pagano, R. Reis, T. Santos, M. Pagano, D. Thesmar, S. Van Nieuwerburgh, and D. Vayanos (2016). The sovereign-bank diabolic loop and ESBies. American Economic Review, P\&P 106, pp. 508-12.

Calvo, G. A., A. Izquierdo, and E. Talvi (2006). Phoenix miracles in emerging markets: recovering without credit from systemic financial crises. Technical report, National Bureau of Economic Research.

Campbell, J. Y. and N. G. Mankiw (1989). Consumption, income and interest rates: Reinterpreting the time series evidence. NBER Macroeconomics Annual 4, 185-246.

Cantor, R. and F. Packer (1995, June). Sovereign credit ratings. Current Issues in Economics and Finance 1(3), 1-6.

Chambers, J. (2011, February). Sovereign defaults and rating transition data, 2010 update. Standard 83 Poor's Global Credit Portal.

Christiano, L. J., M. Eichenbaum, and C. L. Evans (2005, February). Nominal Rigidities and the Dynamic Effects of a Shock to Monetary Policy. Journal of Political Economy 113(1), 1-45. 
Corden, M. W. and J. P. Neary (1982). Booming sector and de-industrialisation in a small open economy. The Economic Journal 92(368), 825-848.

Dornbusch, R. and A. Werner (1994). Mexico: stabilization, reform, and no growth. Brookings papers on economic activity 1994(1), 253-315.

Eggertsson, G. and P. Krugman (2012). Debt, deleveraging, and the liquidity trap:a fisher-minsky-koo approach. Quarterly Journal of Economics (127(3)), 1469-1513.

Eichengreen, B., A. Rose, and C. Wyplosz (1995, October). Exchange market mayhem: The antecedents and aftermath of speculative attacks. $0(21), 249-96$.

Farhi, E. and J. Tirole (2016, January). Deadly embrace: Sovereign and financial balance sheets doom loops. Working Paper 21843, National Bureau of Economic Research.

Faria-e-Castro, M. (2016). Fiscal policy and financial crises in a monetary union. Manuscript, New York University.

Gali, J. and T. Monacelli (2008). Optimal monetary and fiscal policy in a currency union. Journal of International Economics 76, 116-132.

Garber, P. M. (1999, December). The target mechanism: Will it propagate or stifle a stage III crisis? Carnegie-Rochester Conference Series on Public Policy 51(1), 195-220.

Gertler, M. and N. Kiyotaki (2010). Financial intermediation and credit policy in business cycle analysis. Working Paper, NYU.

Gourinchas, P.-O. and M. Obstfeld (2012). Stories of the twentieth century for the twenty-first. American Economic Journal Macro 4 (1), 226-265.

Gourinchas, P.-O., R. O. Valdés, and O. Landerretche (2001, Spring). Lending booms: Latin america and the world. Economia 1(2), 47-99.

Guerrieri, V. and G. Lorenzoni (2010). Credit crises, precautionary savings and the liquidity trap. Chicago-Booth Working Paper.

Hyppolite, P.-A. (2016, March). Towards a theory on the causes of the greek depression. mimeo, Paris School of Economics. 
Iacoviello, M. (2015, January). Financial Business Cycles. Review of Economic Dynamics 18(1), $140-164$.

Ilzetzki, E. I., C. M. Reinhart, and K. S. Rogoff (2010). Exchange rate arrangements entering the 21st century: Which anchor will hold?

Ingram, J. C. (1973, April). The case for European monetary integration. Number 98 in Essays in International Finance. Princeton University Press.

Jermann, U. and V. Quadrini (2012). Macroeconomic effects of financial shocks. American Economic Review 102(1), 238-71.

Kaminsky, G. L. and C. M. Reinhart (1999, June). The twin crises: The causes of banking and balance of payments problems. $89(3), 473-500$.

Korinek, A. and E. G. Mendoza (2013). From sudden stops to fisherian deflation: Quantitative theory and policy implications. NBER WP 19362.

Korinek, A. and E. G. Mendoza (2014). From sudden stops to fisherian deflation: Quantitative theory and policy. Annual Review of Economics 6(1), 299-332.

Krugman, P. (2012, June 24). Revenge of the optimum currency area. http://krugman.blogs. nytimes.com/2012/06/24/revenge-of-the-optimum-currency-area

Mankiw, N. G. (2000). The savers-spenders theory of fiscal policy. American Economic Review Papers and Proceedings, 120-125.

Martin, P. and T. Philippon (2014). Inspecting the mechanism: Leverage and the great recession in the eurozone. Working Paper NYU.

Mendoza, E. G. (2010). Sudden stops, financial crises, and leverage. American Economic Review 100, $1941-1966$.

Midrigan, V. and T. Philippon (2010). Household leverage and the recession. NYU Working Paper.

Moody's (2009, March). Sovereign default and recovery rates, 1983-2008. Moody's Global Credit Policy.

Philippon, T. (2011). Has the us finance industry become less efficient? on the theory and measurement of financial intermediation. NBER WP 18077. 
Ranciere, R., A. Tornell, and F. Westermann (2008). Systemic crises and growth. The Quarterly Journal of Economics, 359-406.

Reinhart, C. M. and K. S. Rogoff (2004). The Modern History of Exchange Rate Arrangements: A Reinterpretation. The Quarterly Journal of Economics 119(1), 1-48.

Reinhart, C. M. and K. S. Rogoff (2009). This Time Is Different: Eight Centuries of Financial Folly. Princeton University Press.

Schmitt-Grohe, S. and M. Uribe (2003). Closing small open economy models. Journal of International Economics 61, 163-185.

Schumacher, J. and B. Weder di Mauro (2015, Fall). Greek debt sustainability and official crisis lending. Brookings Papers on Economic Activity, 279-305.

Sturzenegger, F. and J. Zettelmeyer (2007). Debt Defaults and Lessons from a Decade of Crises. Cambridge, MA: The MIT Press.

\section{Appendix}

\section{A Empirical Appendix}

\section{A.1 List of countries}

The list of countries and regions is in Table 6 .

\section{A.2 Definition and List of Episodes}

We adopt the following definition of episodes:

1. Sudden Stop: Our sudden stop episodes are constructed by combining an output collapse filter and a capital flow reversal filter. To construct the output collapse filter, we first identify all cumulated episodes of real GDP decline (Source: annual real GDP growth from International Financial Statistics). We define an 'output collapse' as in Calvo et al. (2006), when the cumulated decline in output exceeds the within group median (AE and EME). To construct the capital flow 
Region

Latin America (13)

Asia (11)

Middle East and North Africa (10)

Central and Eastern European (15)

South Saharan Africa (3)

Commonwealth of Independent

States (5)

Advanced Economies (22)
Countries

Argentina, Brazil, Chile, Colombia, Dominican Republic, Ecuador, El Salvador, Jamaica, Mexico, Panama, Peru, Uruguay, Venezuela

China, Hong-Kong, India, Indonesia, South Korea, Malaysia, Pakistan, Philippines,

Singapore, Sri Lanka, Thailand

Egypt, Iraq, Israel, Jordan, Kuwait, Lebanon, Morocco, Oman, Tunisia, United Arab Emirates

Bosnia, Bulgaria, Croatia, Czech Republic, Estonia, Hungary, Latvia, Lithuania, Macedonia, Poland, Romania, Serbia, Slovak Republic, Slovenia, Turkey

Cote d'Ivoire, Nigeria, South Africa

Belarus, Georgia, Kazakhstan, Russian

Federation, Ukraine

Australia, Austria, Belgium, Canada, Denmark, Finland, France, Germany, Greece, Iceland, Ireland, Italy, Japan, The Netherlands, New Zealand, Norway, Portugal, Spain, Sweden, Switzerland, United Kingdom, United States

Table 6: List of Countries. 


\begin{tabular}{|cccc|}
\hline Country & Years & Country & Years \\
\hline \multicolumn{4}{c|}{ Advanced Economies } \\
\hline Canada & 1982 & Denmark & 2009 \\
Germany & 2009 & Iceland & 2010 \\
Japan & 2009 & Netherlands & 2009 \\
Spain & 2010,2013 & Sweden & 1993 \\
Switzerland & 2009 & U.K. & 1981 \\
U.S. & 2009 & & \\
\hline \multicolumn{4}{c}{} \\
\hline Argentina & $1982,1990,2002$ & Bulgaria \\
Chile & 1983 & Colombia & 1999 \\
Cote d'Ivoire & 1984 & Croatia & 2014 \\
Ecuador & 1999 & Estonia & 2009 \\
Hong Kong & 1998 & Hungary & 2009 \\
Indonesia & 1998 & Korea & 1998 \\
Lithuania & 2009 & Malaysia & 1998 \\
Mexico & 1983,1995 & Philippines & 1985 \\
Romania & 1999,2010 & Russia & 1998,2009 \\
Slovak R. & 2009 & Slovenia & 2009 \\
Thailand & 1998 & Turkey & $1994,2001,2009$ \\
U.A.E & 2009 & Ukraine & $1999,2009,2014$ \\
Uruguay & 1984 & & \\
\hline
\end{tabular}

Table 7: List of Sudden Stop Episodes with Output Collapse

filter, we measures the changes in net capital flows as follows: (a) year on year change in the (opposite of the) current account relative to output, $\Delta_{4}\left(-C A_{t} / Y_{t}\right)$ as in Korinek and Mendoza (2013), where $\Delta_{k} x_{t}=x_{t}-x_{t-k}$; (b) year-on-year change in the (opposite of the) current account plus change in official reserves, relative to output: $\Delta_{4}\left(\left(-C A_{t}+\Delta R E S_{t}\right) / Y_{t}\right)$. This measure attempts to measure private capital flows; (c) year-on-year change in the cumulated change in the (opposite of the) current account + change in official reserves, relative to cumulated output, $\Delta_{4}\left(\left(-\tilde{C A_{t}}+\Delta R \tilde{E} S_{t}\right) / \tilde{Y}_{t}\right)$ where $\tilde{X}_{t}=\sum_{s=0}^{3} X_{t-s}$. (Source: current account, official reserves and output in US dollars from IFS). For each measure of net capital inflows, an episode is triggered when net capital inflows fall more than two standard deviations away from the mean (both mean and standard deviation are country specific). Consecutive episodes less than 8 quarters apart are merged into a single episode. Finally, a sudden stop occurs in year $t$ when the trough of the output collapse (output collapse filter) overlaps with a sudden stop episode, according to any of the above definitions.

2. Sovereign Defaults. Sovereign defaults are defined as in Gourinchas and Obstfeld (2012), based on the tabulations of Reinhart and Rogoff (2009); Cantor and Packer (1995); Chambers (2011). The year tof a sovereign debt crisis corresponds to the year identified with a default on 


\begin{tabular}{lcc|cc|}
\hline Country & Years & Country & Years \\
\hline Argentina & $1982,1989,2001^{*}$ & Brazil & $1983,1986,1990,2002$ \\
Bulgaria & 1990 & Chile & $1983^{*}$ \\
Cote d'Ivoire & 1983,2000 & Croatia & 1993 \\
Dominican R. & 1982,2005 & Ecuador & $1982,1999^{*}, 2008$ \\
Egypt & 1984 & El Salvador & 1981 \\
Indonesia & $1998^{*}, 2002$ & Iraq & 1990 \\
Jamaica & 2010 & Jordan & 1989 \\
Kuwait & 1990 & Mexico & $1982^{*}$ \\
Morocco & 1983,1986 & Nigeria & $1982,2001,2004$ \\
Pakistan & 1981,1999 & Panama & 1983,1987 \\
Peru & 1980,1984 & Philippines & 1983 \\
Poland & 1981 & Romania & 1981,1986 \\
Russia & $1991,1993,1998^{*}$ & Serbia & 1983,1992 \\
South Africa & $1985,1989,1993$ & Sri Lanka & 1981,1996 \\
Turkey & $1982,2001^{*}$ & Ukraine & 1998,2000 \\
Uruguay & $1983^{*}, 1987,1990,2003^{*}$ & Venezuela & $1982,1990,1995,1998,2005$ \\
\hline
\end{tabular}

Table 8: List of Sovereign Debt Crises. 'Trifecta' episodes are marked with a '*',

domestic or external debt in these sources.

3. Lending Boom/Bust. We define a lending boom/bust episode as in Gourinchas et al. (2001), using the deviation of the ratio of credit to the non-financial sector to output from its trend (source: bank credit to the non financial sector from BIS; and depository corporations survey, claims on the private sector, IFS). The trend is an hp filter with smoothing parameter $\lambda=1000$. Define $c y_{t}^{T}$ for the trend component of the credit to output ratio $c y_{t}$. A boom occurs whenever $c y_{t}>1.14 c y_{t}^{T}$ (boom threshold). The boom begins when $c y_{t}>1.05 c y_{t}^{T}$ (limit threshold) and ends when that limit threshold is crossed again. Episodes less than 2 years apart are combined. The year $t$ of the lending boom is the year in which the maximum deviation from trend is achieved, within a given episode.

4. 'Trifecta'. Trifecta crises are defined as a sovereign debt crisis that occurs during a sudden stop and a lending boom episode. These episodes are marked with a ${ }^{(*)}$ in Table 8

\section{B Calibration}

This appendix contains more details on the calibration. Table 11 contains the parameters that we choose to match steady state targets for Greece. Table 12 contains the fiscal rule parameters that we calibrate rather than estimate. 


\begin{tabular}{|c|c|c|c|}
\hline Country & Years & Country & Years \\
\hline \multicolumn{4}{|c|}{ Advanced Economies } \\
\hline Australia & 1980 & Canada & 1982 \\
\hline Denmark & 2009 & Finland & 1989 \\
\hline Greece & 1985 & Iceland & 1982,2006 \\
\hline Ireland & 1981,2009 & Norway & 1988,2007 \\
\hline Portugal & $1984,2001,2009$ & Spain & 1982,2007 \\
\hline Sweden & 1990 & & \\
\hline \multicolumn{4}{|c|}{ Emerging Market Economies } \\
\hline Argentina & 1999,2013 & Belarus & 2010 \\
\hline Bosnia & 1997,2008 & Brazil & 1995 \\
\hline Bulgaria & 1991,2008 & Chile & 1984,2003 \\
\hline Colombia & 1984, 1997, 2014 & Croatia & 1998 \\
\hline Czech R. & 1997 & Dominican R. & 1989,2003 \\
\hline Ecuador & 1984,1997 & Egypt & 1981, 2001 \\
\hline El Salvador & 2000 & Estonia & 2009 \\
\hline Georgia & 1997,2008 & Hog Kong & 1983,1997 \\
\hline Hungary & 1990,2009 & Indonesia & 1998 \\
\hline Iraq & 2004 & Israel & 2002 \\
\hline Jamaica & $1983,1989,2000,2008$ & Jordan & 2006 \\
\hline Kazakhstan & 1993,2007 & Korea & 1998 \\
\hline Kuwait & $1988,1998,2009$ & Latvia & 2010 \\
\hline Lebanon & 2000 & Lithuania & 2008 \\
\hline Macedonia & 2008 & Malaysia & 1997 \\
\hline Mexico & 1981, 1994 & Morocco & 1981,1997 \\
\hline Nigeria & 1986,2009 & Oman & 1998 \\
\hline Pakistan & 1986,2008 & Panama & 1981, 2001 \\
\hline Peru & 1983, 1998 & Philippines & $1983,1997,2014$ \\
\hline Poland & 1992,2009 & Romania & 1996, 2008 \\
\hline Russia & 1995,2009 & Serbia & 2000,2010 \\
\hline Slovak R. & 1999,2008 & Slovenia & 1991, 2009 \\
\hline South Africa & 2008 & Sri Lanka & $1983,1995,2006$ \\
\hline Thailand & 1997 & Tunisia & 1989 \\
\hline Turkey & 1987,1997 & U.A.E & $1988,1998,2009$ \\
\hline Ukraine & 2008 & Uruguay & 1982, 2002 \\
\hline Venezuela & 2007,2013 & & \\
\hline
\end{tabular}

Table 9: List of Lending Booms 
Table 10: Standard Parameters

\begin{tabular}{|c|c|c|}
\hline Parameter & Description & Value \\
\hline \hline$\beta$ & Discount Factor & 0.97 \\
\hline$\alpha$ & Capital Share & $1 / 3$ \\
\hline$\epsilon_{h}$ & Elasticity between H and F & 1 \\
\hline$\epsilon_{f}$ & Elasticity between exports & 1 \\
\hline$\varphi$ & Inverse labor supply elasticity & 1 \\
\hline$\gamma$ & Risk Aversion & 1 \\
\hline$\vartheta$ & Price Stickiness & 0.5 \\
\hline$\varepsilon$ & Elasticity of Substitution Goods & 6 \\
\hline$\vartheta_{w}$ & Wage Stickiness & 0.5 \\
\hline$\varepsilon_{w}$ & Elasticity of Substitution Labor & 6 \\
\hline$\epsilon_{r}$ & Elasticity of $R$ to $N F A$ & 0.0001 \\
\hline$\varphi_{k}$ & Adjustment Cost & 1 \\
\hline$\delta$ & Depreciation & 0.07 \\
\hline$F C$ & Fixed cost of production, $10 \%$ of $Y$ & 0.0955 \\
\hline
\end{tabular}

Table 11: Internally Calibrated Parameters for Greece

\begin{tabular}{|c|c|c|}
\hline Parameter & Description & Value \\
\hline$\varpi$ & 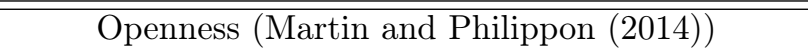 & 0.3 \\
\hline $\bar{\chi}$ & Fraction of Impatient (Martin and Philippon $(2014))$ & 0.65 \\
\hline$\Delta$ & Annual lending spread of $2 \%$ & 1.02 \\
\hline$\frac{\bar{B}^{h}}{Y}$ & Household debt to GDP of $50 \%$ & 0.5 \\
\hline$\frac{B^{g}}{Y}$ & Government debt to GDP of $120 \%$ & 1.2 \\
\hline$\frac{G}{Y}$ & Government consumption to GDP of $20 \%$ & 0.2 \\
\hline$\frac{T}{V}$ & Public social expenditure to GDP of $20 \%$ & 0.2 \\
\hline$\frac{Y}{d^{h}}$ & Steady state default rate for Households & $5.4 \%$ \\
\hline$d^{k}$ & Steady state default rate for Corporates & $5.4 \%$ \\
\hline$\frac{B^{k}}{Y}$ & Corporate debt to GDP of $50 \%$ & 0.5 \\
\hline$\psi_{s k}$ & Working Capital Constraint & 1 \\
\hline$\tau$ & Tax rate, budget balance in $\mathrm{SS}$ & 0.436 \\
\hline$L$ & Leverage scaling & 1 \\
\hline
\end{tabular}

Table 12: Other Parameters

\begin{tabular}{|c|c|c|}
\hline Parameter & Description & Value \\
\hline \hline$F_{b}$ & Elasticity of govt. spending to public debt & 0.05 \\
\hline$F_{n}$ & Elasticity of govt. spending to employment & 0.025 \\
\hline$F_{r}$ & Elasticity of govt. spending to the int. rate & 0.5 \\
\hline$F_{l}$ & Persistence of govt. spending & 0.75 \\
\hline
\end{tabular}


Table 13: Steady State Values

\begin{tabular}{|c|c|c|}
\hline Variable & Description & Value \\
\hline \hline$Y$ & Output & 0.9548 \\
\hline$C=C^{b}=C^{s}$ & Consumption & 0.6315 \\
\hline$N$ & Labor & 0.7830 \\
\hline$W$ & Wage rate & 0.8767 \\
\hline$R=R^{g}$ & SOE and Sovereign Rates & $\frac{1}{\beta}=1.0309$ \\
\hline$G=T$ & Government Spending and Transfers & 0.1910 \\
\hline$K$ & Capital & 1.8897 \\
\hline$Q$ & Investment Q & 1 \\
\hline$R^{k}=R^{h}$ & Corporate Debt and Household Debt Rates & 1.1116 \\
\hline$Z_{k}$ & Rental Rate of Capital & 0.1816 \\
\hline$R^{s k}$ & Working Capital Rate & 1.02 \\
\hline$B^{g}$ & Government Debt & 1.1457 \\
\hline$B^{h}$ & Household Debt & 0.4774 \\
\hline
\end{tabular}

The following table describes the steady state of the model for reference. We focus on a zero inflation steady state, and normalize all price levels to 1, so that there is no distinction between variables in euros, or real variables deflated by either the CPI or the PPI. We also assume, for simplicity, that $N F A=0$ at the steady state, and that trade is balanced. This is straightforward to generalize, by appropriately adapting the interest rate equation. Finally, we assume that steady state transfers from the government to the borrower are such that both agents choose the same amount of labor and consumption.

\section{Estimation}

Our priors impose that most estimated parameters be in the $[0,1]$ interval, with the exception of some of the elasticities for which we assume Gamma priors.

Figure 31 plots the priors in orange and the estimated posterior distributions in blue for the dynamic parameters, with the posterior mode highlighted in black. Our default priors for shock persistence and variances are Beta distributions with mean 0.85 and variance 0.1 , and mean 0.2 and variance 0.1, respectively. The only exceptions are the spending and household debt shocks, where we lower the persistence and raise the variance due to the presence of an autoregressive term in the structural equations for these variables.

Using the Kalman Smoother at the posterior mode, we can retrieve sequences for the structural shocks in the model, which are shown in 32 . These are obtained by applying the Kalman Smoother 


\begin{tabular}{|c|c|c|c|c|c|c|c|}
\hline Parameter & Description & Prior & Prior Mean & Prior SD & Post. Mean & \multicolumn{2}{|c|}{ Post. $90 \%$ Interval } \\
\hline \multicolumn{8}{|c|}{ Shock parameters } \\
\hline$\rho_{\operatorname{tax}}$ & Persistence of Tax Shock & Beta & 0.85 & 0.1 & 0.8441 & 0.7178 & 0.9851 \\
\hline$\sigma_{\operatorname{tax}}$ & SD of Tax Shock & Beta & 0.2 & 0.1 & 0.0269 & 0.0118 & 0.0429 \\
\hline$\rho_{r}$ & Persistence of Sudden Stop Shock & Beta & 0.85 & 0.1 & 0.6727 & 0.5452 & 0.8033 \\
\hline$\sigma_{r}$ & SD of Sudden Stop Shock & Beta & 0.2 & 0.1 & 0.0067 & 0.0047 & 0.0089 \\
\hline$\rho_{\text {spend }}$ & Persistence of Spending Shock & Beta & 0.25 & 0.1 & 0.2785 & 0.1221 & 0.4310 \\
\hline$\sigma_{\text {spend }}$ & SD of Spending Shock & Beta & 0.7 & 0.2 & 0.0533 & 0.0359 & 0.0688 \\
\hline$\rho_{b h}$ & Persistence of Credit Shock & Beta & 0.25 & 0.1 & 0.4030 & 0.2114 & 0.5860 \\
\hline$\sigma_{b h}$ & SD of Credit Shock & Beta & 0.7 & 0.2 & 0.0955 & 0.0595 & 0.1301 \\
\hline$\rho_{d g}$ & Persistence of Sov Risk Shock & Beta & 0.85 & 0.1 & 0.6442 & 0.4548 & 0.8215 \\
\hline$\sigma_{d g}$ & SD of Sov Risk Shock & Beta & 0.2 & 0.1 & 0.2635 & 0.1463 & 0.3809 \\
\hline$\rho_{\pi h}$ & Persistence of Markup Shock & Beta & 0.85 & 0.1 & 0.8067 & 0.6627 & 0.9522 \\
\hline$\sigma_{\pi h}$ & SD of Markup Shock & Beta & 0.1 & 0.05 & 0.0188 & 0.0085 & 0.0299 \\
\hline$\rho_{w}$ & Persistence of Wage Shock & Beta & 0.85 & 0.1 & 0.7922 & 0.6320 & 0.9632 \\
\hline$\sigma_{w}$ & SD of Wage Shock & Beta & 0.1 & 0.05 & 0.0056 & 0.0017 & 0.0097 \\
\hline$\rho_{\text {def }}$ & Persistence of Default Shock & Beta & 0.85 & 0.1 & 0.8701 & 0.7775 & 0.9693 \\
\hline$\sigma_{d e f}$ & SD of Default Shock & Beta & 0.2 & 0.1 & 0.1384 & 0.0642 & 0.2157 \\
\hline \multicolumn{8}{|c|}{ Variance of Measurement Errors } \\
\hline$\sigma_{\text {error }}^{\pi}$ & SD of PPI Meas. Error & Beta & 0.2 & 0.1 & 0.0278 & 0.0168 & 0.0376 \\
\hline$\sigma_{\text {error }}^{w}$ & SD of Wage Infl. Meas. Error & Beta & 0.2 & 0.1 & 0.0079 & 0.0018 & 0.0142 \\
\hline$\sigma_{\text {error }}^{\text {def }}$ & SD of NPL Meas. Error & Beta & 0.2 & 0.1 & 0.0691 & 0.0138 & 0.1157 \\
\hline $\bar{d}_{g}$ & Impact of $\frac{B^{g}}{Y}$ on Sovereign Risk & Beta & 0.2 & 0.1 & 0.1052 & 0.0613 & 0.1456 \\
\hline \multicolumn{8}{|c|}{ Dynamic Parameters } \\
\hline $\bar{d}_{y}$ & Elasticity of default to GDP & Gamma & 5 & 1 & 4.6718 & 3.4850 & 5.7238 \\
\hline $\bar{d}_{b}$ & Elasticity of default to debt & Beta & 0.1 & 0.05 & 0.1020 & 0.0222 & 0.1751 \\
\hline$\psi_{b h}$ & Adjustment Speed of $b^{h}$ & Beta & 0.85 & 0.1 & 0.9536 & 0.9118 & 0.9926 \\
\hline$\xi^{b h}$ & Elasticity of credit to funding cost & Gamma & 2 & 1 & 1.7388 & 0.4233 & 2.9881 \\
\hline$\xi^{d}$ & Impact of default on funding cost & Beta & 0.001 & 0.0005 & 0.0009 & 0.0003 & 0.0015 \\
\hline
\end{tabular}

Table 14: Priors and Posteriors. Note: The table present Bayesian estimates of model parameters. It specifies the distribution for the prior, its mean, standard deviation, as well as the posterior mean, and $90 \%$ confidence interval. 

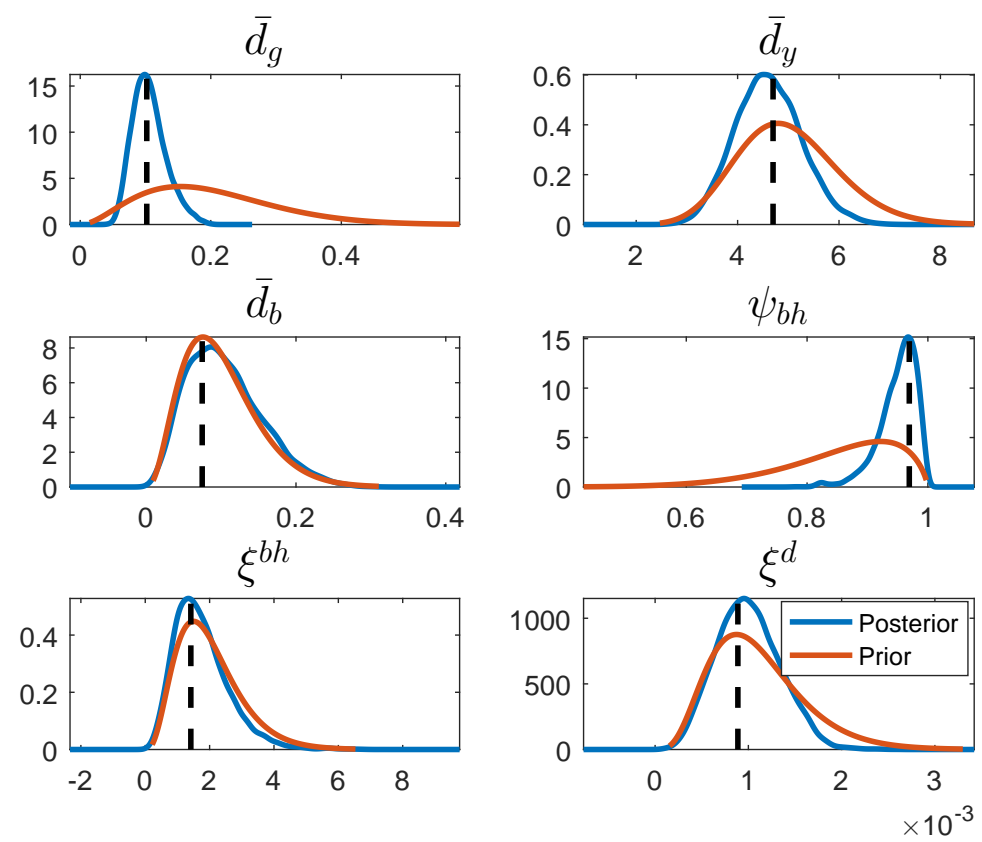

Figure 31: Priors, Posteriors and Mode for the dynamic parameters. Note: The blue line is the posterior density, the orange line is the prior density and the black dashed line is the posterior mode.

for the sequence of observables, with all parameters set at their posterior modes.

\section{Impulse Responses}

Figure 33 shows the impulse response to a private default shock, $\varepsilon_{t}^{\text {def }}$. The surge in private defaults increases the private sector funding cost and reduces the spending of impatient households who are at their borrowing constraint. This adversely affects investment, output and employment. As the economy enters a recession, sovereign yields increase. Government expenditures are the result of two offsetting forces: the recession increases spending (automatic stabilizers), but the increase in public debt triggers some automatic consolidation. The net effect is a mild decline in spending. Net exports improve as both competitiveness increases (lower domestic inflation), and domestic absorption declines.

Figure 34 shows the response of the economy to credit demand shock, $\varepsilon_{t}^{b h}$. Impatient households borrow to finance consumption. This initially stimulates output and employment, and inflation, but crowds out investment as credit risk increases and therefore private funding costs leading to a subsequent output decline. The increase in absorption exceeds output, so the current account deteriorates. 

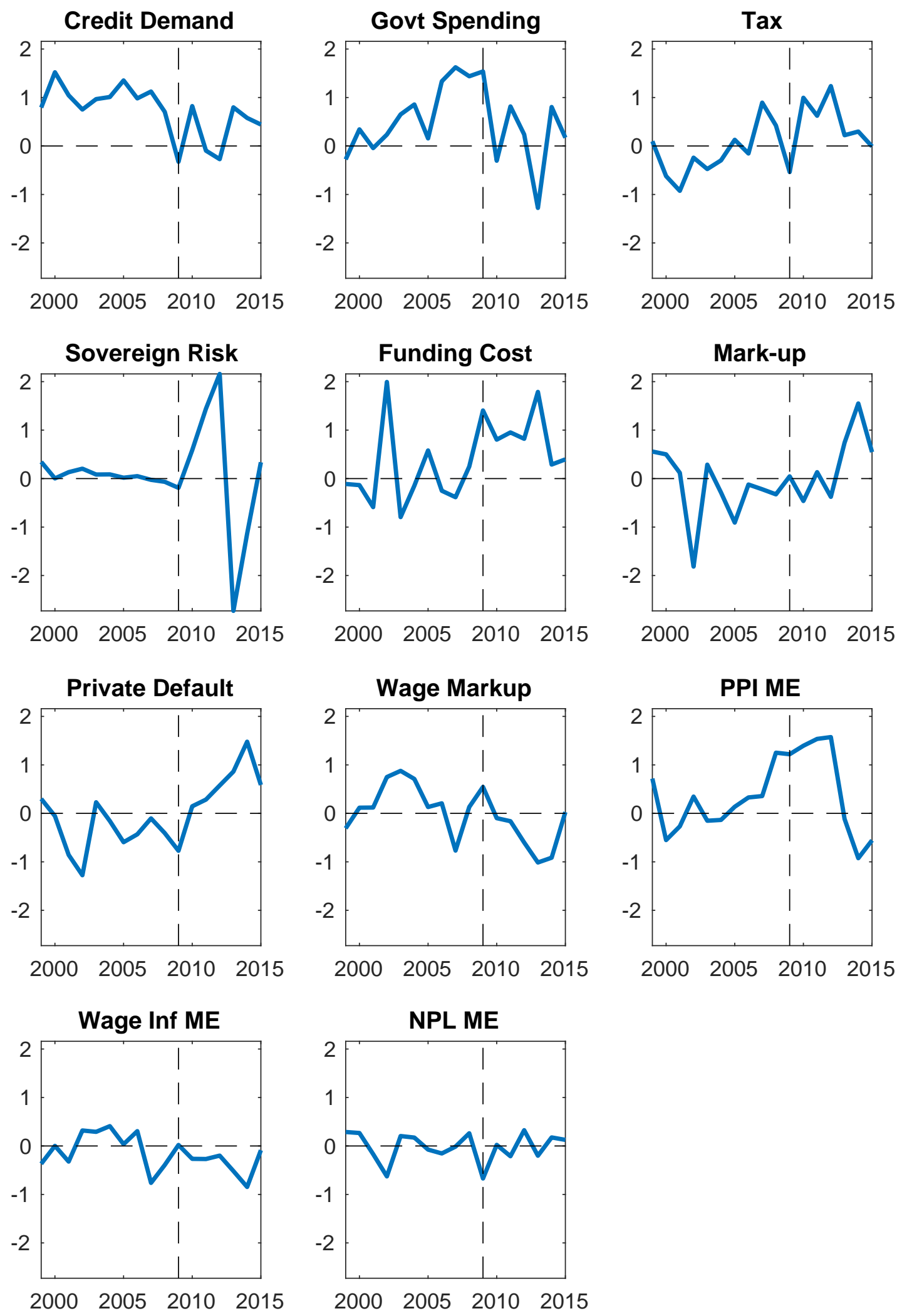

Figure 32: Smoothed Shocks 
Priv. Def.
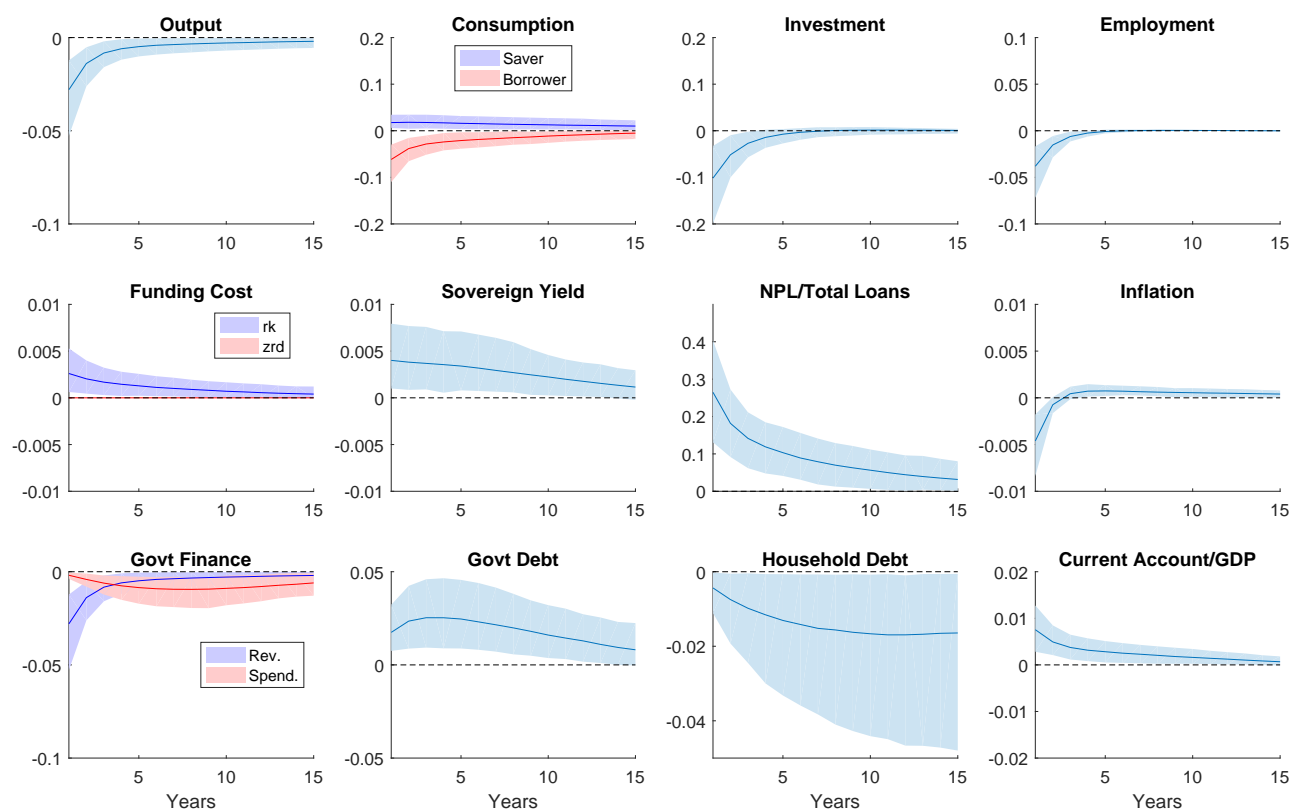

Figure 33: Private Default Shock. Note: The figure reports 90\% Bayesian confidence bands.

Credit Demand
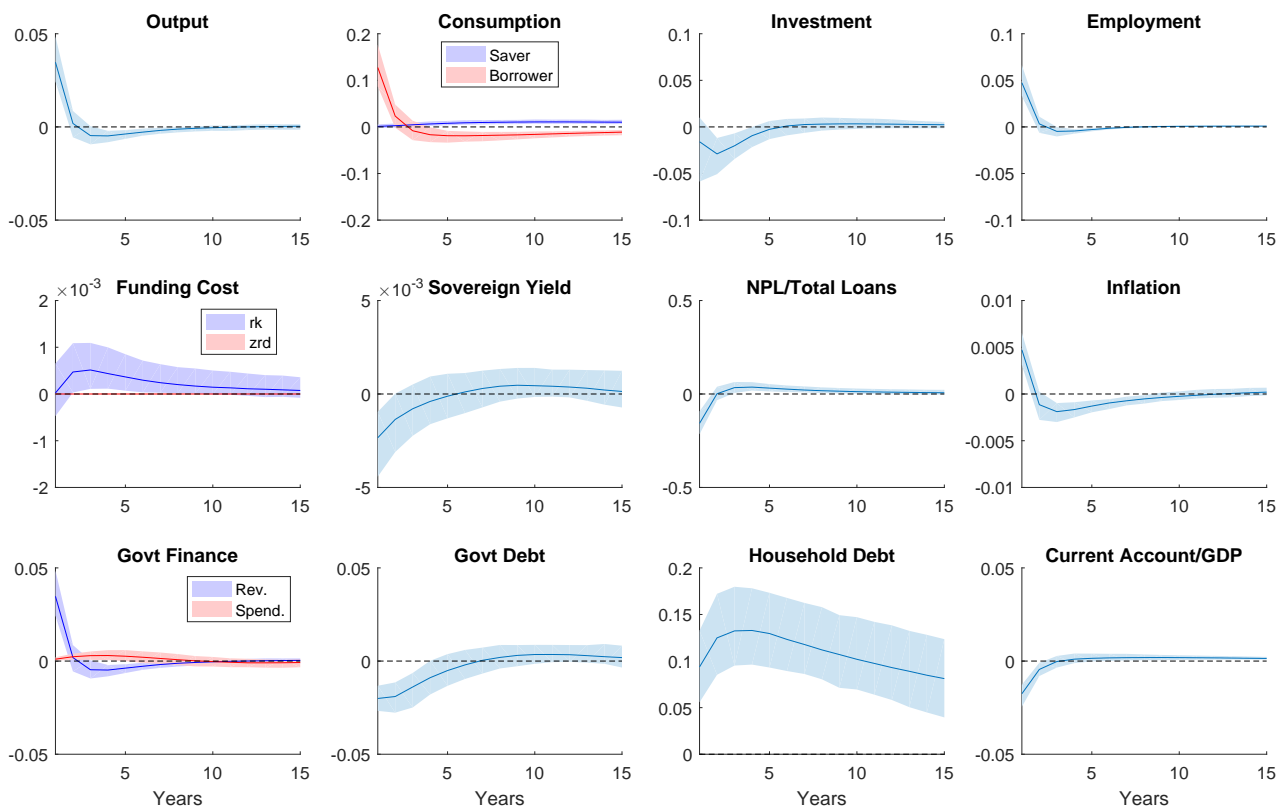

Figure 34: Household Credit Demand Shock. Note: The figure reports 90\% Bayesian confidence bands. 